ISA RODRIGUES DA SILVEIRA CABRAL DE MENEZES

\title{
AVALIAÇÃO DA CONFORMIDADE DE PRÁTICAS DE CONTROLE E PREVENÇÃO DA PNEUMONIA ASSOCIADA À VENTILAÇÃO MECÂNICA EM UM HOSPITAL PÚBLICO DE ENSINO
}

Dissertação apresentada à Escola de Enfermagem da Universidade de São Paulo para obtenção do título de Mestre em Ciências.

Área de concentração: Enfermagem na Saúde do Adulto. Orientador: Profa. Dra . Rúbia Aparecida Lacerda 
FOLHA DE APROVAÇÃO

Nome: Isa Rodrigues da Silveira Cabral de Menezes

Título: Avaliação da conformidade de práticas de controle e prevenção da pneumonia associada à ventilação mecânica em um hospital público de ensino

Dissertação apresentada à Escola de Enfermagem da Universidade de São Paulo para obtenção do título de Mestre em Ciências.

Área de concentração: Enfermagem na Saúde do Adulto.

Aprovada em:

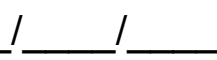

\section{Banca Examinadora}

Prof. Dr. Instituição:

Julgamento: Assinatura:

Prof. Dr. Instituição:

Julgamento: Assinatura:

Prof. Dr. Instituição: Julgamento: Assinatura: 
"Quando nada é certo, tudo é possível"

Margaret Drabble

Inglaterra 


\section{DEDICATÓRIA}

Ao Papai e Mamãe,

Por compartilharem comigo todas as minhas dores e conquistas.

Ao meu Querido Hamilton,

Por reconhecer os momentos que necessito do seu apoio, demonstrando o seu amor por mim e por me ensinar que dedicação e perseverança são qualidades que devemos colocar em prática. 


\section{AGRADECIMENTOS ESPECIAIS}

Às Professoras da EEUSP,

Rúbia Aparecida Lacerda, pela idealização e incentivo para a realização desse estudo, por acreditar em mim, aceitando o desafio de me orientar e compartilhar suas experiências. Seu apoio e competência foram fundamentais para eu chegar até aqui, meus agradecimentos e admiração.

Ruth Teresa Natalia Turrini, por sua disponibilidade e dedicação pelos ensinamentos quanto à análise estatística e acima de tudo pela generosidade em me auxiliar na fase final com tanto afinco, mesmo nas adversidades. 


\section{AGRADECIMENTOS}

Aos meus queridos irmãos Nita, Ruthinha e Paulinho, por me ensinarem que o amor fraterno é uma dádiva.

Aos meus sogros, Dona Ida e Seu Hamilton, por me acolherem como uma filha.

Ao Controle de Controle de Infecção Hospitalar do Hospital Universitário da USP pelo apoio contínuo e por favorecer a elaboração desse estudo.

À Dra. Valéria Cassetari Chiaratto, por seu incansável apoio, paciência ao me mostrar o melhor caminho para condução deste estudo desde o início, por sua competência profissional e amizade.

À Enfermeira Ana Cristina Balsamo, por trabalhar de forma voluntária na coleta de dados, por seu incentivo, amizade e contribuições no desenvolvimento deste estudo.

Ao Dr. Fábio Franco, por compreender minhas ausências no setor e colaborar no meu aprendizado.

À Cristina de Matos Martins, pela dedicação carinhosa na revisão da língua portuguesa e por me auxiliar sempre nos momentos que precisei.

À Michela Peanho, pela valiosa colaboração e disponibilidade na elaboração do banco de dados, possibilitando a realização deste estudo.

À Professora Kasuko Uchikawa Graciano, pelo apoio e contribuições acadêmicas.

Às enfermeiras da UTI-Adulto, representadas pelas Enfermeiras Flavia Maia, Tatiana Augusto e Luciana Inaba Senyer, pela dedicação aos pacientes, competência profissional e pela disponibilidade em me auxiliar tantas vezes. 
Aos demais membros da Equipe de Enfermagem e a todos da Equipe de fisiotarapeutas da UTI-Adulto, por colaborarem na realização do estudo.

À Professora Maria Julia Paes da Silva e sua Equipe de Diretores do Departamento de Enfermagem do Hospital Universitário da USP, por oferecer oportunidades para melhoria da minha capacitação profissional e pelo apoio contínuo.

Às estudantes de Graduação de Enfermagem: Juliana Rizzo Gnatta, Jane de Assis, Gisele Cardoso Bertoni e Josiane Mendes Silva, a minha gratidão pelo profissionalismo, ética e empenho em participarem da coleta de dados, fundamental para o desenvolvimento da pesquisa.

À Maria Alice de França Rangel Rabello, pelas correções e organização das referências bibliográficas e a Roseli Barboza Campos Marian, pela gentileza e competência na busca das referências bibliográficas.

Ao Ricardo Luís Barbosa, pela valiosa participação, contribuição estatística e resistência, mesmo nos momentos de indecisão.

A Maria Helena Vargas, pela valiosa e competente editoração gráfica e acima de tudo pelo acolhimento.

A todos os pacientes que no anonimato contribuíram para este estudo. 


\section{RESUMO}

Cabral de Menezes IRS. Avaliação da conformidade de práticas de controle e prevenção da pneumonia associada à ventilação mecânica em um hospital público de ensino [dissertação]. São Paulo Escola de Enfermagem, Universidade de São Paulo; 2009.

Há praticamente consenso de que o processo de trabalho de controle e prevenção de infecção associada a serviços de saúde (IASS) atualmente hegemônico, pautado em indicadores de resultados, ou seja, eventos de IASS, são limitados para reconhecer as condições reais em que as práticas assistenciais são realizadas. Para tanto, avaliações processuais vêm sendo demandadas, para conhecer o grau de conformidade dessas ocorrências com as recomendações dadas por evidências científicas atualmente disponíveis. Este estudo teve a finalidade de avaliar a conformidade de práticas de controle e prevenção de pneumonia associada à ventilação mecânica (PAVM), por meio de indicadores clínicos processuais especificamente elaborados. Tais práticas corresponderam a: a) Avaliação da adesão às medidas específicas de prevenção e controle de PAVM: manutenção da cabeceira elevada a $30-45^{\circ}$; atendimento diário de fisioterapia respiratória; utilização de soluções estéreis para nebulizadores e inaladores; material de terapia respiratória em uso respeitando a rotina de troca estabelecida; b) Avaliação da adesão à realização de higiene bucal; c) Avaliação da adesão á higiene das mãos em procedimentos de aspiração orotraqueal, troca de cadarço da cânula orotraqueal e higiene bucal. Tratou-se de uma pesquisa aplicada envolvendo achados sobre o desempenho de práticas e procedimentos, buscando acessar sua qualidade, com delineamentos prospectivo, transversal e analítico. O cenário constituiu da UTIAdulto de um Hospital Público de Ensino. A casuística correspondeu às oportunidades de avaliação das práticas selecionadas, realizadas por enfermeiros, auxiliares e técnicos de enfermagem e fisioterapeutas, nos três turnos de trabalho, em pacientes com intubação orotraqueal. A amostra baseou-se na conformidade esperada de $80 \%$, acarretando 1748 avaliações distribuídas entre as práticas selecionadas, realizadas por meio de observação direta e registros em prontuários. Instrumentos e avaliadores foram submetidos à testes de aferição de concordância. $O$ índice de conformidade geral obtido na adesão às medidas específicas de controle e prevenção de PAVM foi $68,0 \%$, sendo que o turno da tarde apresentou o maior índice $(72,4 \%)$ e o da manhã, o menor $(63,2 \%)$. O índice de conformidade geral da prática de higiene bucal foi $60,1 \%$, sendo que o turno da manhã apresentou o melhor índice $(72,4 \%)$ e noturno, o menor $(47,4 \%)$. Dentre as modalidades 
prescritas, a que apresentou maior conformidade foi a aplicação apenas de $\mathrm{CHX}$ $0,12 \%$, em todos os turnos, mas somente o da manhã atingiu a conformidade mínima esperada (90\%-manhã; 73,7\%-noite; $72,9 \%$-tarde). A modalidade menos acatada foi a escovação de dentes e aplicação de $\mathrm{CHX} 0,12 \%$, em todos os turnos de trabalho (3,6\%-noite; $28,6 \%$-tarde; 33,3\%-manhã). A conformidade geral da prática de higiene das mãos na realização dos procedimentos selecionados foi apenas $10,7 \%$, sendo que a aspiração orotraqueal obteve maior conformidade $(18,9 \%)$, seguindo-se troca de cadarço $(7,9 \%)$ e higiene bucal $(5,3 \%)$. O turno da manhã obteve maior adesão $(16,7 \%)$ e o noturno a menor $(3,1 \%)$. Nesta prática, o maior índice de conformidade foi obtido entre os fisioterapeutas $(25,8 \%)$, seguindose os enfermeiros $(15,6 \%)$ e, por último, auxiliares e técnicos $(4,4 \%)$. Concluiu-se que embora as práticas avaliadas não tenham alcançado a conformidade geral esperada de $80 \%$ em nenhuma das avaliações, os resultados obtidos permitem inferir que as realidades observadas justificam a revisão de normas e rotinas instituídas, bem como a elaboração de estratégias que assegurem a adesão duradoura das práticas de controle e prevenção de PAVM, associado à análise contínua de infra-estrutura e condições de trabalho. Tornou-se evidente, também, a relevância de avaliações processuais constituírem atividades rotineiras de programas de controle e prevenção de IASS.

Descritores: Pneumonia associada à ventilação mecânica/prevenção e controle. Infecção hospitalar. Indicadores de qualidade. 


\begin{abstract}
Cabral de Menezes IRS. Evaluation of compliance to the practices of control and prevention of ventilator-associated pneumonia in a public teaching hospital [dissertation] São Paulo Nursing School, São Paulo University; 2009.
\end{abstract}

There is a present consensus that the process of control and prevention of infection associated to health services (IAHS) based on result indicators is limited to recognize the real conditions in which assistance practices are performed. So, processual evaluations have been required to know the conformity level of these events in relation to recommendations given by scientific evidence now available. The aim of this study was to analyze the conformity of adhesion to the practices of control and prevention of ventilator-associated pneumonia (VAP) by means of specifically elaborated processual clinical indicators. These practices corresponded to: a) Evaluation of adherence to specific measures of prevention and control of VAP: maintaining the bed in a 30-45 degrees head-up position; daily respiratory physiotherapy; use of sterile solutions for nebulizers and inhalers; material of respiratory therapy in use respecting established routine of change; b) Evaluation of adherence to oral hygiene; c) Evaluation of adherence to hand-washing procedures when performing orotracheal aspiration, change of tape of the orotracheal cannula and oral hygiene. This was an applied research involving findings on performance of practices and procedures aiming to access its quality, through a prospective transversal and analytical design. It took place in an Adult-ICU of a Public Teaching Hospital. The casuistic corresponded to opportunities of evaluation of the selected practices performed by nurses, nursing assistant, nursing technicians and physiotherapists in the three work shifts in patients with orotracheal intubation. The sample was based on the expected conformity of $80 \%$, with 1,748 evaluations distributed among the selected practices performed by means of direct observation and registers in patient records. Instruments and evaluators were submitted to tests for measuring compliance. The general conformity adhesion index obtained in the specific measures of control and prevention of VAP was $68.0 \%$, of which the afternoon shift presented the greatest index $(72.4 \%)$ and the morning shift with the lowest index $(63.2 \%)$. The index of general conformity to the practice of oral hygiene was $60.1 \%$, of which the morning shift presented the best index $(72.4 \%)$ and the night shift with the worst $(47.4 \%)$. Among the mentioned modalities the largest conformity was the $\mathrm{CHX} 0.12 \%$ application in all shifts, but only the morning shift reached the minimum expected conformity $(90 \%$ in the morning; $73.7 \%$ at night and $72.9 \%$ in the afternoon). The less accepted modality was teeth cleaning and $\mathrm{CHX}$ 
$0.12 \%$ application in all shift works $(3.6 \%$ at night; $28.6 \%$ in the afternoon; $33.3 \%$ in the morning). General conformity of hand hygiene practice in the performance of selected procedures was only $10.7 \%$, the largest conformity represented by orotracheal aspiration $(18.9 \%)$, followed by tape change $(7.9 \%)$ and oral hygiene $(5.3 \%)$. The morning shift obtained the best adherence $(16.7 \%)$ and night shift the worst $(3.1 \%)$. In this practice the best index of conformity was observed among the physiotherapists $(25.8 \%)$, followed by nurses $(15.6 \%)$ and the nursing assistants and technicians $(4.4 \%)$. We concluded that the lack of the expected general adherence of $80 \%$ in all the evaluations justify a review of the rules and routines established, as well as the elaboration of strategies capable to assure a permanent adherence to the control and prevention practices of VAP, associated to a continuum analysis of infrastructure and work conditions. It was also evident the relevance of processual evaluations as routine activities of control and prevention programs of VAP.

Descriptors: Pneumonia, ventilator-associated/prevention \& control measures. Cross infection. Quality of indicators, health care. 


\section{LISTA DE ABREVIATURAS E SIGLAS}

AACN - American Association of Critical-Care Nurses

ANA - Associação das Enfermeiras Americanas

APACHE- Agude Physiology and Chronic Health Evaluation

ATS - American Thoracic Society

CCCS - Canadian Critical Care Society

CCIH - Comissão de Controle de Infecção Hospitalar

CDC - Centers for Disease Control and Prevention

CHX - Clorexidina

DPOC - Doença pulmonar obstrutiva crônica

EBA - Escovado bronco-alveolar protegido

EEUSP - Escola de Enfermagem da Universidade de São Paulo

EPIC - European Prevalence of Infection in Intensive Care

ETF - European Task Force

EUA - Estados Unidos da América

HICPAC - Healthcare Infection Control Practices Advisory Commitee

HM - Higiene das mãos

HMSEL - Higiene das mãos em procedimentos selecionados

IASS - Infecção adquirida em serviços de saúde

ICC - Insuficiência cardíaca congestiva

IH - Infecções hospitalares

IOT - Intubação Orotraqueal

IRHB - Higiene bucal

IRPR - Medidas de prevenção e controle de PAVM

JCAHO - Joint Commission on Accreditation of Healthcare Organizations

k - Teste de Kappa

LBA - Lavado bronco-alveolar

NCQA - National Committee for Quality Assurance

NNIS - National Nosocomial Infections Surveillance System

OD - Observação direta 
OMS - Organização Mundial da Saúde

ONA - Organização Nacional de Acreditação

PAVM - Pneumonia associada à ventilação mecânica

PVP-I - Polivinilpirrolidona lodo

SAE - Sistema de Assistência de Enfermagem

SNG - Sonda nasogástrica

SPSS - Statistical Package for the Social Sciences

TCLE - Termo de Consentimento Livre e Esclarecido

UFC/g - Unidade Formadora de Colônia/grama

UTI - Unidades de Terapia Intensiva 


\section{LISTA DE QUADROS}

Quadro 1 - Classificação das evidências segundo o desenho dos estudos. ................... 44

Quadro 2 - Diretrizes ou recomendações para prevenção de pneumonias hospitalares .................................................................................... 46

Quadro 3 - Forças das evidências científicas segundo as instituições ETF, CDC, CCCS e ATS. 


\section{LISTA DE TABELAS}

Tabela 1 - Distribuição da amostra para avaliação de conformidade das medidas específicas de prevenção e controle de pneumonia em pacientes de alto risco. São Paulo, 2009

Tabela 2 - Distribuição da amostra para avaliação de conformidade da higiene das mãos nos seguintes procedimentos selecionados. São Paulo, 2009

Tabela 3 - $\quad$ Aferição de concordância obtida entre as duplas de avaliadores para os componentes dos indicadores IRPR e IRHB. São Paulo, 2009.

Tabela 4 - $\quad$ Aferição de concordância obtida entre as duplas de avaliadores para os componentes do indicador HMSEL. São Paulo, 2009.

Tabela 5 - Distribuição de conformidade geral e por turno de trabalho das medidas específicas de prevenção e controle de PAVM (IRPR). São Paulo, 2009

Tabela 6 - Distribuição de conformidade e não conformidade de cada medida específica de controle e prevenção de PAVM, segundo o turno de trabalho. São Paulo, 2009

Tabela 7 - Distribuição de situações de não conformidade das medidas específicas de controle e prevenção de PAVM, segundo o turno de trabalho. São Paulo, 2009

Tabela 8 - Distribuição de conformidade geral e por turno de trabalho referente à prática de higiene bucal. São Paulo, 2009.

Tabela 9 - Distribuição de conformidade e não conformidade da higiene bucal, segundo prescrição de enfermagem e turno de trabalho. São Paulo, 2009

Tabela 10 - Distribuição de não conformidades observadas referentes à higiene bucal, segundo modalidade de prescrição de Enfermagem. São Paulo, 2009

Tabela 11 - Distribuição de conformidade geral e por procedimento selecionado para a higiene das mãos. São Paulo, 2009.

Tabela 12 - Distribuição de conformidade da higiene das mãos nos três turnos de trabalho. São Paulo, 2009

Tabela 13 - Distribuição das oportunidades de higiene das mãos, segundo o turno de trabalho e categoria profissional. São Paulo, 2009

Tabela 14 - Distribuição de conformidade da higiene das mãos, segundo a categoria de profissional. São Paulo, 2009

Tabela 15 - Distribuição de conformidade da higiene das mãos, segundo o tipo de procedimento observado e turno de trabalho. São Paulo, 2009 
Tabela 16 - Distribuição de conformidade da higiene das mãos, segundo os procedimentos selecionados e a categoria profissional. São Paulo, 2009 .... 94

Tabela 17 - Distribuição de conformidade e não conformidade da higiene das mãos nos procedimentos de aspiração orotraqueal e troca de cadarço, segundo categoria profissional e turno de trabalho. São Paulo, 2009.

Tabela 18 - Distribuição de não conformidade e conformidade da higiene das mãos, segundo categoria profissional e tipo de procedimento. São Paulo, 2009 .... 97

Tabela 19 - Distribuição de não conformidade e conformidade da higiene das mãos, segundo o tipo de procedimento e o turno de trabalho. São Paulo, 2009 .... 98

Tabela 20 - Distribuição de conformidade e não conformidade da higiene das mãos, segundo o tipo de procedimento e a categoria profissional. São Paulo, 2009 


\section{LISTA DE GRÁFICOS}

Gráfico 1 - Distribuição de conformidade das medidas específicas de prevenção e controle de PAVM (IRPR), segundo o turno de trabalho. São Paulo, 2009

Gráfico 2 - Distribuição de conformidade de cada medida específica de prevenção e controle de PAVM, segundo o turno de trabalho. São Paulo, 2009......

Gráfico 3 - Distribuição de conformidade obtida na realização da higiene bucal, segundo turno de trabalho. São Paulo, $2009 .$.

Gráfico 4 - Distribuição de situações de não conformidade observadas referentes à higiene bucal, segundo tipo de prescrição de enfermagem e turno de trabalho. São Paulo, 2009 


\section{SUMÁRIO}

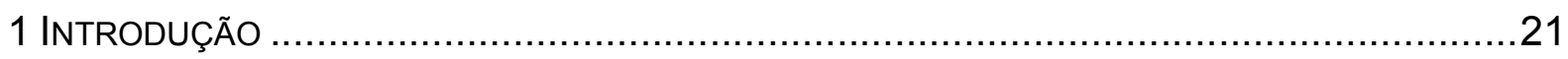

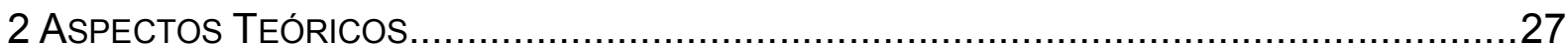

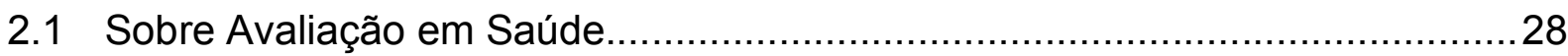

2.1.1 Modalidades de avaliação em saúde.....................................................28

2.1.2 Indicadores clínicos como ferramentas de avaliação em saúde ....................31

2.1.3 Elaboração e validação de indicadores clínicos para avaliar práticas de controle de infecção hospitalar ...........................................................33

2.2 Sobre Controle e Prevenção de Pneumonia Hospitalar.....................................35

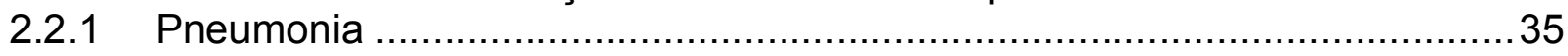

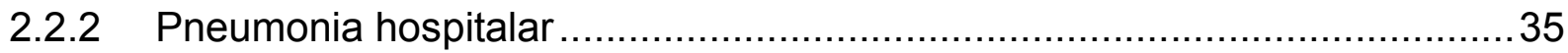

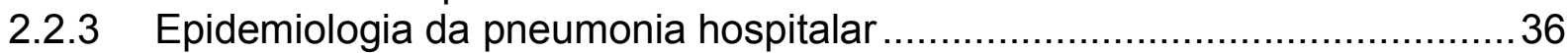

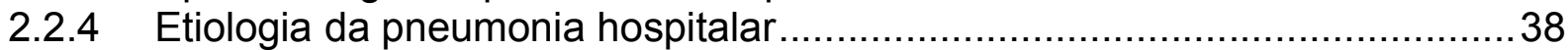

2.2.5 Diagnóstico de pneumonia hospitalar e pneumonia associada à

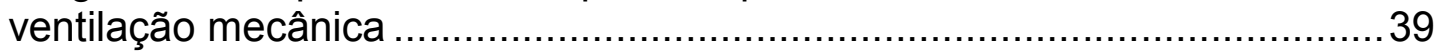

2.2.6 Fatores de risco para pneumonia hospitalar.........................................40

2.2.7 Magnitude da pneumonia associada à ventilação mecânica.......................42

2.2.8 Medidas de controle e prevenção da pneumonia hospitalar.........................43

2.2.9 Higiene bucal como nova prática relevante na prevenção e controle da pneumonia associada à ventilação mecânica ........................................48

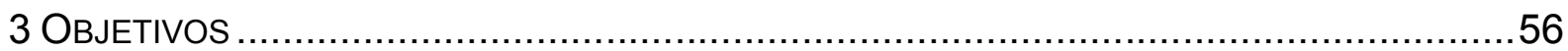

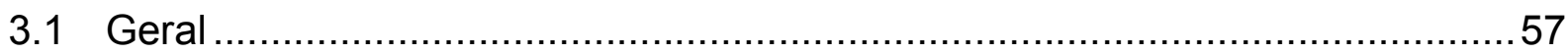

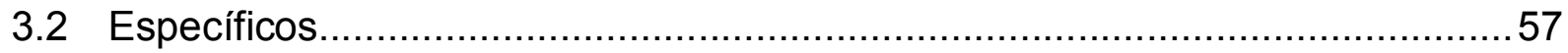

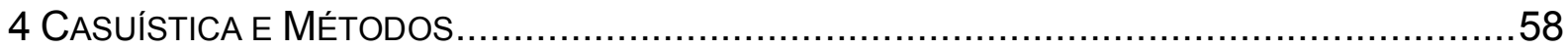

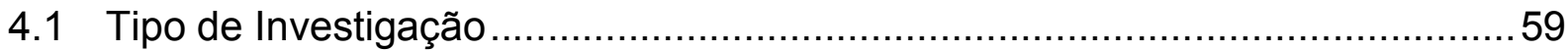

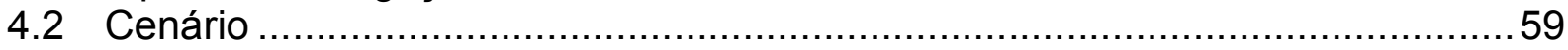

4.3 Práticas de Controle e Prevenção de PAVM Selecionadas para

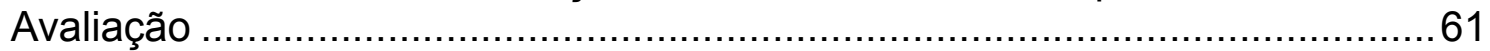

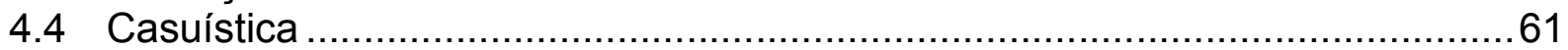

4.5 Cálculo do Tamanho da Amostra...............................................................62

4.6 Instrumentos para Avaliação das Práticas de Controle e Prevenção de

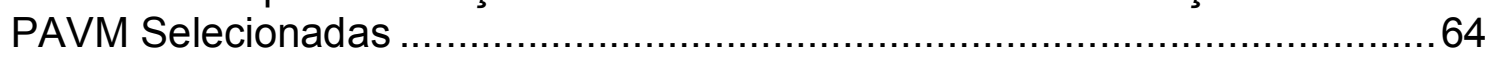

4.7 Testes de Precisão dos Instrumentos de Avaliação ......................................66

4.7.1 Instrumentos e treinamento dos avaliadores ..........................................66

4.7.2 Aferição de concordância inter-observadores, intra-instrumentos e

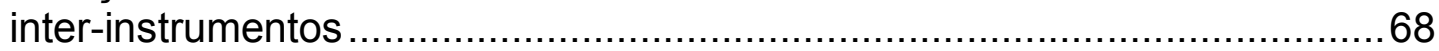

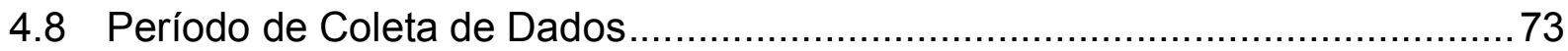

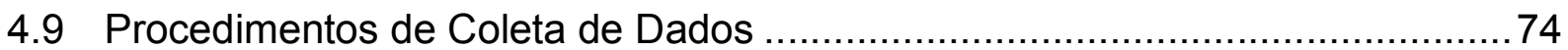

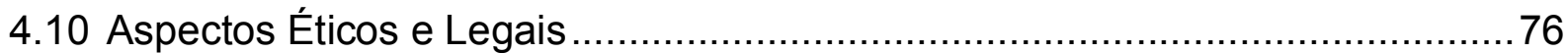

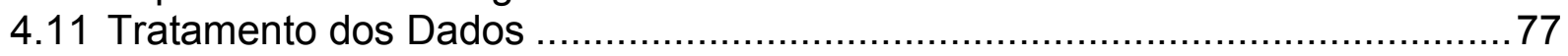


5 RESULTADOS.....

5.1 Adesão às medidas específicas de prevenção e controle de PAVM (Indicador IRPR)

5.2 Adesão à realização de higiene bucal conforme rotina da instituição (Indicador IRHB)

5.3 Adesão à higiene das mãos em procedimentos selecionados (Indicador HMSEL)

6 DISCUSSÃO 101

7 CONCLUSÕES 129

8 REFERÊNCIAS 132

9 APÊNDICES 148

10 ANEXOS 155 
1 INTRODUÇÃO 
A preocupação com as infecções hospitalares $(\mathrm{IH})$ tem demandado estudos para estabelecer critérios de investigação, identificação, epidemiologia dos agentes infecciosos e população suscetível, incluindo os fatores de risco associados.

Em nível nacional, a Portaria $n^{0} 2.616$ do Ministério da Saúde recomenda a implantação de um sistema de vigilância epidemiológica das $\mathrm{IH}$ nos hospitais brasileiros de formas sistemática, ativa, contínua e pautada na própria legislação e nas prioridades de cada instituição, além de determinar a constituição da Comissão de Controle de Infecção Hospitalar (CCIH). Essa Portaria também dispõe sobre a identificação de procedimentos, eventos e fatores de risco da população atendida. Quando aplicadas, as informações geram os indicadores epidemiológicos, na forma de taxas: incidência e prevalência de $\mathrm{IH}$, pacientes com IH, $\mathrm{IH}$ por procedimentos, IH por topografias, entre outras (Brasil, 1998).

A infecção hospitalar é definida, nesta Portaria, como toda infecção adquirida ou transmitida após a admissão do paciente, cuja manifestação clínica ocorreu durante o período de internação ou após a alta hospitalar, podendo ser relacionada com a internação ou procedimentos hospitalares (Brasil, 1998). Hoje, é praticamente um consenso que esta definição, circunscrita ao hospital, não é mais suficiente, ao se considerar que procedimentos de assistência, principalmente aqueles invasivos, que podem ocasionar tal ocorrência, são realizados em vários outros locais que não exigem internação, como clínicas, ambulatórios, laboratórios de análise e diagnóstico, e até mesmo na assistência domiciliária. Assim sendo, outros termos vêm sendo incorporados nesta área: infecção adquirida em serviços de saúde, infecção relacionada à assistência à saúde, entre outros.

Independente do local de sua transmissão ou ocorrência, as práticas para seu controle e prevenção são praticamente as mesmas, de acordo com o tipo de procedimento. Várias já são bastante conhecidas, seja a partir de evidências de resultados de estudos científicos e/ou de guias nacionais e internacionais de recomendações, inclusive relacionadas à pneumonia hospitalar (Tablan et al. 2004). 
Embora nem todos os casos de IH sejam evitáveis, estima-se que o estabelecimento e a aplicação de um programa de controle e prevenção efetivo contribuem para reduzir a $\mathrm{IH}$ em torno de 32\% (Haley et al., 1985).

Kelleghan et al. (1993), contudo, afirmam que a existência e o estabelecimento de práticas recomendadas pelas melhores evidências não são suficientes, por si sós, para a redução das $\mathrm{IH}$, sendo fundamental avaliar se elas estão sendo efetivamente executadas.

Torna-se necessário, então, a utilização de estratégias para reconhecer se as práticas de controle de $\mathrm{IH}$ recomendadas estão sendo de fato realizadas. O principal instrumento de reconhecimento atualmente disponível e difundido no controle de $\mathrm{IH}$ pauta-se predominantemente na investigação da frequência de eventos de $\mathrm{IH}$, na forma de indicadores epidemiológicos, conforme apresentados acima e recomendados pela Portaria $n^{\circ}$ 2.616/1998. Tais indicadores, porém, são limitados para reconhecer as condições reais em que as práticas assistenciais são realizadas em consonância com aquelas recomendadas, porque constituem avaliações de resultados das ocorrências, portanto, apresentam medidas de maneira retrospectiva (Lacerda, 2003a).

Diante da insuficiência dos indicadores disponíveis, faz-se necessária a adoção de outros critérios de trabalho no controle de $\mathrm{IH}$, que permitam reconhecer as condições reais em que as práticas são realizadas, ou seja, o seu desempenho, assim como medir seu grau de conformidade com o que é recomendado e, dessa maneira, gerar políticas de melhoria contínua de qualidade dirigidas especificamente aos problemas observados.

Tal estratégia significa uma ampliação do processo de trabalho de controle e prevenção de $\mathrm{IH}$, contribuindo para gerar capacitação dos recursos profissionais, materiais e estruturais, além de ajustes de metas.

A avaliação do sistema de saúde, com uso de medidas de desempenho, já vem sendo realizada desde a década de 90 do século $X X$, tornando-se uma nova modalidade, em que conceitos como qualidade, eventos adversos, custo da assistência, gestão, satisfação do cliente e prática baseada em evidência, tornaramse familiares aos profissionais de saúde (Sanders, 1997).

Vários sistemas de acreditação já atuam dessa maneira, como o Joint Commission on Accreditation of Healthcare Organizations (JCAHO), National Committee for Quality Assurance (NCQA), American Accreditation Healthcare 
Comission e o National Institute for Clinical Excellence. No Brasil, o sistema mais conhecido é a Organização Nacional de Acreditação (ONA).

A necessidade de criação de novas estratégias de avaliação, que permitam o reconhecimento das condições em que as práticas de controle de $\mathrm{IH}$ são realizadas, foi o tema central do Congresso Brasileiro de Controle de Infecção e Epidemiologia Hospitalar, realizado em 2004. E, no Congresso seguinte, em 2006, várias propostas foram apresentadas. Tal necessidade foi corroborada, nos Estados Unidos da América (EUA), pelo Comitê Consultivo de Práticas de Controle de IH na Assistência à Saúde, apoiada, dentre outros aspectos, por uma revisão de literatura em que foi constatada insuficiência de informações sobre a eficácia dos sistemas de divulgação atuais, tornando necessário utilizar medidas que possam aferir os resultados do desempenho das práticas (McKibben et al., 2005).

Neste caminho, desde 1996, os serviços de saúde e as diretrizes governamentais do Departamento de Saúde de Londres têm trabalhado para que unidades de cuidados críticos examinem as práticas, a fim de assegurar a aplicação das medidas baseadas em evidências científicas e garantir a qualidade da assistência (Fulbrook e Mooney, 2003).

Em consonância com tal modalidade e, buscando atender à demanda por novos sistemas de avaliação na área de controle e prevenção de $\mathrm{IH}$, iniciou-se, em 2003, um projeto de políticas públicas, financiado pela Fundação de Amparo à Pesquisa do Estado de São Paulo, para a construção de indicadores clínicos de avaliação da qualidade de práticas de controle de $\mathrm{IH}$. Com sede na Escola de Enfermagem da Universidade de São Paulo (EEUSP), em parceria com a Divisão de Infecção Hospitalar do Centro de Vigilância Epidemiológica da Secretaria Estadual de Saúde de São Paulo e com a participação de vários profissionais enfermeiros e médicos de diversas instituições de ensino e hospitalares, o projeto foi intitulado de Manual de Avaliação da Qualidade de Práticas de Controle de Infecção Hospitalar, concluído em 2006, que encontra-se disponível no endereço eletrônico http://www.cve.saude.sp.gov.br/htm/ih/lH_MANUALFAPESP06.pdf (São Paulo, 2006).

Este manual apresenta 59 indicadores, distribuídos em cinco grupos temáticos: a) Programas de Controle de $\mathrm{IH}$; b) Antimicrobianos; c) Procedimentos Assistenciais; d) Processamento de Artigos Odonto-Médico-Hospitalares e e) Riscos Ocupacionais Biológicos (São Paulo, 2006). 
O grupo de procedimentos assistenciais, por sua vez, foi desdobrado nas seguintes práticas: controle e prevenção de $\mathrm{IH}$ da corrente sanguínea associada a cateter vascular central de curta permanência; controle e prevenção de IH do sítio cirúrgico; controle e prevenção de infecção respiratória; controle e prevenção de IH do trato urinário associado a cateterismo vesical; indicação e aplicação de normas de isolamento e precauções e higiene das mãos (São Paulo, 2006).

Uma prática relevante no controle de $\mathrm{IH}$ é a prevenção da pneumonia hospitalar, principalmente quando associada à ventilação mecânica. A sua epidemiologia e os fatores de risco demonstram o quanto é importante uma execução adequada das recomendações já existentes para a redução e prevenção dessa infecção. De forma geral, a pneumonia é a causa mais comum de $\mathrm{IH}$ em Unidades de Terapia Intensiva (UTI), e sua incidência pode variar de 10 a 65\% (Vincent et al., 1995). A pneumonia associada à ventilação mecânica (PAVM) permanece como a causa mais importante de morbi-mortalidade em pacientes críticos, contribuindo para a elevação de custos hospitalares e do tempo de hospitalização (Sierra et al., 2005). Em um estudo nacional, do tipo controlado, a média de permanência hospitalar foi de 22 dias para os casos de PAVM e de seis dias para os pacientes-controle (Medeiros, 1993).

Também é atribuído aumento da mortalidade em pacientes com PAVM, principalmente nos casos de PAVM tardia, mesmo com antibioticoterapia apropriada (Vallés et al., 2007).

Apesar dos avanços tecnológico, terapêutico, diagnóstico etiológico e vacina, a pneumonia hospitalar em pacientes internados em UTI continua frequente e grave (Medeiros, Menezes, Valle, 2005).

Considera-se que o reconhecimento da conformidade das práticas de controle e prevenção executadas em relação às recomendações já preconizadas contribua para a redução dos casos de PAVM por meio de intervenções focadas nas inadequações encontradas.

Diante das dificuldades e das complexidades que envolvem o controle e as intervenções preventivas contra a PAVM, este estudo pretende avaliar a conformidade de práticas de controle e prevenção da PAVM em UTI adulto por meio da aplicação dos indicadores dispostos no Manual de avaliação da qualidade de práticas de controle de infecção hospitalar (São Paulo, 2006). 
Embora o reconhecimento e a importância da adesão às medidas de controle e prevenção da PAVM sejam bem estabelecidos, as evidências na prática mostram níveis insatisfatórios. Portanto, a hipótese deste estudo é que os níveis de conformidades esperados não alcançarão sua totalidade em todas as práticas selecionadas. 
2 Aspectos TeóRICOS 


\subsection{Sobre Avaliação em Saúde}

\subsubsection{Modalidades de avaliação em saúde}

A avaliação em saúde constitui área em construção conceitual e metodológica. Durante os últimos 40 anos, especialistas têm trabalhado para desenvolver métodos, os mais eficientes possíveis, para alcançar a qualidade da assistência à saúde. Muitos avanços e refinamentos nesse campo foram alcançados e têm permitido ampliar o domínio de métodos de avaliação que indicam os processos e resultados de assistência à saúde. Para Donaldson (1999), a finalidade da avaliação é o que vai definir o método mais adequado.

Com referência às modalidades de pesquisa avaliativa, Novaes (2000) selecionou, a partir de revisão de literatura, critérios ou variáveis que auxiliam na definição, sendo a) Objetivo da avaliação: deve priorizar as condições de produção ou utilização do conhecimento, tanto para tomadas de decisão e/ou para aprimorar a gestão; b) Posição do avaliador pode ser externa ou interna à instância sob avaliação; c) Enfoque priorizado: também pode ser interno, de caracterização e/ou compreensão de um contexto, ou externo, de quantificação e/ou comparação de impactos de intervenções; d) Metodologia predominante: pode ser quantitativa ou qualitativa, situacional, experimental ou quase-experimental; e) Contexto da avaliação: controlado ou natural; f) Forma de utilização da informação produzida: inclui demonstração e/ou comprovação ou informação, instrumentalização; g) Tipo de juízo formulado: pode ser comprovação e/ou negação de hipóteses, recomendações ou normas; $h$ ) Temporalidade da avaliação: pontual, corrente e contínua.

Partindo da combinação entre esses critérios ou variáveis, a mesma autora identifica três grandes tipos de avaliações: a) investigação avaliativa ou pesquisa de avaliação; b) avaliação para decisão; c) avaliação para gestão.

A pesquisa de avaliação tem como principal objetivo a geração de conhecimento, para orientar decisões. Geralmente, é desenvolvida em instituições acadêmicas, com a finalidade de implementar ou reorientar macro políticas. O 
enfoque diz respeito à identificação de impactos obtidos pelas ações a serem avaliadas. A metodologia proposta ainda é a de pesquisa quantitativa, mas com crescente participação dos estudos de natureza qualitativa, porém orientadas para uma generalização. Isso implica certo controle sobre o contexto em que se desenvolve a pesquisa e a elaboração das metodologias experimentais ou quaseexperimentais, buscando atingir o equilíbrio entre o controle da subjetividade e a garantia de uma objetividade, a viabilidade e a ética - dilemas sempre presentes nas investigações, principalmente, nas de avaliação. A informação produzida é utilizada para a demonstração dos pressupostos iniciais. Quanto à temporalidade, normalmente, tem por objetivo responder a questões não planejadas com antecedência e, dado o seu elevado custo, ela é habitualmente de natureza pontual, podendo eventualmente ser replicada, temporal ou espacialmente, para efeito comparativo (Novaes, 2000).

$\mathrm{Na}$ avaliação para a decisão, o principal objetivo é produzir respostas para perguntas colocadas por aqueles que vivenciam o objeto avaliado. Dessa forma, o avaliador interno tem uma posição decisiva no processo e o enfoque priorizado é o do reconhecimento do objeto, na profundidade necessária para a sua adequada compreensão, além de identificação dos problemas e alternativas de equacionamento possíveis. São utilizadas as metodologias qualitativa e quantitativa, de natureza situacional, com desenhos relativamente abertos e específicos para cada tipo de aproximação e apreensão da realidade buscada, em contextos que se deseja manter natural, e cujos resultados deverão ser articulados no momento da análise geral, ao se tomar por referência uma teoria geral que permita a sua integração. Os resultados constituem informações habitualmente reconhecidas como as melhores construídas, mais sistematizadas, sendo medidas pela sua capacidade de se transformar em recomendações positivas, isto é, capazes de contribuir para a solução dos problemas identificados. Esse tipo de avaliação é de natureza corrente, porque é geralmente prevista para acontecer quando da proposição e implantação do objeto sob avaliação (Novaes, 2000).

$\mathrm{Na}$ avaliação para gestão, o objetivo principal é a produção de informações que contribuam para o aprimoramento do objeto avaliado, buscando o melhoramento de uma dada situação. A presença do avaliador interno é condição necessária. O enfoque prioriza a caracterização de uma condição e a sua tradução em medidas que possam ser quantificadas e replicadas. Sobressaem as 
metodologias de natureza quantitativa e observacional, desenvolvidas em contexto natural ou até mesmo de rotina administrativa, em que os desenhos das avaliações são construídos pela agregação de medidas representativas de uma totalidade. A informação obtida é voltada essencialmente para o desenvolvimento e aprimoramento de indicadores como partes que representam um todo. $\mathrm{O}$ resultado desejado é a proposição de critérios ou normas a serem incorporadas na utilização desses indicadores no desempenho rotineiro do objeto avaliado, contribuindo para a garantia do seu bom funcionamento (Novaes, 2000).

Outros autores, Polit et al. (2004a) classificam as pesquisas de avaliação em três modalidades de análise: processo ou implementação; resultado ou desfecho e impacto.

A análise de processo ou de implementação é empreendida quando há necessidade de informações descritivas sobre o processo pelo qual um programa ou procedimento foi implementado e como eles funcionam na atualidade. É tipicamente desenhada para direcionar questões como: o programa funciona tal como foi inicialmente proposto? Quais aspectos do programa parecem ser mais fortes e mais fracos? Quais são, se existirem, as barreiras para implementar o programa com sucesso? Tal tipo de avaliação também pode ser referido como formativa. Em outras circunstâncias, seu propósito pode ser primariamente descrever um programa, de maneira que ele possa ser replicado por outros. Em qualquer caso, tal avaliação envolve um exame em profundidade da operacionalização de um programa, com coleta de dados tanto qualitativos quanto quantitativos.

A análise de resultados foca comumente um programa ou normas de trabalho, isto é, se ele é efetivo de acordo com seus objetivos. Tais avaliações são denominadas sumativas, em contraste com avaliações formativas. A intenção é auxiliar nas decisões quanto ao funcionamento e a efetividade de tal programa, isto é, se deve ser descartado, substituído, modificado, continuado ou replicado. Essa avaliação tende a ser descritiva e não utiliza desenhos metodológicos rigorosos; as análises simplesmente documentam a extensão na qual os objetivos são atendidos, isto é, o quanto ocorrem resultados positivos.

A análise de impacto busca identificar as redes de impacto de uma intervenção, isto é, os impactos que podem ser atribuídos exclusivamente à intervenção, independente de outros fatores (tais como os efeitos de uma intervenção padrão). Utiliza costumeiramente desenhos metodológicos experimentais ou quaseexperimentais, porque o objetivo é atribuir uma influência causal à intervenção 
específica. Nessa análise, é comum incluir também a análise de custo-benefício, para determinar se os benefícios de certo programa superam os custos.

Para Akerman e Nadanovsky (1992), a avaliação é um processo em que se elabora um julgamento explícito e, a partir deste ponto, desencadeia-se um movimento de transformação na direção da qualidade desejada.

A pesquisa de avaliação proposta no presente estudo insere-se, predominantemente, na modalidade de avaliação para gestão, segundo Novaes (2000), e de processo, segundo Polit et al. (2004a).

\subsubsection{Indicadores clínicos como ferramentas de avaliação em saúde}

Independentemente da modalidade da avaliação, sua realização implica a construção de ferramentas que norteiem a aplicação. Um recurso que vem sendo utilizado para avaliar a qualidade de práticas assistenciais de uma forma geral é a construção de indicadores clínicos, conceituados como medidas quantitativas de variáveis, características ou atributos de um dado processo ou sistema, que permitem reconhecer resultados desejáveis ou indesejáveis (Pringle et al., 2002).

Esses indicadores são constituídos de numerador e denominador. O primeiro corresponde ao evento que está sendo medido ou reconhecido e o segundo, à população sob avaliação de risco para um dado evento definido no numerador (Campbell et al., 2002). Nem sempre, contudo, é possível contemplar todos ou, ao menos, os principais aspectos de uma dada prática com um único indicador, necessitando-se recorrer a um conjunto de indicadores (Ferreira, 2002).

A classificação dos indicadores de qualidade em três dimensões foi formulada na década de 60 por Donabedian e citada por Donaldson em 1999. Tais indicadores

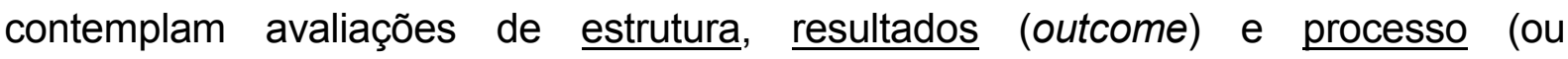
desempenho). Os de estrutura avaliam a capacidade do serviço de efetuar assistência de qualidade, incluindo recursos humanos e materiais, protocolos de assistência, suporte financeiro, área física, acessibilidade, entre outros. Os de resultados medem quão frequentemente um evento acontece, permitindo estimar fatores de risco ao identificar efeitos desejáveis ou não do tratamento, relevância de sintomas, entre outros, além de estabelecer limites máximos e mínimos aceitáveis de tais eventos. É o caso dos atuais indicadores epidemiológicos de $\mathrm{IH}$. Os de processo avaliam como 
uma dada prática assistencial é realizada, permitindo determinar o que se faz, por que se faz, como se faz, com o que se faz e quem faz. De outro modo, também possibilitam analisar a conformidade do que está sendo feito com padrões de evidência ou consenso previamente definidos (Donaldson, 1999). A avaliação de processo, portanto, determina uma avaliação crítica de qualidade.

As três tipologias de indicadores complementam-se para obtenção de uma melhor avaliação. A aplicação de um tipo de indicador sobre outro está na adequação do seu uso, conforme o evento a ser medido. O indicador que avalia a estrutura de um serviço, apesar de determinar padrões mínimos de capacidade de funcionamento de serviços de assistência e de prover cuidados coordenados e acessíveis, não assegura, no entanto, se a assistência que está sendo praticada é de alta qualidade ou se é realmente necessária. $O$ de resultado é mais indicado para formulação de julgamento, do que para a melhoria de qualidade, em razão de, algumas vezes, proporcionar informação insuficiente para o desenvolvimento de planos de ação de melhoria da prática. Para constituir uma avaliação válida, o resultado precisa estar estreitamente relacionado a processos de assistência que possam ser mudados. O indicador de processo encoraja os profissionais a se concentrarem naquilo que realmente possa contribuir diretamente para melhorar os resultados de saúde. Ele é mais sensível para mensurar a qualidade do cuidado. No entanto, para ser válido, precisa estar estreitamente relacionado com um resultado ou, mesmo, influenciá-lo. Apesar de constituir uma avaliação crítica de qualidade, ele ainda não se encontra bem desenvolvido (Donaldson, 1999).

Indicadores, porém, não devem ser criados e aplicados indiscriminadamente, pois há o risco de sua multiplicação desnecessária e consequente banalização. Alguns critérios precisam ser estabelecidos. O primeiro deles é o reconhecimento prévio sobre a melhor prática disponível a ser avaliada (padrão-ouro), a qual é fundamentada, preferencialmente, por meio de estudos de evidência científica, como revisão sistemática e metanálise e/ou ensaios clínicos controlados aleatórios. $\mathrm{Na}$ ausência desses, porém, dado o reconhecimento da importância da avaliação de uma certa prática, diretrizes clínicas de recomendações, protocolos já disponibilizados, consenso de especialistas, relação com um resultado ou influência no mesmo, entre outros, também podem ser utilizados como padrão-ouro (Atkins et al., 2004; Campbell et al., 2002; Donaldson, 1999; McGlynn, Steven, 1998; Ovretveit, Gustafson, 2003; Pringle, Wilson, Grol, 2002; SHEA, 1995) 
Outros critérios referem-se: à importância da condição ou problema a ser avaliado, isto é, se contribui significativamente para a morbidade e mortalidade; à associação com altos índices de utilização ou com tratamento de alto custo; ao potencial para a implementação ou melhoria de qualidade (McGlynn e Steven, 1998). Vale ressaltar que a necessidade de controle e qualificação por norma ou legislação governamental também deve ser considerada.

A pesquisa proposta no presente estudo consiste em avaliações processuais e se justifica ao atender a todos os critérios acima descritos, seja pela existência de padrão-ouro, seja porque as práticas a serem avaliadas estão relacionadas com índices significativos de morbidade e mortalidade, utilização e alto custo de tratamento. Além disso, também estão inseridas entre os eventos de infecção hospitalar que são exigidos para controle e prevenção por legislação governamental.

\subsubsection{Elaboração e validação de indicadores clínicos para avaliar práticas de controle de infecção hospitalar}

A avaliação a ser realizada neste estudo pauta-se no sistema proposto pelo Manual de avaliação de práticas de controle e prevenção de infecção hospitalar (São Paulo, 2006).

A modalidade de avaliação, ao estabelecer previamente a melhor qualidade disponível para uma dada prática, orienta-se predominantemente para a caracterização e o diagnóstico de situação, ou seja, como as práticas estão ocorrendo e qual a sua conformidade em relação à melhor qualidade esperada, com vistas à obtenção de recursos de informação e instrumentalização para a melhoria contínua de qualidade.

Os indicadores elaborados no Manual contemplam avaliações de estrutura, processo e resultado, conforme as decisões dos pesquisadores sobre as modalidades com melhores condições para avaliar e mensurar a conformidade de uma dada ação ou aspecto da prática previamente selecionada. Cada indicador orientou-se pela construção conceitual, denominada de Construto Operacional ou Manual Operacional. O construto operacional define os termos de operações concretas e indica o que se avalia e como deve ocorrer a coleta de informações e 
sua mensuração. Buscou-se, com isso, garantir uniformidade na avaliação e legitimidade da representação empírica dos dados.

É necessário que um sistema de avaliação por meio de instrumentos de medida seja previamente validado quanto ao seu conteúdo, antes de sua aplicação. Considera-se um instrumento válido quando ele é capaz ou suficiente para medir aquilo que se propõe a medir, isto é, capaz de captar, revelar ou representar um dado fenômeno.

No caso dos indicadores propostos para avaliação de práticas de controle de $\mathrm{IH}$, presentes no referido Manual (São Paulo, 2006), tal validade foi obtida pela fundamentação teórico-científica disponível sobre as melhores práticas disponíveis, por meio de diretrizes clínicas, estudos científicos e normas governamentais. Para Lynn (1986), contudo, a validade precisa ser submetida a um processo de duas etapas: a) desenvolvimento; b) julgamento-quantificação.

Assim sendo, para a validação dos indicadores elaborados no Manual (São Paulo, 2006), optou-se por também acatar a orientação desse processo, buscando o reconhecimento do quanto uma medida incorpora e reflete o domínio do fenômeno sob estudo, ou seja, se ela determina representatividade ou relevância dos itens ou componentes do instrumento de medida ou, de outro modo, se assegura que os itens de um instrumento representam e cobrem adequadamente aquilo que se pretende mensurar.

Nesse processo, a validade de conteúdo ocorre quando houver consenso de que ele mede o que se propõe a medir. Trata-se de um julgamento quanto à clareza, compreensibilidade ou redundância dos itens ou escalas do instrumento (Menezes, 1998; Morley, Sanith, 1989; Westmoreland et al., 2000)

Para validar os indicadores construídos por meio desse processo, foi elaborado um instrumento contendo julgamento dos seguintes atributos: a) consistência dos itens do indicador para aplicação da avaliação, no sentido de conter informações necessárias e adequadas para efetuar a medida; b) representatividade, isto é, capacidade da avaliação representar ou acessar o fenômeno; c) aplicabilidade, isto é, se a avaliação é aplicável e mensurável. Para o julgamento dos atributos, utilizou-se a técnica de consenso (Lynn, 1986; Westmoreland et al., 2000), por meio de escala psicométrica.

Esse instrumento foi julgado, individual e anonimamente, por profissionais médicos e enfermeiros com experiência na área de controle de $\mathrm{IH}$. $\mathrm{O}$ instrumento 
utilizado para o julgamento também contemplava comentários e sugestões elaboradas pelos especialistas (São Paulo, 2006).

Dentre os indicadores validados por esse processo, encontram-se aqueles utilizados no presente estudo.

\subsection{Sobre Controle e Prevenção de Pne $\square$ monia Hospitalar}

\subsubsection{Pne $\square$ monia}

A pneumonia, de uma forma geral, é uma inflamação que ocorre no parênquima pulmonar, isto é, na parte distal dos pulmões, comprometendo bronquíolos respiratórios, alvéolos e interstícios, os quais são preenchidos por exsudato inflamatório, o que prejudica as trocas gasosas. Esse processo instala-se quando microrganismos alcançam os pulmões. Os agentes infecciosos podem ser bactérias, vírus, fungos, protozoários, helmintos ou ainda fenômenos tromboembólicos, imuno-alérgicos, obstrutivos bronco-pulmonares entre outros (Fernandes, Zamorano, Torezan, 2000; Medeiros, Menezes, Valle, 2005).

Portanto, o processo inicia-se quando um inóculo entra em contato com os alvéolos. A partir daí, ocorre ruptura dos mecanismos de defesa do indivíduo, promovendo proliferação do agente nas unidades alveolares, causando lesão da mucosa respiratória, descamação celular, inundação alveolar e brônquica por células secretoras, edema, acúmulo de secreção, infiltração de células macrófagas, formação de atelectasia e progressão com acometimento do parênquima circunvizinho, com ou sem disseminação (Fernandes, Zamorano, Torezan, 2000; Medeiros, Menezes, Valle, 2005).

\subsubsection{Pne $\square$ monia hospitalar}

A pneumonia hospitalar é uma patologia dinâmica adquirida em ambiente hospitalar, após 48 a 72 horas de hospitalização, e que não foi causada por germes previamente incubados no momento da admissão do paciente (Medeiros, Menezes, Valle, 2005; Vicente et al., 1995).

Há quatro vias relacionadas à fisiopatogênese da pneumonia hospitalar, contribuindo para a colonização e infecção: aspiração de conteúdo orofaríngeo; contaminação de equipamento respiratório; transmissão cruzada de microrganismos e 
disseminação hematogênica proveniente de outros focos extrapulmonares como endocardites, infecções pélvicas, feridas cirúrgicas, flebites e translocação de trato gastrointestinal (Fernandes, Zamorano, Torezan, 2000; Medeiros, Menezes, Valle, 2005).

A aspiração de secreções da orofaringe, redução da saliva, lesões e ressecamento do epitélio da mucosa bucal e da traquéia pela presença da cânula endotraqueal podem levar ao desenvolvimento de infecções hospitalares em pacientes submetidos à ventilação mecânica (Bontem, 2002).

A ventilação mecânica através do uso de uma via aérea artificial é provavelmente a principal causa de pneumonia hospitalar, pois determina altas taxas de morbidade, mortalidade, letalidade, levando ao aumento de dias de internação e administração prolongada de antibióticos. Os pacientes intubados perdem a barreira natural entre a orofaringe e a traquéia, eliminando o reflexo da tosse e promovendo o acúmulo de secreções contaminadas acima do cuff da cânula endotraqueal, o que permite maior colonização da árvore traqueobrônquica e a aspiração de secreções contaminadas para as vias aéreas inferiores.

A ventilação mecânica é um procedimento adotado para pacientes críticos com insuficiência respiratória severa, estando associada a múltiplas complicações como infecções respiratórias hospitalares, maior necessidade de sedação e, consequentemente, ao aumento de fatores de risco para a pneumonia (Fernandes, Zamorano, Torezan, 2000; Medeiros, Menezes, Valle, 2005).

\subsubsection{Epidemiologia da pne $\square$ monia hospitalar}

Em 1995, Vincent et al. divulgaram os resultados de um estudo do European Prevalence of Infection in Intensive Care (EPIC) sobre as IH em 17 países, a saber: Áustria, Bélgica, Dinamarca, República da Irlanda, Finlândia, França, Alemanha, Grécia, Itália, Luxemburgo, Holanda, Portugal, Espanha, Suécia, Suíça, Reino Unido e Noruega. Nesse estudo, a pneumonia hospitalar foi a infecção mais importante $(46,9 \%)$, sendo $20,6 \%$ adquiridas nas UTI; a Itália foi o país com o maior índice $(31,6 \%)$.

Prade et al. (1995) realizaram um estudo em UTI de 99 hospitais de várias regiões brasileiras, cuja taxa global de $\mathrm{IH}$ foi 20,3\%; dos 28,9\% das infecções respiratórias hospitalares, $4,5 \%$ eram pneumonias. Outro estudo de prevalência, 
transversal, conduzido em UTI de um Hospital Universitário terciário de São Paulo em 2000, avaliou 1126 pacientes, dos quais 30,6\% desenvolveram IH. De todas as infecções respiratórias $(58,5 \%)$, a pneumonia foi a mais frequente $(59,9 \%)$ e com uma taxa de mortalidade de 34,7\% (Toufen Junior et al., 2003).

Craven e Steger (1995) relataram que a letalidade entre os pacientes internados com pneumonia hospitalar pode variar de 2 a 10 vezes mais do que em pacientes sem essa infecção.

As maiores incidências de pneumonia hospitalar ocorrem em pacientes internados em UTI, e submetidos à assistência respiratória com ventilador mecânico, principalmente com cânula endotraqueal ou traqueostomias (Fernandes, Zamorano, Torezan, 2000; Medeiros, Menezes, Valle, 2005).

Alguns estudos apontam que pacientes com ventilação mecânica apresentam de 3 a 21 vezes mais chances de desenvolver pneumonia em relação aos pacientes sem esse tipo de assistência (Craven; Steger, 1995; Fernandes, Zamorano, Torezan, 2000; Medeiros, 1993; Medeiros, Menezes, Valle, 2005).

O Centro de Controle e Prevenção de Doenças (Centers for Disease Control and Prevention - CDC), em Atlanta, nos EUA, desde a década de 70, vem monitorando as IH nos hospitais americanos por meio do Sistema Nacional de Vigilância das Infecções Hospitalares (National Nosocomial Infections Surveillance System - NNIS). As taxas de PAVM foram analisadas conforme o tipo de UTI e a definição de casos incluíram critérios clínicos, laboratoriais e o cálculo de ventiladordia. Em 2002-2004, as UTI de traumas apresentaram as maiores taxas $(15,2 \%)$, seguidas das UTI de queimados (12\%), neurocirurgia $(11,2 \%)$ e $5,4 \%$ nas UTI médico-cirúrgicas de hospitais-escola (NNIS, 2004). Ao comparar essas taxas com as dos anos de 2006-2007, evidencia-se a redução significativa da PAVM, pois as UTI apresentaram os seguintes resultados: UTI de trauma $(9,3 \%)$, de queimado $(10,7 \%)$, neurocirurgia $(6,5 \%)$ e nas UTI médico-cirúrgicas dos hospitais-escola a taxa média foi de 3,3\% (Edwards et al., 2008).

O tempo de internação e o custo de tratamento nos casos de pneumonia hospitalar têm sido foco de interesse de pesquisadores. Shorr e O'Malley (2001) estimaram os custos da PAVM em US\$ 5.365. O cálculo considerou o tempo de internação na UTI, exames diagnósticos e uso de antibióticos para tratamento por 14 dias (ceftazidima associada à gentamicina). Esses autores afirmaram que os custos podem ter sido subestimados, em virtude da não inclusão de todos os gastos com 
radiografias e exames laboratoriais adicionais, entre outros. Rello et al., em 2002, avaliaram os fatores de risco associados a PAVM, assim como a taxa de mortalidade, recursos utilizados e custo hospitalar em 842 pacientes e identificaram um custo em torno de US\$ 41.294 para cada episódio de PAVM.

\subsubsection{Etiologia da pne $\square$ monia hospitalar}

A American Thoracic Society (ATS) em 2005 elaborou um algoritmo para potenciais agentes etiológicos da pneumonia hospitalar, que varia conforme o período de desenvolvimento da infecção. Definiu como pneumonia de início precoce aquela que ocorre nos primeiros cinco dias de internação. Geralmente os microrganismos mais prováveis nesse tipo de pneumonia são os mesmos encontrados nas pneumonias comunitárias, como o Streptococcus pneumonie, Haemophyllus influenzae, Moraxella catarrhalis, Staphylococcus aureus sensível à meticilina, provenientes da região orofaríngea, Escherichia coli e outras enterobactérias (ATS, 2005). Na pneumonia de início tardio (após cinco dias), os microrganismos mais encontrados (bacilos Gram-negativos) apresentam resistências aos antibióticos e são associados ao aumento da morbi-mortalidade dos pacientes. São eles: Pseudomonas aeruginosa, Acinetobacter baumannii, Enterobacter spp e Staphylococcus aureus, incluindo os resistentes à meticilina. Os vírus podem ser identificados tanto na pneumonia de início precoce quanto na tardia. As leveduras, fungos, Legionellae spp e Pneumocystis carinii e, atualmente, também Pneumocystis jiroveci são comuns na pneumonia de início tardio (Horan, Andrus, Dudeck, 2008; Medeiros, Menezes, Valle, 2005; Tablan et al., 2004).

A pneumonia hospitalar causada pelos bacilos Gram-negativos tem merecido destaque, pois essas bactérias possuem maior potencial de virulência e consequentemente aumentam o risco dos pacientes desenvolverem pneumonia hospitalar (Craven, Steger, 1995).

Os métodos utilizados para determinação da etiologia da pneumonia, podem ser invasivos e não-invasivos. Entre os invasivos, considera-se pontos de corte para as amostras cultivadas: tecido do parênquima pulmonar $\geq 10^{4} \mathrm{UFC} / \mathrm{g}$ (Unidade Formadora de Colônia/grama); espécimes obtidos por broncoscopia como lavado bronco-alveolar $(\mathrm{LBA}) \geq 10^{4} \mathrm{UFC} / \mathrm{mL}$, LBA Protegido $\geq 10^{4} \mathrm{UFC} / \mathrm{mL}$, escovado 
bronco-alveolar protegido (EBA) $\geq 10^{4} \mathrm{UFC} / \mathrm{mL}$ (ATS, 2005; Rello et al., 2002;). Destacam-se também o aspirado endotraqueal ou coleta de secreção traqueal com cultura quantitativa $\geq 10^{6} \mathrm{UFC} / \mathrm{mL}$ (Medeiros. Menezes, Valle, 2005).

\subsubsection{Diagnóstico de pne $\square$ monia hospitalar e pne $\square$ monia associada à ventilação mecânica}

Por ser uma síndrome complexa quanto à definição, tratamento e prevenção, é necessário melhorar o diagnóstico com a aplicação de técnicas não-invasivas, aplicar e aumentar a aderência dos profissionais de saúde às ações preventivas (Bontem, 2002).

Tanto a Portaria $n^{\circ} 2.616$ (Brasil, 1998), quanto Medeiros, Menezes e Valle (2005) definem IH como o aparecimento de qualquer manifestação infecciosa a partir de 72 horas após a internação do paciente. Nos casos de pneumonia, esse limite de tempo pode ser desconsiderado quando houver procedimento invasivo do trato respiratório inferior, mas considerando o período de incubação. Nesse caso, os sintomas clínico-radiológicos poderão ocorrer em qualquer momento da internação, e o diagnóstico passa a ser considerado uma infecção hospitalar.

A PAVM pode se desenvolver após aspiração de secreções provenientes da orofaringe ou por inoculação direta de microrganismos aerossolizados de equipamentos contaminados para o trato respiratório inferior em pacientes com os mecanismos de defesa reduzidos (Cardenõsa Cendrero et al., 1999).

Isakou e Kollef (2006) estabeleceram para o diagnóstico de PAVM os seguintes critérios: toda manifestação infecciosa que ocorrer em 48 horas ou mais, após o uso de cânula endotraqueal, com apresentação de achados clínicos, como os infiltrados novos na radiografia de tórax, sem qualquer relação com o período de incubação dos microrganismos no momento da admissão hospitalar. Contudo, os achados radiológicos podem estar relacionados a outros processos não infecciosos como edema agudo de pulmão, atelectasias, insuficiência cardíaca congestiva (ICC), displasia broncopulmonar, dentre outras complicações.

Para a ATS (2005), o diagnóstico inicia-se com a história clínica e realização de radiografia do tórax. Frequentemente, os critérios clínicos para o diagnóstico de PAVM são: presença de um novo infiltrado pulmonar e pelo menos dois dos 
seguintes sintomas: febre $<38^{\circ} \mathrm{C}$, leucocitose ou leucopenia e secreção traqueal com aspecto purulento.

O CDC publicou pela primeira vez, em 1985, critérios epidemiológicos que norteavam as notificações das $\mathrm{IH}$, visando homogeneidade e padronização na definição das $\mathrm{IH}$. Um desses critérios era o tempo de internação, porém a versão de 2008 estabelece IH apenas como condição localizada ou sistêmica gerada por reações adversas, devido à presença de um agente infeccioso ou de toxinas, cujos sintomas não estavam evidentes, tampouco o agente infeccioso em período de incubação, no momento da internação. A definição para pneumonia hospitalar apresenta três critérios: a) pneumonia clinicamente definida; b) pneumonia causada por bactérias, leveduras, fungos, vírus e microrganismos incomuns e com achados laboratoriais específicos e c) pneumonia em pacientes imunossuprimidos (Horan et al., 2008).

\subsubsection{Fatores de risco para pne $\square$ monia hospitalar}

Os fatores de risco tornam-se relevantes para a compreensão e manejo da fisiopatologia da pneumonia hospitalar (ATS, 2005; Niederman, 2004; Vincent et al., 1995). Aqueles considerados mais importantes a todos os pacientes são: presença de doença pulmonar obstrutiva crônica (DPOC), gravidade da doença na admissão na UTI, pós-operatório de cirurgia torácica e abdominal, idade acima de 60 anos, aspiração de conteúdo gástrico com inóculo de microrganismo suficiente para atingir as vias aéreas inferiores, presença de sonda gastroenteral e uso de antimicrobiano prévio (Fernandes, Zamorano, Torezan., 2000).

Além desses, a colonização da cavidade bucal por microrganismos provenientes de outras áreas também é considerada fator de risco. Esse fator é complexo e exige novas pesquisas, principalmente para a população mais idosa e de pacientes críticos. Alguns autores sugerem que uma higiene bucal precária contribui para a pneumonia aspirativa em idosos, devido à permanência da placa dental, causando um desequilíbrio da microbiota local e favorecendo assim a colonização da orofaringe por outros microrganismos (Isakou, Kollef, 2006; Terpening, 2005).

Em relação à pneumonia em idoso, foi realizado um estudo brasileiro com 322 pacientes de um Hospital Universitário do Estado de São Paulo, em 1999, cuja taxa global de IH foi de $23,6 \%$ (76) e com uma incidência maior entre os idosos da faixa 
etária de 80-91 anos $(47 \%$ e $p<0,05)$. Das IH, a infecção respiratória foi a prevalente $(27,6 \%)$ e dos 61 pacientes com IH, $14(22,9 \%)$ evoluíram para óbito $(p<0,05)$. A taxa de letalidade desses pacientes foi 22,3\% (Villas-Bôas, Ruiz, 2005).

Alguns fatores de risco são comuns aos dois grupos de pacientes considerados críticos (sem VM e com VM). Para pacientes sem VM destacam-se: tempo de duração de cirurgia, estado nutricional deficiente, uso de imunossupressores, nível de consciência rebaixado, depressão dos reflexos das vias aéreas, patologias com comprometimento muscular, sexo masculino, colonização da orofaringe com bacilos Gram-negativos, esofagite de refluxo, pneumonia prévia e obesidade (Bontem, 2002; Carvalho, 2006; Medeiros, Menezes, Valle, 2005; Tablan et al., 2004).

Já, para pacientes com VM destacam-se: duração da VM, traumas cranianos extensos e severos, re-intubação, aspiração de microrganismos provenientes das placas dentais, intubação de emergência, terapia inibitória da acidez gástrica, troca de circuitos respiratórios em intervalos menores de 48 horas, meses frios do ano, decúbito horizontal, realização de broncoscopia recente, choque, sangramento macroscópico gástrico, duração da internação, sedação com barbitúricos, autoextubação e traqueostomia (Fernandes, Zamorano, Torezan, 2000; Medeiros, Menezes, Valle, 2005).

É preciso destacar a participação dos profissionais de saúde envolvidos na assistência direta, pois concorrem para o aumento do risco das $\mathrm{IH}$, quando não adotam ou não aderem corretamente às medidas de controle e prevenção. Eles contribuem para a disseminação de microrganismos entre os pacientes pela ausência ou redução da higienização das mãos, contaminação ambiental com microrganismos resistentes aos antimicrobianos, reprocessamento e manuseio inadequado dos materiais médico-hospitalares, dentre outras medidas (Fernandes, Zamorano, Torezan, 2000; Medeiros, Menezes, Valle, 2005; Vincent et al., 1995). 


\subsubsection{Magnit $\square$ de da pne $\square$ monia associada à ventilação mecânica}

Apesar dos avanços tecnológicos no suporte ventilatório para o tratamento da insuficiência respiratória e o desenvolvimento dos antibióticos, a maioria das questões relacionadas à PAVM permanece controversa e sem consenso (Niederman, 2004; Torres, Carlet, 2001).

A utilização da ventilação mecânica invasiva consiste em aplicar uma pressão positiva nos pulmões por meio de uma cânula introduzida nas vias aéreas. Entretanto, esse suporte ventilatório pode causar eventos adversos como instabilidade hemodinâmica, principalmente em pacientes com hipovolemia e infecções respiratórias hospitalares, pois a presença da cânula reduz as barreiras de defesa do organismo e causa lesões associadas às altas pressões nos alvéolos, justificadas pelas condições clínicas do paciente (Carvalho, 2006).

A Coordenação de Vigilância de Saúde da Prefeitura da Cidade de São Paulo em parceria com o Núcleo Municipal de Controle de Infecção divulgou os indicadores epidemiológicos de resultados de $\mathrm{IH}$ do primeiro semestre de 2007. Os dados analisados foram provenientes de 76 UTI do município de São Paulo. Os dados referentes à taxa de Densidade de Incidência de PAVM (242.340 pacientes-dia) ocorreram nos seguintes percentis: $10 \%(6,64), 25 \%(9,55), 50 \%(13,67), 75 \%(19,13)$ e no percentil $90 \%(28,55)$ dos hospitais apresentaram casos de PAVM (Assis et al., 2008).

Fagon et al. (1993), encontraram taxas de mortalidade que variam de 2,2 a 4,4 em pacientes com PAVM semelhantes às encontradas em pacientes sem PAVM.

Kollef et al., em 1995, demonstraram que o risco de mortalidade aumenta entre os pacientes que desenvolvem PAVM tardia pelos agentes etiológicos: Pseudomonas aeruginosa, Acinetobacter spp. multirresistentes e Stenotrophomonas maltophilia.

Os fatores de risco associados à mortalidade na PAVM são VM prolongada, paciente com diagnóstico médico-cirúrgico, idade $\geq 60$ anos, doença de base fatal ou com APACHE 11-30 (Agude Physiology and Chronic Health Evaluation), pneumonia severa, coma no momento da admissão, falência múltipla de órgãos, choque séptico, pneumonias causadas por Pseudomonas aeruginosa, Acinetobacter baumannii, Stenotrophomonas maltophilia e Staphylococcus aureus resistente à meticilina e outros microrganismos resistentes aos antimicrobianos, uso de antibioticoterapia prévia e tratamento inicial inadequado (Fernandes, Zamorano, Torezan, 2000; Kollef et al., 1995; Medeiros, Menezes, Valle, 2005; Vincent et al., 1995). 
Os estudos que abordam a relação entre custo e estadia dos pacientes com pneumonia hospitalar podem apresentar valores variados devido ao emprego de metodologias diferentes no tratamento dos doentes.

Warren et al. (2003) realizaram um estudo com 819 pacientes sobre custo da PAVM em um hospital não escola e atribuíram um custo de US\$11. 897 (IC 95\% = US\$5.265 a US\$26.214) para cada episódio dos 127 (15,5\%) pacientes com PAVM.

Para prevenir um episódio de pneumonia hospitalar em paciente de UTI e, consequentemente, reduzir a morbi-mortalidade com a adoção de medidas baseadas em evidências, é necessário um custo em torno de US\$13.340 (Van Nieuwenhoven et al., 2004).

Diante das implicações de morbi-mortalidade, custos e dias de internação, entre outros danos relacionados com a PAVM para o paciente, justifica-se a importância da adesão por parte dos profissionais de saúde às medidas de controle e prevenção das infecções respiratórias não só em pacientes críticos. É preciso considerar a gravidade e a representação de uma infecção hospitalar em um paciente e todas as suas implicações, pois muitos episódios de IH envolvem fatores intrínsecos (pacientes) e extrínsecos (materiais e equipamentos, procedimentos invasivos, contaminação cruzada, falta de adesão às medidas preventivas e de implementação de protocolos, tratamento e diagnósticos inadequados, entre outros).

\subsubsection{Medidas de controle e prevenção da pne $\square$ monia hospitalar}

As estratégias preventivas em uma instituição de saúde podem ser específicas, mas o seu sucesso depende da educação contínua da equipe profissional durante a assistência aos pacientes (Zack et al., 2002).

A prevenção da pneumonia hospitalar tem como objetivos principais diminuir a transmissão cruzada de microrganismos aos pacientes, reduzir a colonização de reservatórios com microrganismos relacionados às infecções, prevenir o avanço desses agentes para os alvéolos pulmonares e/ou auxiliar nas defesas do hospedeiro (Fernandes, Zamorano, Valle, 2000).

Várias medidas de controle e prevenção para as pneumonias hospitalares estão reunidas em diretrizes clínicas, como os Guidelines for preventing for healthcare-associated pneumonia (guias clínicos), recomendações do CDC e Healthcare 
Infection Control Practices Advisory Commitee (HICPAC). Esses guias utilizam recursos que fundamentam as recomendações, sendo um deles a evidência científica, que auxilia na avaliação quanto à força do estudo e sua aplicabilidade, bem como na utilização das evidências na forma de intervenções práticas e/ou na formulação de novos estudos (Tablan et al., 2004).

As diretrizes clínicas têm o objetivo de reduzir práticas inadequadas, como a aplicação de novas tecnologias e procedimentos que não apresentam vantagens em reduzir desconforto ou minimizar as técnicas invasivas aos pacientes (Oliveira, 2003).

Os Serviços de Controle de Infecção Hospitalar utilizam as diretrizes clínicas dos guias como ferramentas de trabalho há décadas, entre as quais as medidas de controle e prevenção para pneumonia estão incluídas (Sierra et al., 2005).

Existem diversas formas de classificar as evidências científicas, uma delas é pela força dos estudos científicos, que se baseia na qualidade e a quantidade dos estudos. Essa classificação é muito utilizada para a elaboração de revisão sistemática e estudos de metanálises, conforme apresentado no Quadro 1.

\section{$\mathbf{Q} \square$ adro 1 - Classificação das evidências seg $\square$ ndo o desenho dos est $\square$ dos}

\begin{tabular}{|c|l|}
\hline $\begin{array}{c}\text { Nível/Desenho } \\
\text { do est } \square \text { do }\end{array}$ & \multicolumn{1}{c|}{ Critério/Descrição } \\
\hline 1 & $\begin{array}{l}\text { Forte evidência com pelo menos um estudo de metanálise ou revisão } \\
\text { sistemática ou vários estudos controlados e bem delineados e aleatórios. } \\
\text { Forte evidência com pelo menos um estudo controlado bem delineado e } \\
\text { aleatório. } \\
\text { Evidência de estudo bem delineado e não aleatório, coorte, série-histórica } \\
\text { ou caso-controle. } \\
\text { Evidência de estudo não aleatório, coorte sem controle e série-histórica. } \\
\text { Opinião de autoridades respeitadas, evidências baseadas nas experiências } \\
\text { clínicas, estudos descritivos ou relatos de comitês de especialistas. }\end{array}$ \\
\hline 5 &
\end{tabular}

Fonte: extraído parcialmente de Collard, Saint, Matthay, 2003; Fulbrook, Mooney, 2003; Oliveira, 2003.

As diretrizes clínicas do CDC e HICPAC para prevenção das pneumonias hospitalares difundidas e aplicadas nas instituições hospitalares são baseadas nas seguintes categorias de evidências: 
- Categoria IA: fortemente recomendado para implementação e fortemente embasado por estudos experimentais, clínicos ou epidemiológicos bem elaborados.

- Categoria IB: fortemente recomendado para implementação e embasado por alguns estudos experimentais, clínicos ou epidemiológicos e uma racionalidade teórica forte.

- Categoria IC: exigido por regulamentação, leis ou padronizações estatais ou federais.

- Categoria II: sugerido para a implementação e embasado por estudos clínicos sugestivos ou epidemiológicos ou uma racionalidade teórica.

- Não recomendado: significa questão não resolvida, pois a evidência não é suficiente para embasar determinadas práticas ou não existe consenso em relação à eficácia existente (Tablan et al., 2004).

Basicamente, as diretrizes clínicas dividem-se em medidas não medicamentosas e medicamentosas e são compostas por mais de oitenta recomendações.

Essas diretrizes ou recomendações para controle e prevenção de pneumonias hospitalares estão representadas de forma sintetizada e foram extraídas parcialmente do Guidelines for preventing health-care associated pneumonia (Tablan et al., 2004). Sendo citadas aqui apenas as que auxiliam na compreensão da temática e que atendem às propostas desta pesquisa (Quadro 2). 


\section{Q $\square$ adro 2 - Diretrizes $0 \square$ recomendações para prevenção de pne $\square$ monias hospitalares}

\begin{tabular}{|c|c|c|c|}
\hline Tópico & Medida de controle & Recomendação & Categoria \\
\hline Educação em Saúde & $\begin{array}{l}\text { Treinamento dos } \\
\text { profissionais. }\end{array}$ & Em relação à epidemiologia e prevenção. & IA \\
\hline \multirow[t]{3}{*}{$\begin{array}{l}\text { Vigilância de infecção e } \\
\text { microbiológica }\end{array}$} & \multirow[t]{2}{*}{$\begin{array}{l}\text { Indicadores } \\
\text { epidemiológicos }\end{array}$} & $\begin{array}{l}\text { Medir risco do procedimento para identificar } \\
\text { tendências, calcular taxas e divulgar dados. }\end{array}$ & IB \\
\hline & & Agentes isolados e perfil de sensibilidade. & IB \\
\hline & $\begin{array}{l}\text { Monitorização } \\
\text { microbiológica }\end{array}$ & $\begin{array}{l}\text { Não realizar culturas rotineiras em pacientes e } \\
\text { equipamentos. }\end{array}$ & II \\
\hline \multirow[t]{13}{*}{$\begin{array}{l}\text { Prevenção de transmissão de } \\
\text { microrganismo. }\end{array}$} & $\begin{array}{l}\text { Reprocessamento de } \\
\text { equipamentos }\end{array}$ & Limpeza prévia & IA \\
\hline & \multirow[t]{2}{*}{ Artigos semi-críticos } & Esterilização ou desinfecção de alto nível & IA \\
\hline & & $\begin{array}{l}\text { Enxágue preferencialmente com água estéril } \\
\text { ou potável com ou sem álcool na secagem. }\end{array}$ & IB \\
\hline & Ventiladores mecânicos & $\begin{array}{l}\text { Não esterilizar ou desinfetar maquinaria } \\
\text { interna. }\end{array}$ & II \\
\hline & \multirow[t]{4}{*}{ Circuitos respiratórios } & $\begin{array}{l}\text { Não trocar rotineiramente, somente quando } \\
\text { estiver visivelmente sujo ou com mau } \\
\text { funcionamento mecânico. }\end{array}$ & IA \\
\hline & & $\begin{array}{l}\text { Drenar e descartar rotineiramente qualquer } \\
\text { condensado nos circuitos. }\end{array}$ & IB \\
\hline & & $\begin{array}{l}\text { Usar luvas para realizar o procedimento acima } \\
\text { e ou manipular o condensado dos circuitos. }\end{array}$ & IB \\
\hline & & Filtro no circuito expiratório. & Não resolvida \\
\hline & \multirow[t]{2}{*}{ Umidificadores } & Água estéril para umidificadores. & II \\
\hline & & Sistema contínuo de umidificação fechado. & Não resolvida \\
\hline & \multirow[t]{3}{*}{$\begin{array}{l}\text { Nebulizador de } \\
\text { medicação de pequeno } \\
\text { volume }\end{array}$} & $\begin{array}{l}\text { Entre tratamentos no mesmo paciente, limpar, } \\
\text { desinfetar, enxaguar com água estéril e } \\
\text { realizar secagem. }\end{array}$ & IB \\
\hline & & Fluido estéril para nebulização. & IA \\
\hline & & $\begin{array}{l}\text { Uso de medicações aerossolizadas em frascos } \\
\text { de dose única; se utilizado em frascos de } \\
\text { múltiplas doses, seguir instruções do } \\
\text { fabricante. }\end{array}$ & IB \\
\hline \multirow[t]{3}{*}{$\begin{array}{l}\text { Transmissão cruzada entre } \\
\text { pessoa-a-pessoa. }\end{array}$} & Higiene das mãos & $\begin{array}{l}\text { Contatos com membranas mucosas, secreções } \\
\text { respiratórias, ou fómites contaminados } \\
\text { independente de uso de luvas e equipamentos } \\
\text { contaminados, independente do uso de luvas. }\end{array}$ & IA \\
\hline & \multirow[t]{2}{*}{ Traqueostomia } & Técnica asséptica & II \\
\hline & & $\begin{array}{l}\text { Cânula submetida à esterilização ou } \\
\text { desinfecção de alto nível. }\end{array}$ & IB \\
\hline $\begin{array}{l}\text { Prevenção da broncoaspiração } \\
\text { associada à nutrição enteral. }\end{array}$ & $\begin{array}{l}\text { Pacientes com VM e/ou } \\
\text { com Nutrição Enteral. }\end{array}$ & $\begin{array}{l}\text { Elevar cabeceira do leito a } 30-45^{\circ} \text {, quando } \\
\text { possível. }\end{array}$ & II \\
\hline $\begin{array}{l}\text { Precauções para prevenção da } \\
\text { aspiração. }\end{array}$ & $\begin{array}{l}\text { Prevenção da } \\
\text { aspiração associada à } \\
\text { intubação. }\end{array}$ & Preferir intubação orotraqueal. & IB \\
\hline \multirow[t]{3}{*}{$\begin{array}{l}\text { Prevenção ou modulação da } \\
\text { colonização orofaríngea. }\end{array}$} & \multirow[t]{3}{*}{$\begin{array}{l}\text { Colonização } \\
\text { orofaríngea }\end{array}$} & $\begin{array}{l}\text { Limpeza e descontaminação da cavidade } \\
\text { orofaríngea com antisséptico e implementar } \\
\text { programa para higiene bucal }\end{array}$ & II \\
\hline & & $\begin{array}{l}\text { Bochecho com clorexidina } 0,012 \% \text { para } \\
\text { pacientes em pré-operatório de cirurgia } \\
\text { cardíaca. }\end{array}$ & II \\
\hline & & $\begin{array}{l}\text { Bochecho com clorexidina para todos } \\
\text { pacientes em pós-operatório de cirurgia } \\
\text { cardíaca ou doenças críticas ou de alto risco. }\end{array}$ & Não resolvida \\
\hline \multirow{2}{*}{$\begin{array}{l}\text { Prevenção da pneumonia pós- } \\
\text { operatória. }\end{array}$} & \multirow[t]{2}{*}{ Fisioterapia } & Pacientes em pré-operatório com alto risco. & IB \\
\hline & & $\begin{array}{l}\text { Espirometria em pacientes em pós-operatório } \\
\text { com alto risco. }\end{array}$ & IB \\
\hline Fonte: extraído parcialmente & ablan et al. (20 & & \\
\hline
\end{tabular}


Tolentino-DelosReyes, Ruppert e Shiao (2007) ponderam que, apesar das recomendações do CDC e HICPAC (Tablan et al., 2004) quanto à prevenção da colonização da orofaringe e da broncoaspiração associada à nutrição enteral, o próprio guia clínico não fornece estratégias de como realizar a higiene bucal ou de como medir o volume residual gástrico de paciente com sonda nasogástrica (SNG), também não sugerem outras orientações, como suspensão da dieta durante mudança de decúbito ou elevação da cabeceira do leito do paciente antes de iniciar a dieta.

A Associação Americana das Enfermeiras de Cuidados Críticos (American Association of Critical-Care Nurses - AACN), em 2007, recomenda a implementação das práticas baseadas nas diretrizes clínicas para redução da PAVM, como: cabeceira elevada de $30-45^{\circ}$; se não houver contra-indicação; cânula endotraqueal com sonda para aspiração contínua de secreções sub-glóticas; não trocar o circuito do ventilador-mecânico em menos de 48 horas de uso e higiene das mãos após contato entre os pacientes. São medidas não medicamentosas, seguras, de baixo custo, efetivas e praticáveis. Existem vários pacotes de medidas sendo implantados, porém o mais difundido nos EUA e Reino Unido é composto basicamente de quatro medidas: profilaxia para trombose venosa profunda e úlcera gástrica por estresse, decúbito elevado de $30-45^{\circ}$ e protocolo para sedação (Crunden et al., 2005).

Em 2002, a empresa de gestão em saúde VHA, localizada no Texas (EUA), e o Institute for Healthcare Improvement em Boston (EUA), estabeleceram algumas medidas preventivas de $\mathrm{IH}$, visando melhorias na assistência prestada aos pacientes de UTI. A JCAHO, em parceria com essas instituições, implementou um estudo piloto com as medidas sugeridas e concluiu que as quatro medidas já citadas acima, apresentaram resultados significativos quanto à redução das infecções respiratórias hospitalares em pacientes sob VM (Berenholtz et al., 2004).

Antes de iniciar o processo para a implantação de um pacote de medidas, é preciso estabelecer critérios baseados nas evidências e avaliar a qualidade das recomendações adotadas anteriormente pela instituição, para identificar se outras medidas preventivas, consideradas básicas, são executadas pelos profissionais durante a assistência. É importante ressaltar que o pacote de medidas deve ser pautado nas necessidades dos pacientes e instituições (Cason et al., 2007; Crunden et al. 2005; Tolentino-DelosReyes, Ruppert, Shiao, 2007). 


\subsubsection{Higiene $b$ cal como nova prática relevante na prevenção e controle da pne $\square$ monia associada à ventilação mecânica}

Embora a higiene bucal seja uma prática tradicional na assistência ao paciente, até recentemente não havia evidências científicas de sua relevância direta para a prevenção de IH, principalmente pneumonia. Tanto é verdade, que as atuais diretrizes e recomendações para o controle de infecção respiratória do CDC e HICPAC não categorizam tal prática como recomendação baseada em fortes evidências (Tablan et al., 2004). Vários estudos isolados e posteriores a tais diretrizes, inclusive aqueles de melhores evidências científicas, como revisões sistemáticas e metanálises, vêm, contudo, determinando a higiene bucal como uma medida significativa para reduzir a PAVM em pacientes de cirurgias cardíacas e demais pacientes críticos (Azarpazhooh, Leake, 2006; Berry et al., 2007; Chan et al., 2007; Garcia, 2005; Kola, Gastmeier, 2007; Lorente, Blot, Rello, 2007; Scannapieco, Stewart, Mylotte, 1992).

Para entender essa relação, é preciso revisar aspectos fisiológicos e microbiológicos da cavidade bucal e o desenvolvimento da PAVM. A microbiota da cavidade bucal normal é composta por mais de 300 espécies de bactérias diferentes que, sob condições normais, mantêm-se em equilíbrio. Porém, podem sofrer interferências de fatores relacionados aos hospedeiros.

Os pacientes críticos apresentam um aumento dos níveis da enzima protease nas secreções orais, a qual remove das superfícies dos dentes uma substância protetora denominada fibronectina. A perda dessa substância reduz o mecanismo de defesa intermediado pelas células reticuloendoteliais (Gibbsons, 1989).

A fibronectina é uma glicoproteína capaz de inibir a aderência de bacilos Gram-negativos na orofaringe e a sua redução pode contribuir para fixação dessas bactérias, substituindo a microbiota previamente existente por bactérias epidemiologicamente importantes nas infecções hospitalares, como a Pseudomonas aeruginosa nas células epiteliais faríngeas e orais (Medeiros, Menezes, Valle, 2005).

A placa dental é um importante reservatório para vários microrganismos em pacientes de UTI e em instituições de longa permanência, porém é possível reduzir a colonização da cavidade bucal com a implantação e melhoria da higiene bucal (Scannapieco, Stewart, Mylotte, 1992). 
As bactérias que colonizam a orofaringe, seios faciais, nariz, placa dental e o trato gastrointestinal, podem sofrer alterações devido ao aparecimento de sinusites, aumento do $\mathrm{pH}$ gástrico e do uso de antibióticos. Já, os pacientes que apresentam acidose, uremia, Diabetes mellitus descompensada, hipotensão, leucocitose, leucopenia e etilismo, possuem frequentemente uma colonização maior nessas regiões (Medeiros, Menezes, Valle, 2005).

Além dos fatores endógenos, a microbiota normal da cavidade bucal e do trato respiratório superior também sofrem modificações em razão da utilização de equipamentos respiratórios contaminados (circuitos respiratórios do ventilador mecânico, equipamentos de inaloterapia, entre outros), dietas enterais, contato direto e indireto com outros pacientes, higiene inadequada das mãos de profissionais implicando contaminação cruzada entre os pacientes (Medeiros, Menezes, Valle, 2005; Scannapieco, Stewart, Mylotte, 1992).

Quanto às vias respiratórias inferiores, a colonização pode acontecer por várias situações, tais como: micro ou macro-aspiração do volume de secreções provenientes da orofaringe, inalação de aerossóis com microrganismos viáveis ou até mesmo por via hematogênica (Medeiros, Menezes, Valle, 2005).

Diversos autores apontam a bronco-aspiração de secreções contaminadas com microrganismos provenientes da orofaringe e placa dental como um dos fatores de risco para pneumonia em pacientes críticos, principalmente submetidos à ventilação mecânica, pois promove a colonização da traquéia e dos pulmões (Cardeñosa Cendrero et al., 1999; Gibbsons, 1989; Scannapieco, Stewart, Mylotte, 1992;). A aspiração das secreções ocorre em cerca de $45 \%$ dos casos, durante o sono de pessoas saudáveis, podendo se aproximar de $100 \%$ durante o sono profundo e nos indivíduos etilistas ou, ainda, nas seguintes situações: nível de consciência rebaixado, intubação endotraqueal, sonda nasogástrica e posição supina (Huxley et al., 1978; Medeiros, Menezes, Valle, 2005).

Schleder, Stott e Lloyd (2002) afirmam que a higiene bucal precária, isto é, inadequada ou ausente, contribui para a colonização da cavidade bucal, especialmente pelos microrganismos associados à PAVM, estando presentes em $67 \%$ das secreções de pacientes com mais de 24 horas de intubação endotraqueal e nos equipamentos respiratórios utilizados por eles.

Um estudo que avaliou a prevalência da colonização da placa dental em 49 pacientes idosos, críticos e submetidos à ventilação mecânica, demonstrou que $57 \%$ 
estavam colonizados por bactérias aeróbias, sendo $45 \%$ Staphylococcus aureus, 42\% pelas bactérias entéricas e 13\% por Pseudomonas aeruginosa. Dos pacientes que desenvolveram pneumonia hospitalar (14/29\%), dez possuíam as mesmas bactérias na placa dental e no aspirado traqueal. Mesmo com uma amostra reduzida, esses resultados sugerem que a placa dental pode ser reservatório de microrganismos importantes para o desenvolvimento da pneumonia hospitalar (ElSolh et al.; 2004).

Segundo Garcia (2005), uma higiene bucal frequente auxilia na eliminação da placa dental, reduzindo a colonização bacteriana. Ele conclui que a colonização da região da orofaringe e da placa dental são os maiores precursores das infecções respiratórias, principalmente da PAVM.

A participação dos microrganismos da cavidade bucal como potenciais agentes etiológicos da pneumonia hospitalar não é assunto novo. Em 1972, Johanson e Pierce estabeleceram a relação entre a colonização do trato respiratório superior com o desenvolvimento da PAVM. Contudo, a questão continua controversa, pois a escolha do antisséptico ou antibióticos, padronização da técnica de higiene bucal, seleção de paciente, frequência e dias de uso para a descontaminação da cavidade bucal e do trato gastrointestinal não estão bem estabelecidos pelas principais diretrizes clínicas nacionais e internacionais.

Para Berry et al. (2007), a relação entre colonização da placa dental e os microrganismos das vias aéreas para o desenvolvimento da pneumonia ainda permanece pouco difundida, impedindo a adoção de protocolos de higiene bucal para pacientes de UTI. Inferiram que, devido à ausência de evidências sobre as melhores práticas, os enfermeiros frequentemente realizam a higiene bucal nos pacientes de acordo com suas preferências ou por experiências da própria prática.

Azarpazhooh e Leake (2006) analisaram uma revisão sistemática com 19 estudos, referentes às recomendações relacionadas à pneumonia e outras doenças respiratórias. Os autores identificaram níveis de evidências e as categorizações das recomendações. Nessa revisão, classificaram a associação entre pneumonia e a saúde bucal como nível II e categoria B. Quanto à redução ou frequência das doenças respiratórias pela descontaminação da cavidade bucal com antimicrobiano, consideraram nível I e categoria $A$, independentemente do tipo de intervenção adotada. A realização da higiene bucal em pacientes críticos como medida preventiva de pneumonia, classificaram como nível I e categoria A. Os autores 
enfatizam a necessidade de treinamentos dos profissionais para realização da higiene bucal em pacientes idosos de instituições de longa-permanência e em pacientes de UTI ${ }^{1}$.

Cabe ressaltar que a clorexidina $(\mathrm{CHX})$ tem sido apontada como 0 antisséptico alternativo para redução e descolonização do trato gastrointestinal, devido ao risco de desenvolvimento de resistência bacteriana pelo uso rotineiro de antibióticos (Kola, Gastmeier, 2007).

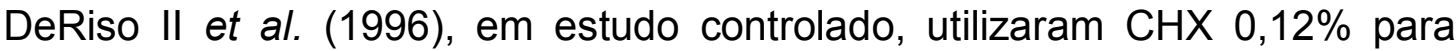
higiene bucal no pré-operatório, momentos antes da Intubação Orotraqueal (IOT) dos pacientes submetidos à cirurgia cardíaca, e demonstraram uma ocorrência maior de PAVM (10\%) no grupo placebo, quando comparado ao grupo que utilizou clorexidina (3\%). A partir desses resultados, os autores relacionaram o antisséptico à uma redução significativa da taxa de PAVM nessa população.

Portanto, não há dúvida quanto à importância da higiene bucal, pois o CDC e o HICPAC sugerem como uma de suas recomendações, a implantação de um programa que contemple a higiene bucal e a descontaminação da cavidade bucal com antissépticos em pacientes com quadro agudo, internados em instituições de longa permanência e com risco aumentado para a pneumonia hospitalar (categoria II). No que diz respeito à $\mathrm{CHX} 0,12 \%$, recomendam-na durante o período de préoperatório de pacientes que se submeterão à cirurgia cardíaca (categoria II). No entanto, para todos os pacientes com doenças críticas, pós-operatório ou com alto risco de desenvolver pneumonia, a recomendação da $\mathrm{CHX}$ é categorizada como questão não resolvida (Tablan et al., 2004).

Lorente, Blot e Rello (2007) revisaram 22 recomendações para prevenção de PAVM de quatro importantes instituições como European Task Force on ventilatorassociated pneumonia (ETF), CDC, Canadian Critical Care Society (CCCS) e ATS. Comparam entre elas as categorizações das evidências científicas. Foram destacadas apenas duas recomendações, por serem consideradas prioritárias para a compreensão deste estudo, conforme Quadro 3.

\footnotetext{
Os autores citam a definição estabelecida pela Canadian Task Force Methodology, levels of evidence. Research design rating. Disponível em: <http: www.ctfphc.org>. Acesso em 5 jan 2006. Nível de evidências: I. Para pelo menos um estudo aleatório e controlado; II. 2. Estudo analítico de coorte ou caso-controle bem delineado, preferencialmente realizado por mais de um Centro ou grupo de pesquisa. Categoria das recomendações: A. Boa evidência para sustentar a recomendação; $\mathbf{B}$. Razoável evidência para sustentar a recomendação para que a condição seja especificamente considerada em um exame periódico de saúde.
} 


\section{Q $\square$ adro 3 - Forças das evidências científicas seg $\square$ ndo as instit $\square$ ições $E T F$, CDC, CCCS e ATS}

\begin{tabular}{|c|c|c|c|c|}
\hline Recomendação & ETF (2001) & CDC (2004) & $\begin{array}{l}\text { CCCS } \\
(2004)\end{array}$ & ATS (2005) \\
\hline $\begin{array}{l}\text { Descolonização } \\
\text { seletiva digestiva }\end{array}$ & $\begin{array}{l}\text { Questão sem } \\
\text { controvérsia }\end{array}$ & $\begin{array}{l}\text { Questão não } \\
\text { resolvida }\end{array}$ & $\begin{array}{l}\text { Evidências } \\
\text { insuficientes }\end{array}$ & Categoria I* \\
\hline $\begin{array}{l}\text { Higiene oral com } \\
\text { clorexidina }\end{array}$ & $\mathrm{NR}^{*}$ & $\begin{array}{l}\text { Categoria } I^{*} \\
\text { em pacientes com } \\
\text { pré-operatório para } \\
\text { cirurgia cardíaca }\end{array}$ & $\mathrm{NR}^{*}$ & $\begin{array}{l}\text { Categoria I* em } \\
\text { pacientes com pré- } \\
\text { operatório de } \\
\text { cirurgias } \\
\text { cardíacas }\end{array}$ \\
\hline
\end{tabular}

*Categorias: NR- a questão não foi revisada; I - evidência bem conduzida, com estudo aleatório e controlado; II - evidência bem desenhada, com estudo controlado, mas não aleatório. [Fonte: extraído parcialmente: Lorente, Blot, Rello (2007)].

As quatro instituições citadas recomendam o uso associado de antibióticos via oral e intravenoso para descolonização seletiva da orofaringe e estômago. No entanto, essa prática não é muito difundida atualmente e os autores destacam que é preciso considerar a questão da resistência microbiana aos antibióticos. Concluem que a utilização de antibióticos para descolonização é complexa e exige monitoramento microbiológico dos pacientes durante seu uso, a fim de se detectar o desenvolvimento de resistência das bactérias aos antimicrobianos. Embora a adoção do antisséptico $\mathrm{CHX}$ associado à limpeza da cavidade bucal para a remoção mecânica da placa dental seja necessária, a higiene bucal com CHX, mesmo diante das evidências, talvez seja insuficiente se utilizada como única medida de prevenção (Lorente, Blot, Rello, 2007).

Quanto aos produtos, existem várias opções disponíveis para a higiene bucal: solução de $\mathrm{CHX}$ nas concentrações: $0,12 \%, 0,2 \%$ e a $2 \%$; peróxido de hidrogênio, solução de Polivinilpirrolidona lodo (PVP-I), soluções com mentol (enxaguatórios), bicarbonato de sódio, soluções salinas e solução bucal enzimática.

Em 2006, pesquisadores japoneses realizaram um estudo não aleatório e controlado com 1666 pacientes sob VM de UTI médico-cirúrgica, promovendo a higiene bucal com a aplicação de PVPI-I. A incidência de PAVM no grupo caso $(3,9 \%)$ foi significativa em relação ao grupo controle $(10,4 \%)$, assim como o RR 0,37 (IC 95\%=0,22-0,62) e um risco atribuído de -3,96\% (Mori et al., 2006).

Têm merecido destaque os estudos com a $\mathrm{CHX}$, independentemente das formas de apresentações (gel, solução e creme dental) e concentrações $(0,12 \%$, $0,2 \%$ e $2 \%$ ). Esse antisséptico é utilizado mundialmente há mais de trinta anos em diversas situações clínicas. 
A CHX é uma biguanida catiônica, desenvolvida na Inglaterra na década de 50. Sua atividade antimicrobiana é atribuída à sua ligação à membrana citoplasmática da célula, causando sua ruptura e levando à precipitação dos conteúdos celulares. Ela tem boa atividade contra bactérias Gram-positivas e uma ação menor contra as bactérias Gram-negativas, fungos e vírus. Apresenta atividade residual de aproximadamente seis a oito horas, porém esse tempo depende da sua concentração (Larson, 1995). Além disso, sua utilização é bastante variada, pois existem formulações para aplicação em pele intacta, feridas traumáticas e cirúrgicas, membranas mucosas, entre outras.

Vale ressaltar o desenvolvimento de resistência das bactérias aos antissépticos. Russel, em 2001, questiona se a sensibilidade reduzida das bactérias aos antissépticos contribui para o aparecimento de cepas resistentes aos antimicrobianos.

Para Thomas et al. (2000), o uso dos antissépticos pode favorecer ao

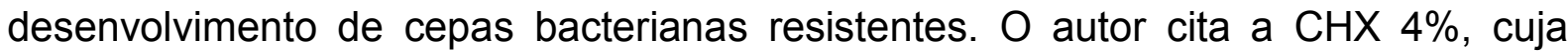
concentração residual vai decaindo, após sua utilização, abaixo da concentração mínima inibitória indicada para destruir determinados microrganismos, expondo-a então à pressão seletiva de cepas bacterianas resistentes.

Apesar dos efeitos do uso contínuo dos antissépticos ainda não terem sido bem esclarecidos, a maioria dos resultados de estudos de revisão sistemática e de metanálise publicados tem sido favorável ao uso de antissépticos para descontaminação da orofaringe em pacientes com risco aumentado para a PAVM.

Chan et al. (2007) conduziram uma revisão sistemática e metanálise, sobre a descontaminação da cavidade bucal para prevenção de PAVM. Dos 11 estudos selecionados: a) seis ocorreram com $\mathrm{CHX}$ em diferentes apresentações (gel, solução e creme dental), concentrações $(0,12 \%, 0,2 \%$ e $2 \%)$ e frequência; b) quatro utilizaram antibióticos; c) apenas um estudo com PVPI-I a 10\% e d) um estudo utilizou $\mathrm{CHX}$ como tratamento $\mathrm{A}$ e antibiótico via oral (creme) como tratamento $\mathrm{B}$. $\mathrm{A}$ partir dos resultados analisados, concluíram que os estudos com os antissépticos mostraram redução significativa das taxas de incidência de PAVM. No entanto, os autores ressaltam que a higiene bucal com antisséptico não deve ser adotada para todos os pacientes até que novos estudos mostrem a relação entre o uso prolongado e a resistência dos microrganismos aos antissépticos. 
Pineda, Saliba e Solh, em 2006, selecionaram quatro estudos publicados entre 1996 a 2005, sobre o efeito da CHX na incidência de pneumonia hospitalar. Desses estudos, dois realizaram a descontaminação da orofaringe com $\mathrm{CHX}$ $0,12 \%$ em pacientes cirúrgicos e os outros dois, com $\mathrm{CHX} 0,2 \%$, em pacientes de UTI. Os autores constataram que a higiene bucal com $\mathrm{CHX}$ não teve resultado significativo na incidência de PAVM (OR 0,77; IC 95\%=0,28-2,11). Considerando esses achados, a metanálise sugere que a aplicação da $\mathrm{CHX}$ para descontaminação da orofaringe deva ser associada a medidas que auxiliem a remoção da placa dental.

Outra metanálise sobre descontaminação oral, publicada em 2007, avaliou estudos de pesquisadores que utilizaram os seguintes produtos para descontaminação bucal: $\mathrm{CHX} 0,12 \%$ em duas UTI de cirurgia cardíaca e em uma UTI de trauma; $\mathrm{CHX}$ 0,2\% em duas UTI médico-cirúrgicas e a $2 \%$ em uma UTI de clínica médica e uma UTI que não foi especificada no estudo. Os autores analisaram sete estudos publicados entre 1996 a 2006 e concluíram que a utilização da CHX tópica reduziu a PAVM, porém foi mais efetiva entre os pacientes de UTI de cirurgia cardíaca. Entretanto, essa metanálise não considerou as diferentes definições para PAVM, população, concentração das $\mathrm{CHX}$ utilizadas nos estudos. Portanto, novos estudos devem ser realizados para a determinação da concentração ideal do antisséptico para cada tipo de população, frequência de aplicação, custo e o impacto na resistência bacteriana da microbiota oral (Chlebicki, Safdar, 2007).

Em 2007, pesquisadores alemães conduziram uma metanálise, com estudos do tipo controlado e aleatório, sobre a prevenção das infecções do trato respiratório inferior com a aplicação de $\mathrm{CHX}$ em pacientes sob VM. Desses, três estudos avaliaram pacientes cirúrgicos e o antisséptico de escolha foi $\mathrm{CHX} 0,12 \%$. Os outros cinco estudos incluíram pacientes de UTI médico-cirúrgica e a $\mathrm{CHX}$ em diversas concentrações (um estudo com $\mathrm{CHX} 0,12 \%$; três a $0,2 \%$ e mais um a $2 \%$ ). Apesar de considerar as diferentes concentrações do antisséptico e populações, os resultados analisados indicaram que a $\mathrm{CHX}$ pode figurar entre as medidas preventivas para a PAVM de início precoce (Kola, Gastmeier, 2007).

Apesar das controvérsias, as evidências apontam que a higiene bucal com antisséptico e remoção da placa dental devem ser adotadas e padronizadas na assistência, principalmente em pacientes com IOT, devido ao risco aumentado para desenvolverem PAVM. Contudo, é fundamental a implementação não só de outras 
medidas de controle e prevenção, mas também da avaliação da adesão dessas medidas propostas.

Tendo isso em vista, a higiene bucal foi incluída no indicador de avaliação de práticas de controle e prevenção de pneumonia em pacientes de alto risco neste estudo como mais uma prática significativa para controle e prevenção de PAVM. 
3 Objetivos 


\subsection{Geral}

Avaliar a conformidade de práticas de controle e prevenção da pneumonia associada à ventilação mecânica.

\subsection{Específicos}

a) Calcular os índices de conformidade de práticas de controle e prevenção da pneumonia da pneumonia associada à ventilação mecânica, por meio de aplicação de indicadores clínicos de avaliação;

b) Correlacionar fatores associados com os índices de conformidade obtidos. 
4 Casuística e Métodos 


\subsection{Tipo de Investigação}

Tratou-se de pesquisa aplicada envolvendo achados sobre o desempenho de programas, práticas, procedimentos ou normas, buscando acessar a qualidade ou o sucesso desse desempenho. Nas tipologias apresentadas por Polit et al. (2004b), ela se insere na avaliação de análise de processo. Já, de acordo com Novaes (2000), situa-se predominantemente na avaliação para gestão.

Quanto ao desenho, optou-se pelo método prospectivo, transversal e analítico, como o mais apropriado para o alcance dos objetivos propostos. Este foi também um estudo de observação, pois os dados foram coletados pela observação direta dos eventos sob avaliação.

\subsection{Cenário}

O estudo foi desenvolvido em uma UTI-Adulto de um hospital público, estadual e de ensino na cidade de São Paulo, que presta assistência geral de média complexidade e conta, atualmente, com 258 leitos ativos. Sua clientela provém principalmente do Distrito de Saúde da região em que está localizado, além da comunidade formada por docentes, discentes, demais funcionários e seus respectivos dependentes.

A UTI-Adulto atende pacientes a partir dos 15 anos, de ambos os sexos, e presta assistência geral. Possui doze leitos, porém no período do estudo apresentava onze leitos ativos, distribuídos em quatro salas (com dois leitos cada) e quatro quartos utilizados como isolamentos para pacientes com suspeita ou com doenças infecto-contagiosas e portadores de bactérias com multirresistência a determinados antibióticos.

Os profissionais da saúde na UTI-Adulto são distribuídos nas seguintes equipes:

a) Equipe médica: cinco a seis assistentes nos turnos da manhã e da tarde e dois em cada turno da noite, além de cinco ou mais alunos do sexto ano. 
b) Equipe de fisioterapeutas: um a dois profissionais e dois a três estagiários para cada turno da manhã e tarde. No turno da noite não há fisioterapeutas.

c) Farmacêutico: um no período da manhã.

d) Nutricionista: um em cada período da manhã e tarde.

e) Equipe de enfermagem: uma enfermeira-chefe, em horário administrativo (segunda a sexta-feira); três a quatro enfermeiros assistenciais, cinco a seis auxiliares e/ou técnicos de enfermagem para cada turno da manhã e da tarde; dois a três enfermeiros assistenciais e cinco a seis auxiliares e/ou técnicos de enfermagem em cada turno da noite; um atendente de enfermagem responsável pelos encaminhamentos de exames laboratoriais no turno da manhã; um técnico e um auxiliar de enfermagem que atuam exclusivamente com os materiais e equipamentos hospitalares e uma técnica administrativa. Esses quatro últimos atuam em horário administrativo.

A jornada de trabalho das equipes de enfermagem, fisioterapeutas, nutricionista e farmacêutico é de 36 horas semanais e da equipe médica é de 24 horas semanais.

Cada enfermeiro assistencial é responsável por dois a quatro pacientes, nos quais realiza procedimentos assistenciais exclusivos dos enfermeiros, além de desenvolver o Sistema de Assistência de Enfermagem (SAE), processo de enfermagem implementado em todo hospital desde 1981 pelo Departamento de Enfermagem, cujas etapas adotadas atualmente são: histórico, diagnóstico, evolução e prescrição de enfermagem (Gaidzinski et al., 2008). Os enfermeiros também são responsáveis por: atividades administrativas, supervisão das demais categorias de enfermagem e técnico administrativo, dimensionamento de pessoal, interação com áreas de apoio e com diversas unidades assistenciais, dentre outras. Em situações de redução da equipe de auxiliares e/ou técnicos, devido às ausências previstas (folgas, feriados e férias) e nas não previstas como faltas e licenças (Gaidzinski, Fugulin, Castilho, 2005), o enfermeiro também assume a assistência integral de um paciente.

Cada auxiliar e/ou técnico de enfermagem assume assistência integral a dois pacientes e, em situações excepcionais, a três pacientes. As atividades diárias incluem: administração de medicamentos e dietas, coletas de exames laboratoriais, banhos, curativos, aspiração de vias aéreas, punções de acesso venoso periférico, encaminhamentos de pacientes a exames, limpeza concorrente e de determinados materiais e equipamentos hospitalares, dentre outras atividades. 


\subsection{Práticas de Controle e Prevenção de PAVM Selecionadas para Avaliação}

As práticas selecionadas correspondem àquelas de melhor categoria de recomendações, sendo uma específica para o controle e prevenção de PAVM e outra para controle e prevenção infecção hospitalar em geral, conforme seguem.

a) Adesão às medidas específicas de prevenção e controle de pne $\square$ monia em pacientes de alto risco

- $\quad$ manutenção da cabeceira elevada a 30-45;

- atendimento diário de fisioterapia respiratória nos turnos da manhã e tarde;

- $\quad$ utilização de soluções estéreis para nebulizadores e inaladores;

- material de terapia respiratória (inalador e/ou umidificador) em uso e respeitando a rotina de troca estabelecida;

- realização de higiene bucal.

b) Adesão à higiene das mãos em sit $\square$ ações selecionadas relacionadas com c $\square$ idados do trato respiratório

- $\quad$ aspiração orotraqueal com ou sem coleta de secreção;

- higiene bucal;

- troca de cadarço da cânula orotraqueal.

\subsection{Cas $\square$ ística}

Correspondeu às oportunidades de avaliações das práticas selecionadas, realizadas pelos profissionais de saúde em pacientes internados na UTI-Adulto do referido Hospital. Constituíram critérios de inclusão e exclusão:

\section{Pacientes}

- Inclusão: todos os pacientes sob IOT durante o período do estudo.

- Exclusão: todos os pacientes extubados, mesmo os mantidos em ventilação mecânica por meio de traqueostomia. Os pacientes que estavam em cama sem o instrumento denominado "goniômetro" foram excluídos somente da observação da recomendação de cabeceira elevada a $30-45^{\circ}$, pela impossibilidade de registrar com exatidão o grau que a cabeceira estava no momento da observação direta. 


\section{Profissionais de saúde}

- Inclusão: todos os profissionais de saúde que realizaram as práticas assistenciais previamente selecionadas nos pacientes incluídos, no período da coleta dos dados, durante os turnos da manhã, tarde e noite e que, em razão dos tipos de práticas avaliadas, corresponderam às equipes de enfermagem e fisioterapia.

- Exclusão: profissionais de saúde que não realizaram as práticas previamente selecionadas.

\subsection{Cálc $\square$ lo do Tamanho da Amostra}

Para estimar o tamanho da amostra da proporção de conformidades, pode-se utilizar a seguinte fórmula (para o teste uni-caudal) (Rosner, 2006, p. 275):

$$
n=\frac{p_{0} q_{0}\left(z_{1-\alpha}+z_{1-\beta} \sqrt{\frac{p_{1} q_{1}}{p_{0} q_{0}}}\right)^{2}}{\left(p_{1}-p_{0}\right)^{2}}
$$

onde;

$p_{0}:$ proporção de conformidade esperada ou sob a hipótese nula

$q_{0}=1-p_{0}$ : proporção de não-conformidade

$p_{1}:$ proporção de conformidade alternativa

$q_{1}=1-p_{1}:$ proporção de não-conformidade alternativa

$z_{1-\alpha}$ : escore-z para o nível de significância

$z_{1-\beta}:$ escore-z para o poder do teste

Supondo que a proporção de conformidade é de $80 \%$, a proporção de conformidade alternativa de $88 \%$, significância de $5 \%$ e poder de $95 \%$, o tamanho da amostra para aferição foi de 222 (n aproximado para o próximo inteiro) avaliações das práticas previamente selecionadas. Considerando que esse é o número mínimo estabelecido para a amostra, elevou-se para 228 por conta de possíveis perdas ao longo da coleta de dados, correspondendo a 76 em cada turno de trabalho (manhã, tarde e noite), exceto para as atividades de fisioterapia, que não são realizadas à noite. 
Desta forma, somando-se os componentes de cada prática a ser avaliada (cinco medidas específicas de controle e prevenção de PAVM e três de adesão à higiene das mãos), obteve-se 1064 oportunidades de avaliações de medidas específicas de prevenção e controle de pneumonia e 684 de higiene das mãos, totalizando 1748 avaliações.

A distribuição de tais avaliações é apresentada nas Tabelas 1 e 2.

Tabela 1 - Distrib $\square$ ição da amostra para avaliação de conformidade das medidas específicas de prevenção e controle de pne $\square$ monia em pacientes de alto risco. São $\mathrm{Pa} \square$ lo, 2009

\begin{tabular}{lcccc}
\hline \multicolumn{1}{c}{ Medidas de prevenção } & Manhã & Tarde & Noite & Total \\
\hline Troca de material de terapia respiratória & 76 & 76 & 76 & 228 \\
Fisioterapia* & 76 & 76 & $\ldots$ & 152 \\
Cabeceira elevada a $\geq 30^{\circ}$ & 76 & 76 & 76 & 228 \\
Uso de solução estéril & 76 & 76 & 76 & 228 \\
Higiene bucal & 76 & 76 & 76 & 228 \\
Total & $\mathbf{3 8 0}$ & $\mathbf{3 8 0}$ & $\mathbf{3 0 4}$ & $\mathbf{1 0 6 4}$ \\
\hline
\end{tabular}

*No turno da noite não se realiza fisioterapia

Tabela 2 - Distrib ição da amostra para avaliação de conformidade da higiene das mãos nos seg intes procedimentos selecionados. São Pa $\square$ lo, 2009

\begin{tabular}{lcccc}
\hline Procedimentos & Manhã & Tarde & Noite & Total \\
\hline Aspiração orotraqueal & 76 & 76 & 76 & 228 \\
Troca de cadarço & 76 & 76 & 76 & 228 \\
Higiene bucal & 76 & 76 & 76 & 228 \\
Total & $\mathbf{2 2 8}$ & $\mathbf{2 2 8}$ & $\mathbf{2 2 8}$ & $\mathbf{6 8 4}$ \\
\hline
\end{tabular}

A estratégia utilizada para avaliar tais práticas com uma conformidade de $80 \%$ foi traçada a partir de estudos de avaliação de procedimentos de enfermagem já realizados (Nonino, 2006; Torres, Andrade, Santos, 2005;) e estudos de avaliação de higiene das mãos, em que os autores utilizaram a observação direta para medirem a adesão dos profissionais (Pittet et al., 2000; Rosenthal, Guzman, Safdar, 2005; Sharir et al., 2001; Zimakoff, Stormark, Larsen, 1993).

São poucos, no entanto, os estudos com aplicação de avaliações de processo na área de controle e prevenção de IASS e, consequentemente, são poucas, também, as definições de parâmetros de conformidade existentes, que caracterizem a adesão dessas medidas pelos profissionais. 
Nos dois estudos de avaliação da qualidade de alguns procedimentos de enfermagem, um deles analisou o desempenho dos profissionais na punção venosa periférica, e constatou uma mediana de acerto de $78 \%$ no desempenho (Torres, Andrade, Santos, 2005). O outro adotou como parâmetro para os acertos na execução dos procedimentos banho e curativo, o índice de positividade igual ou superior a $70 \%$ para cada item do instrumento de avaliação e no escore de acertos obtidos em cada procedimento (Nonino, 2006).

Já, estudos de avaliação da adesão à higiene das mãos pelos profissionais de saúde são mais frequentes na área de controle e prevenção de IASS. Neles, as adesões apresentaram variações nos índices de conformidade, desde $23,1 \%$ até $95 \%$ (Pittet et al., 2000; Rosenthal, Guzman, Safdar , 2005; Sharir et al., 2001; Zimakoff, Stormark, Larsen, 1993).

\subsection{Instr $\square$ mentos para Avaliação das Práticas de Controle e Prevenção de PAVM Selecionadas}

Para a aplicação dessas avaliações foram utilizados instrumentos na forma de indicadores clínicos processuais, conforme elaborados e validados quanto ao seu conteúdo, e disponibilizados no Manual de Avaliação da Qualidade de Práticas de Controle de Infecção Hospitalar (São Paulo, 2006).

Cada um desses indicadores contém um construto operacional e uma planilha para registro das avaliações. Os construtos descrevem e orientam a aplicação da avaliação das práticas a eles correspondentes. Eles estão dispostos, portanto, em operações concretas e indicam o que se avalia e como deve ocorrer a coleta de informações e sua mensuração. Com isso, eles buscam garantir uniformidade na avaliação e legitimidade da representação empírica dos dados. Ao apresentarem, também, a melhor prática disponível, fundamentada cientificamente, permitem calcular índices de conformidade após a avaliação. Os itens constitutivos dos construtos operacionais de cada indicador são os que seguem.

Título: identifica o nome do indicador e seu código respectivo.

Descrição: enuncia e justifica a prática a ser avaliada e sua importância para o controle de infecção hospitalar (porquê avaliar). 
Fundamentação científica e/ou legal: relaciona as bases disponíveis utilizadas para evidência ou sustentação do conteúdo sob avaliação de cada indicador, nas formas de estudos científicos isolados, diretrizes clínicas, normas de órgãos governamentais e de sociedades de especialistas e consenso de especialistas.

Tipo de avaliação: explicita se é estrutura, processo ou resultado.

Fórmula do indicador: estabelece numerador e denominador, descrevendo, de maneira mais objetiva possível, o que deve ser medido.

Amostra para cálculo do indicador: orienta sobre a necessidade de proceder a uma amostragem que garanta representatividade da totalidade das ações sob avaliação de um dado período.

Fontes de informações: explicita os locais e formas de coleta das informações necessárias para avaliação de cada indicador, definidas segundo critérios que propiciem maior fidedignidade e/ou acessibilidade possíveis. De acordo com o tipo de indicador, tais fontes podem ser: documental (prontuário, manual de procedimentos, atas de reuniões, etc.), observação direta, entrevista, etc.

Critérios para avaliação: descreve como o dado deve ser coletado e qualificado. Os critérios foram padronizados em: A (Atende); NA (Não Atende); AP (Atende Parcialmente); IN (Inaplicável, quando o serviço não realiza ou não possui o item sob avaliação).

Planilha: para anotação das informações coletadas e anotação de observações.

Cálculo do indicador: espaço reservado para cálculo de conformidade, após todas as aplicações efetuadas.

Para este estudo foram utilizados dois desses indicadores disponibilizados no referido Manual:

- IRPR: Indicador de avaliação da adesão às medidas de controle e prevenção de PAVM, que incluem: manutenção da cabeceira elevada a 3045\%; atendimento diário de fisioterapia respiratória nos turnos da manhã e tarde; utilização de soluções estéreis para nebulizadores e inaladores; material de terapia respiratória (inalador e/ou umidificador) em uso e respeitando a rotina de troca estabelecida (Anexos $A$ e $B$ ).

- HMSEL: Indicador de avaliação da adesão à higiene das mãos (Anexos C e D).

Nos moldes dos indicadores disponibilizados pelo referido Manual (São Paulo, 2006), foi elaborado mais um indicador especificamente para este estudo: 
- IRHB: Indicador de avaliação da adesão à realização de higiene bucal (Apêndices A e B).

Esclareça-se que, apesar de a higiene bucal poder constituir mais um componente do Indicador IRPR, porém ela não foi originalmente contemplada no mesmo. Isto porque a sua evidência científica somente foi fundamentada por estudos posteriores. Ressalte-se, que o próprio Manual (São Paulo, 2006) considera a necessidade de atualização de medidas de controle e prevenção de IASS, conforme forem surgindo novas evidências científicas, e o presente estudo não poderia se furtar a incorporar esta mais recente e relevante medida. Contudo, com o intuito de não alterar o indicador originalmente construído, optou-se avaliá-la isoladamente, ao invés de adicioná-la às medidas já constantes no indicador IRPR.

\subsection{Testes de Precisão dos Instr $\square$ mentos de Avaliação}

A precisão, também conhecida como reprodutibilidade, confiabilidade e consistência, é afetada pelo acaso (erro aleatório), portanto, quanto maior o erro, menos precisa é a medida (Hulley, Martin, Cummings, 2003). Com base nesses conceitos, os testes utilizados para a busca de precisão neste estudo referiram-se a:

- reprodutibilidade inter-avaliador - diferentes avaliadores realizando as medições;

- reprodutibilidade intra-instrumento - um único instrumento foi utilizado em medições repetidas;

- reprodutibilidade inter-instrumento - instrumentos diferentes foram utilizados para as medições em um conjunto de sujeitos.

As etapas para a realização dos testes foram as que seguem.

\subsubsection{Instr $\square$ mentos e treinamento dos avaliadores}

Uma das estratégias indicadas por Hulley, Martin e Cummings (2003) para minimizar possíveis erros aleatórios durante a obtenção dos dados é a padronização dos métodos de medição por meio de instruções por escrito. O Manual de Avaliação da Qualidade de Práticas de Controle de Infecção Hospitalar (São Paulo, 2006) já disponibiliza tais instruções, na forma de construtos operacionais para cada 
indicador. Desta maneira, foi necessária a inclusão de mais duas estratégias indicadas, que são:

- Treinamento dos avaliadores, a fim de testar o domínio das técnicas recomendadas nos construtos operacionais dos indicadores clínicos utilizados no estudo.

- Repetição das avaliações realizadas com os instrumentos propostos.

O treinamento prévio dos avaliadores contribuiu para minimizar a parcialidade da avaliação, já que esta não pode ser totalmente eliminada. Os avaliadores foram os que seguem:

- Avaliador 1: IRSCM - autora deste estudo e enfermeira de CCIH;

- Avaliador 2: JRG - aluna de graduação em enfermagem e bolsista de iniciação científica;

- Avaliador 3: ACB - enfermeira de CCIH e doutora em enfermagem;

- Avaliador 4: JA - enfermeira e aluna de especialização em Licenciatura em Emergências;

- Avaliador 5: GCB - aluna de graduação em enfermagem.

Uma vez que ocorreu substituição dos avaliadores, em razão do período de coleta de dados e de disponibilidade dos mesmos, o treinamento acontecia conforme a incorporação de novos avaliadores, no mesmo turno em que eles realizariam a coleta de dados e acompanhados, inicialmente, pela autora. Esta estratégia foi utilizada para facilitar a adaptação dos mesmos junto à equipe profissional, assim como reconhecer os momentos em que as práticas selecionadas aconteciam com maior frequência e, por conseguinte, aumentar as oportunidades de sua avaliação. Tais momentos foram identificados como sendo sempre as três primeiras horas de cada turno.

Os avaliadores foram orientados quanto a: reconhecer somente os pacientes com IOT; registrar as informações obtidas nas planilhas de avaliação respectivas à medida que as práticas eram realizadas pelos profissionais de saúde; atuar de modo a não interferir na realização da prática; efetuar a avaliação de forma discreta.

Antes do início dos testes, os instrumentos foram ajustados, de modo a adequá-los às rotinas da instituição e objetivos do estudo. Tais ajustes, inclusive, são considerados desejáveis pelo Manual de Avaliação da Qualidade de Práticas de Controle de Infecção Hospitalar (São Paulo, 2006), de onde tais instrumentos se originam. 


\subsubsection{Aferição de concordância inter-observadores, intra-instr $\square$ mentos e inter- instr $\square$ mentos}

Para a aferição, utilizou-se o cálculo do coeficiente de correlação intra-classe, pelo teste de Kappa (k), indicado para avaliar a intensidade da concordância simultânea entre dois ou mais avaliadores, baseando-se no número de respostas concordantes, utilizando um mesmo instrumento, ou, entre um observador utilizando um mesmo instrumento em diferentes oportunidades (Newman, Browner, Cunnings, 2006).

Os parâmetros adotados para medir a concordância foram os sugeridos por Landis e Koch (1977). Estabeleceu-se, também, o nível de significância de 5,0\% $(p<0,05)$ para essa análise, uma vez que tais parâmetros podem variar entre os autores. O programa utilizado para os cálculos foi Statistical Package for the Social Sciences (SPSS), versão 16.0.

O coeficiente de Kappa é aplicado em variáveis nominais e seus parâmetros variam de 0 a 1 , sendo "0" o valor mínimo e o "1" o valor máximo para o grau de concordância entre os observadores. Os parâmetros sugeridos para as categorias e graus de concordância são: < 0,00 ausente; 0,01 a 0,20 fraca; 0,21 a 0,40 discreta; 0,41 a 0,60 moderada; 0,61 a 0,80 substancial; 0,81 a 0,99 quase perfeita e 1,00 concordância perfeita (Landis, Koch, 1977).

Para a análise da concordância, as avaliações foram contabilizadas em duplas, que atuavam simultaneamente e registravam as informações em planilhas independentes, sendo que o número de avaliações para cada dupla variou conforme as oportunidades obtidas. Os componentes do IRPR e IRHB constituíram 922 avaliações e os do HMSEL, 490 observações, portanto foram incluídas na aferição de concordância 1412 observações.

A Tabela 3 apresenta os resultados de concordância entre as informações obtidas pelos avaliadores com os seus respectivos instrumentos, para os componentes dos indicadores IRPR e IRHB. 


\section{Tabela 3 - Aferição de concordância obtida entre as $\mathbf{d}$ plas de avaliadores para os componentes dos indicadores IRPR e IRHB. São Pa $\square$ lo, 2009}

\begin{tabular}{lccc}
\hline \multicolumn{1}{c}{ Variáveis } & $\begin{array}{c}\text { Total } \\
\mathbf{n = 9 2 2}\end{array}$ & Kappa & $\mathbf{p}$ \\
\hline Avaliadores 1 e 2 & & & \\
$\quad$ Troca de material de terapia respiratória & 97 & 1,00 & 0,000 \\
Uso de soluções estéreis & 92 & 1,00 & 0,000 \\
Fisioterapia respiratória & 96 & 0,94 & 0,000 \\
Cabeceira elevada $\geq 30^{\circ}$ & 80 & 0,96 & 0,000 \\
Higiene bucal & 27 & 0,90 & 0,000 \\
Avaliadores 1 e 3 & & & \\
Troca de material de terapia respiratória & 61 & 1,00 & 0,000 \\
Uso de soluções estéreis & 61 & 1,00 & 0,000 \\
Fisioterapia respiratória & 30 & 1,00 & 0,000 \\
Cabeceira elevada $\geq 30^{\circ}$ & 25 & 1,00 & 0,000 \\
Higiene bucal & 15 & 1,00 & 0,000 \\
Avaliadores 1 e 4 & & & \\
$\quad$ Troca de material de terapia respiratória & 57 & 1,00 & 0,000 \\
Uso de soluções estéreis & 57 & 1,00 & 0,000 \\
Fisioterapia respiratória & 57 & 1,00 & 0,000 \\
Cabeceira elevada $\geq 30^{\circ}$ & 45 & 1,00 & 0,000 \\
$\quad$ Higiene bucal & 40 & 1,00 & 0,000 \\
Avaliadores 4 e 5 & & & \\
$\quad$ Troca de material de terapia respiratória & 30 & 1,00 & 0,000 \\
Uso de soluções estéreis & 30 & 1,00 & 0,000 \\
Fisioterapia respiratória & $\ldots$ & $\ldots$ & $\ldots$ \\
Cabeceira elevada $\geq 30^{\circ}$ & $\ldots$ & $\ldots$ & $\ldots$ \\
Higiene bucal & 22 & 1,00 & 0,000 \\
\hline
\end{tabular}

Verifica-se concordância de $100 \%$ entre as duplas 1 e 3, 1 e 4 e 4 e 5 (k= 1,00), para todos os componentes avaliados dos indicadores IRPR e IRHB. Entre as duplas 1 e 2 a concordância obtida foi considerada quase perfeita para higiene bucal $(k=0,90)$, fisioterapia $(k=0,94)$ e troca de material de terapia respiratória $(k=$ $0,96)$, contudo, as diferenças entre os itens discordantes não foram significantes $(p<0,05)$.

Não foram incluídos nessa análise dois componentes de controle e prevenção de pneumonia na dupla 4 e 5: fisioterapia respiratória e cabeceira elevada $\geq 30^{\circ}$, pois o avaliador 5 participou da coleta de dados apenas no turno da noite; nesse horário não se realiza fisioterapia nos pacientes e a amostra necessária para a avaliação de cabeceira elevada $\geq 30^{\circ}$ para os pacientes com IOT, já tinha sido atingida no turno da noite pelos outros avaliadores, portanto o avaliador 5 não foi aferido nesses componentes ao ingressar no grupo de avaliadores.

A Tabela 4 mostra a comparação entre as duplas ao avaliarem os 
componentes do indicador HMSEL. Nota-se concordância de 100\% para as duplas 1 e 3, 1 e 4 e 4 e $5(k=1,00)$ em todas as medidas de higiene das mãos. Destaque-se, mais uma vez, a dupla de avaliadores 1 e 2, que obteve concordância inferior: antes e após a aspiração orotraqueal (0,73 e 0,81), antes e após higiene bucal (0,85 e $0,75)$. Esses resultados são classificados como uma concordância substancial, a qual varia de 0,61-0,80. Mesmo assim, esses graus de concordância inferiores quando comparados com as demais duplas não foram importantes estatisticamente $(p<0,05)$. Em relação à dupla 1 e 3 , o nível de significância encontrado foi $p=0,046$, na higiene das mãos antes e após a troca de cadarço. Apesar deste valor ser muito próximo do nível de significância estabelecido $(p<0,05)$, constatou-se que não houve diferença entre os dois avaliadores. Esse valor se deve muito provavelmente à pequena amostra utilizada para a análise. 
Tabela 4 - Aferição de concordância obtida entre as d $\square$ plas de avaliadores para os componentes do indicador HMSEL. São Pa $\square$ lo, 2009

\begin{tabular}{|c|c|c|c|c|c|c|c|c|c|c|c|c|c|c|c|c|c|c|}
\hline \multirow{3}{*}{$\begin{array}{l}\mathrm{D} \square \text { plas de } \\
\text { avaliadores }\end{array}$} & \multirow{3}{*}{ Total } & \multicolumn{5}{|c|}{ Aspiração orotraq eal } & \multicolumn{6}{|c|}{ Troca de cadarço } & \multicolumn{6}{|c|}{ Higiene $\mathbf{b} \square$ cal } \\
\hline & & \multicolumn{2}{|c|}{ Antes $(n=110)$} & \multicolumn{3}{|c|}{ Após $(n=110)$} & \multicolumn{3}{|c|}{ Antes $(n=66)$} & \multicolumn{3}{|c|}{ Após $(n=64)$} & \multicolumn{3}{|c|}{ Antes $(n=70)$} & \multicolumn{3}{|c|}{ Após $(n=70)$} \\
\hline & & $\mathbf{k}$ & $\mathbf{p}$ & $\mathrm{n}$ & $\mathbf{k}$ & $\mathbf{p}$ & $\mathbf{n}$ & $\mathbf{k}$ & $\mathbf{p}$ & $n$ & $\mathbf{k}$ & $\mathbf{p}$ & $\mathbf{n}$ & $\mathbf{k}$ & $\mathbf{p}$ & $\mathbf{n}$ & k & $p$ \\
\hline Avaliadores 1 e 2 & 42 & 0,73 & 0,000 & 42 & 0,81 & 0,000 & 18 & 1,00 & 0.000 & 16 & 1,00 & 0,000 & 17 & 0,85 & 0,001 & 17 & 0,75 & 0,001 \\
\hline Avaliadores 1 e 3 & 18 & 1,00 & 0,000 & 18 & 1,00 & 0,000 & 4 & 1,00 & 0,046 & 4 & 1,00 & 0,046 & 9 & 1,00 & 0,003 & 9 & 1,00 & 0,003 \\
\hline Avaliadores 1 e 4 & 22 & 1,00 & 0,000 & 22 & 1,00 & 0,000 & 27 & 1,00 & 0,000 & 27 & 1,00 & 0,000 & 27 & 1,00 & 0,000 & 27 & 1,00 & 0,000 \\
\hline Avaliadores 4 e 5 & 28 & 1,00 & 0,000 & 28 & 1,00 & 0,000 & 17 & 1,00 & 0,000 & 17 & 1,00 & 0,000 & 17 & 1,00 & 0,000 & 17 & 1,00 & 0,000 \\
\hline
\end{tabular}

k= Kappa 
Conclui-se que a concordância, de forma geral, foi alta nas diferentes medidas analisadas, considerando que a concordância perfeita é 1,00 e o nível de significância é de 0,05. Porém, é interessante notar que a dupla 1 e 2 foi a que apresentou maior discordância (Tabela 3 e Tabela 4), nos seguintes itens avaliados: cabeceira elevada $\geq 30^{\circ}$, realização de higiene bucal, higiene das mãos antes e após a aspiração orotraqueal, e antes e após higiene bucal.

Apesar de os parâmetros adotados por Landis e Koch (1977), considerarem como uma concordância substancial $(0,61-0,80)$ e uma concordância quase perfeita $(0,81-0,99)$, estatisticamente não houve diferença entre todas as duplas. Ainda assim, os valores encontrados na dupla 1 e 2 podem estar associados a vários fatores, pois ambos foram os primeiros avaliadores a iniciar a coleta de dados, tais como adaptação ao método proposto (observação direta) e às mudanças simples, mas necessárias, realizadas nas planilhas de coleta de dados para melhor captação das informações (aumento de espaços e de letras, inclusão da matrícula e leito do paciente, a fim de facilitar a busca de prontuários).

Esses achados permitiram concluir que tantos os instrumentos quanto os avaliadores estavam aptos para prosseguirem à coleta definitiva dos dados, de forma independente e individual, ou seja, não sendo mais necessário manter dois avaliadores para obtenção da mesma informação.

Uma vez que não houve estatisticamente diferença entre as duplas de avaliadores, foi possível aproveitar para a amostra definitiva parte das avaliações realizadas para os testes de aferição de concordância. Assim, incorporou-se apenas metade das 1412 avaliações ao montante necessário para a amostra definitiva, por elas terem ocorrido de forma duplicada. As 706 avaliações aferidas, portanto, representam 40,4\% do total das 1748 avaliações definidas para a amostra definitiva.

Após a aferição da concordância, os avaliadores foram distribuídos conforme suas disponibilidades de horário e, a partir daí, as avaliações foram contabilizadas individualmente, até a obtenção da amostra definitiva. 


\subsection{Período de Coleta de Dados}

O período compreendeu os meses de janeiro a julho de 2009, contudo, com variações de frequência entre os turnos, à medida que se atingia o total da amostra estabelecida para cada prática selecionada. As avaliações ocorreram de segunda a sexta-feira, nos turnos da manhã (7:50-10:50), tarde (13:30-16:30) e noite (19:3022:30). Os finais de semana e feriados foram excluídos pela possibilidade de redução na escala de profissionais de saúde, contribuindo, assim, para mais um tipo de viés.

O tempo utilizado para a obtenção da amostra (1748 eventos avaliados) correspondeu em 582 horas (165 - manhã; 150 - tarde; 267 - noite). A diferença de horas entre os turnos deveu-se a vários fatores, entre eles: presença de fisioterapeutas nos turnos manhã e tarde, aumentando as chances de avaliações de higiene das mãos; carga horária de trabalho menor em relação ao turno da noite, exigindo dos profissionais maior agilidade para cumprimento das tarefas prescritas e de rotina; priorização, pelos profissionais do noturno, aos pacientes que tinham banho no leito, o que dificultou avaliação, pois nem todos aqueles com IOT recebiam cuidados relacionados às práticas selecionadas no período programado para a avaliação (19:30-22:30).

Com referência a este último fator, foram realizadas avaliações por 12 horas seguidas nos dois turnos da noite (par e ímpar), a fim de avaliar o tempo proposto inicialmente (três horas/dia) para cada turno de trabalho. Concluiu-se que, apesar das 12 horas seguidas de observação, não houve aumento importante no número de oportunidades para avaliação das práticas selecionadas, mesmo nos pacientes com IOT que não recebiam banho, portanto optou-se por manter também às três horas para o turno da noite. 


\subsection{Procedimentos de Coleta de Dados}

Os dados foram coletados conforme as orientações dos construtos operacionais dos indicadores, disponibilizados no referido Manual (São Paulo, 2006), que incluíram predominantemente observação direta, além de análise de registros de prontuários.

Para Polit, Beck e Hungler (2004a), as técnicas de observação têm a vantagem de captar diretamente os comportamentos e os eventos, oferecendo maior variedade de informações em situação real. O ideal é que ela seja realizada sem o conhecimento prévio dos participantes observados, de maneira a evitar alterações de seus modos rotineiros de atuação. A conscientização causa distorções comportamentais, efeito conhecido como reatividade (efeito Hawthorne).

Os profissionais de saúde, sujeitos deste estudo, foram informados parcialmente a respeito da pesquisa; eles sabiam que estavam sendo observados, porém, desconheciam as práticas sob observação. Já, as chefias de equipes médica, enfermagem e fisioterapia foram informadas previamente sobre as práticas a serem observadas por meio de comunicação escrita e cópias do resumo da pesquisa e da autorização do Comitê de Ética em Pesquisa do hospital.

Além das mudanças comportamentais do observado, outros fatores interferem na aplicação da técnica de observação: as emoções e valores do observador, que podem levar a uma inferência inadequada; o interesse e o comprometimento do observador, que podem valorizar o que é visto na direção do que deseja ver e a antecipação do que deve ser observado (Polit, Beck, Hungler, 2004b).

As avaliações foram obtidas por meio de observação direta, com exceção para: realização de fisioterapia respiratória, que foi obtida por registro diário nos prontuários dos pacientes (turnos da manhã e tarde) e para identificar a modalidade de higiene bucal prescrita pelo enfermeiro. Portanto, considerou-se a higiene bucal em conformidade quando o profissional de enfermagem a realizava conforme prescrição de enfermagem. Para a avaliação utilizou-se a prescrição de enfermagem e a observação direta do procedimento. A não conformidade também incluiu a não realização do procedimento no paciente, juntamente com o ato de checar na prescrição de enfermagem como se tivesse executado no período destinado para a observação.

Quanto aos períodos de troca de material de terapia respiratória adotou-se a 
rotina preconizada na unidade (inalador/nebulizador a cada $24 \mathrm{~h}$; circuito do ventilador a cada 7 dias se estiver com copo de nebulização e com condensador higroscópico, somente entre pacientes e condensador higroscópico a cada 24 horas).

No caso da higiene das mãos, a conformidade era conferida somente quando o profissional as higienizava antes e após a realização das práticas previamente selecionadas (aspiração orotraqueal com ou sem coleta de secreção; higiene bucal; troca de cadarço da cânula orotraqueal), seja utilizando água e sabão líquido com antisséptico, seja aplicando álcool-gel. E a não conformidade era conferida quando o profissional não higienizava as mãos antes e após a realização das situações selecionadas e ou nas seguintes situações inadequadas:

- realizou outro procedimento assistencial no paciente logo após o término da aspiração orotraqueal ou da higiene bucal ou da troca de cadarço da cânula orotraqueal;

- retirou-se do quarto do paciente ou do local próximo ao leito para outras áreas sem realizar a higiene das mãos;

- trocou de luvas sem higienizar as mãos;

- sobrepôs luvas de procedimento ou estéreis sobre as mãos já enluvadas e utilizadas no mesmo paciente em outro procedimento.

Antes, porém, da aplicação da avaliação da higiene das mãos, foi realizada uma avaliação adicional da estrutura existente para sua adequada realização, considerando-se a funcionalidade de lavatórios, dispensadores de sabão e papel toalha e dispensadores de álcool-gel. Foram contabilizados sete lavatórios exclusivos para higiene das mãos dos profissionais e dois utilizados tanto por pacientes como profissionais. Todos os lavatórios possuíam dispensadores de sabão líquido e de papel toalha. Lembrando que, cada quarto tinha dois leitos, os lavatórios atendiam aproximadamente esses dois leitos, exceto um lavatório que atendia a quatro leitos. Dos quatro quartos de isolamento, dois deles possuíam lavatórios exclusivos para higiene das mãos dos profissionais, porém nos outros dois quartos os lavatórios eram de uso comum, pois estava localizado dentro dos banheiros dos quartos do pacientes. Quanto à funcionalidade, dois dispensadores de sabão líquido estavam mal fixados na parede, prejudicando o uso. Todos os 14 dispensadores de álcool-gel estavam localizados próximos aos leitos dos pacientes e apenas dois apresentaram entupimento, fato que dificultava a saída do produto. 
Todas as inadequações detectadas foram prontamente resolvidas pela chefia de enfermagem.

\subsection{Aspectos Éticos e Legais}

A pesquisa foi aprovada pelo Comitê de Ética em Pesquisa do hospital selecionado para o estudo, Registro CEP-HU/USP 843/08 - SINESP CAAE 0054.0.198.196-08 (Anexo E).

Após a aprovação, foi encaminhada cópia da mesma e do resumo do projeto de pesquisa às chefias de enfermagem, médica e de fisioterapia da UTI adulto, a fim delas tomarem ciência e favorecerem maior colaboração. Dada, porém, a característica da coleta de dados, que necessitou da técnica de observação direta de da maioria das práticas durante a atuação dos profissionais de saúde, eles foram informados sobre detalhes do estudo somente após a coleta de dados, por meio do Termo de Consentimento Livre e Esclarecido (TCLE) (Apêndice C).

A esse respeito, embora o TCLE tenha sido distribuído, o Comitê de Ética e Pesquisa reavaliou os objetivos do estudo, dispensando a obrigatoriedade e necessidade deste documento junto aos profissionais. Visto que a aplicação de indicadores de processo é uma das atividades da própria $\mathrm{CCIH}$ e reconhecendo a importância do estudo para a instituição. O sigilo das informações obtidas e o anonimato dos profissionais foram garantidos desde a construção dos próprios instrumentos utilizados na coleta de dados.

No que se refere à participação dos pacientes, embora sua seleção fosse baseada em critérios clínicos de inclusão, conforme já citado, a coleta de dados não implicou em qualquer alteração das práticas habitualmente neles realizadas. Do mesmo modo, os resultados, analisados de forma agregada, não implicaram, em momento algum, em identificação individual. Devido a isso, não se vislumbrou, em princípio, necessidade de autorização e consentimento formais dos mesmos, situação confirmada pelo Comitê de Ética e Pesquisa do hospital. 


\subsection{Tratamento dos Dados}

As avaliações realizadas foram lançadas em banco específico para este estudo, no programa Windows/Excel da Microsoft $^{\circledR}$ 2003, e analisadas quantitativamente, em números absolutos e percentuais. Os resultados obtidos foram apresentados em tabelas e gráficos.

Para o cálculo dos índices de conformidades das práticas incluídas nos indicadores aplicados, foram utilizadas as fórmulas recomendadas nos seus construtos operacionais, de dois modos: conformidade geral de cada indicador e conformidade de cada componente avaliado. Assim:

\section{Conformidade geral:}

IRPR: Indicador de avaliação da adesão às medidas de prevenção e controle de pneumonia em pacientes de alto risco.

No total de pacientes incluidos em que todos os componentes
(manutenção de cabeceira elevada a $30-45^{\circ}$.; realizaça de fisioterapia
respiratória; uso de soluções estéreis para nebulizadores e inaladores;
circuito de terapia inalatória em uso e acatando a rotina de troca) estão
corretamente aplicados

IRHB: Indicador de avaliação da adesão à higiene bucal.

\section{$N^{\circ}$ total de pacientes incluídos em que a higiene bucal foi realizada de} acordo com a rotina da instituição

$N^{0}$ total de pacientes incluídos avaliados quanto à higiene bucal

HMSEL: Indicador de Avaliação da Adesão à Higiene das Mãos em Situações Selecionadas.

$N^{\circ}$ total de oportunidades que o profissional de saúde teve para higienizar as mãos (antes e após) e efetivamente o fez na realização de aspiração traqueal, higiene bucal e troca de cadarço da cânula orotraqueal

$N^{\circ}$ total de oportunidades de higiene das mãos observadas nos $\times 100$ procedimentos relacionados no numerador 
Conformidade por componentes dos indicadores:

Foi aplicada a mesma forma de cálculo de conformidade, porém para cada componente dos indicadores, isoladamente.

Quanto à análise dos dados e a realização dos testes estatísticos, utilizou-se o programa estatístico Software SPSS, para Windows, versão 16.0.

Descrição dos testes utilizados: teste do Qui-Quadrado para comparar as proporções de conformidade entre os grupos e os períodos. Quando o teste do QuiQuadrado não pode ser aplicado devido a ocorrência de frequências esperadas menores do que cinco, foi utilizado o teste da Razão da Verossimilhança.

Adotou-se $5 \%(p<0,05)$ como o nível de significância para todos os testes. 
5 Resultados 
Foram realizadas 1748 observações, sendo que $836(47,8 \%)$ relacionaram-se às medidas de prevenção e controle de PAVM (IRPR), $684(39,1 \%)$ à higiene das mãos em procedimentos selecionados (HMSEL) e $228(13,1 \%)$ à higiene bucal (IRHB).

Ressalte-se que, em razão das práticas sob avaliação, somente foi possível observar as atuações das equipes de enfermagem e de fisioterapia.

São apresentadas, a seguir, para cada prática avaliada, as conformidades, não conformidades, associações entre categorias profissionais e turnos de trabalho e motivos de não conformidade.

\subsection{Adesão às medidas específicas de prevenção e controle de PAVM (Indicador IRPR)}

Conforme já descrito, no Capítulo anterior, esta avaliação foi composta de quatro medidas específicas de controle e prevenção de PAVM: troca de material de terapia respiratória respeitando a rotina estabelecida no local do estudo, fisioterapia respiratória, cabeceira elevada a $30-45^{\circ}$, uso de soluções estéreis para nebulizador e inalador.

Para o cálculo de conformidade geral, conforme a fórmula do indicador (IRPR) considerou-se o total de avaliações em que TODAS as medidas estavam em conformidade no MESMO paciente, portanto, o cálculo correspondeu ao número de pacientes, e não ao número total de observações das medidas. Assim, bastava apenas uma das quatro medidas não estar corretamente aplicada, para que a conformidade naquele paciente não fosse obtida. Os resultados são apresentados na Tabela 5. 
Tabela 5 - Distrib $\square$ ição de conformidade geral e por $\mathbf{t} \square$ rno de trabalho das medidas específicas de prevenção e controle de PAVM (IRPR). São $\mathrm{Pa} \square \mathrm{lo}, 2009$

\begin{tabular}{lccc}
\hline \multirow{2}{*}{$\mathbf{T} \square$ rno de trabalho } & Total & \multicolumn{2}{c}{ Conformidade } \\
\cline { 3 - 4 } & & $\mathbf{n}$ & $\mathbf{\%}$ \\
\hline Manhã & 76 & 48 & $63,2 \%$ \\
Tarde & 76 & 55 & $72,4 \%$ \\
Noite & 76 & 52 & $68,4 \%$ \\
Total & $\mathbf{2 2 8}$ & $\mathbf{1 5 5}$ & $\mathbf{6 8 , 0 \%}$ \\
\hline
\end{tabular}

A conformidade geral a todas as medidas de prevenção e controle de PAVM correspondeu a $68,0 \%$. O turno da tarde foi o que apresentou índice maior $(72,4 \%)$ e o da manhã, o índice menor $(63,2 \%)$. Em nenhum dos casos foi alcançada a conformidade geral mínima estabelecida, de 80\%. O Gráfico 1 oferece melhor visualização desses resultados.

Gráfico 1 - Distrib ição de conformidade das medidas específicas de prevenção e controle de PAVM (IRPR), seg $\square$ ndo o $t$ rno de trabalho. São Pa $\square$ lo, 2009

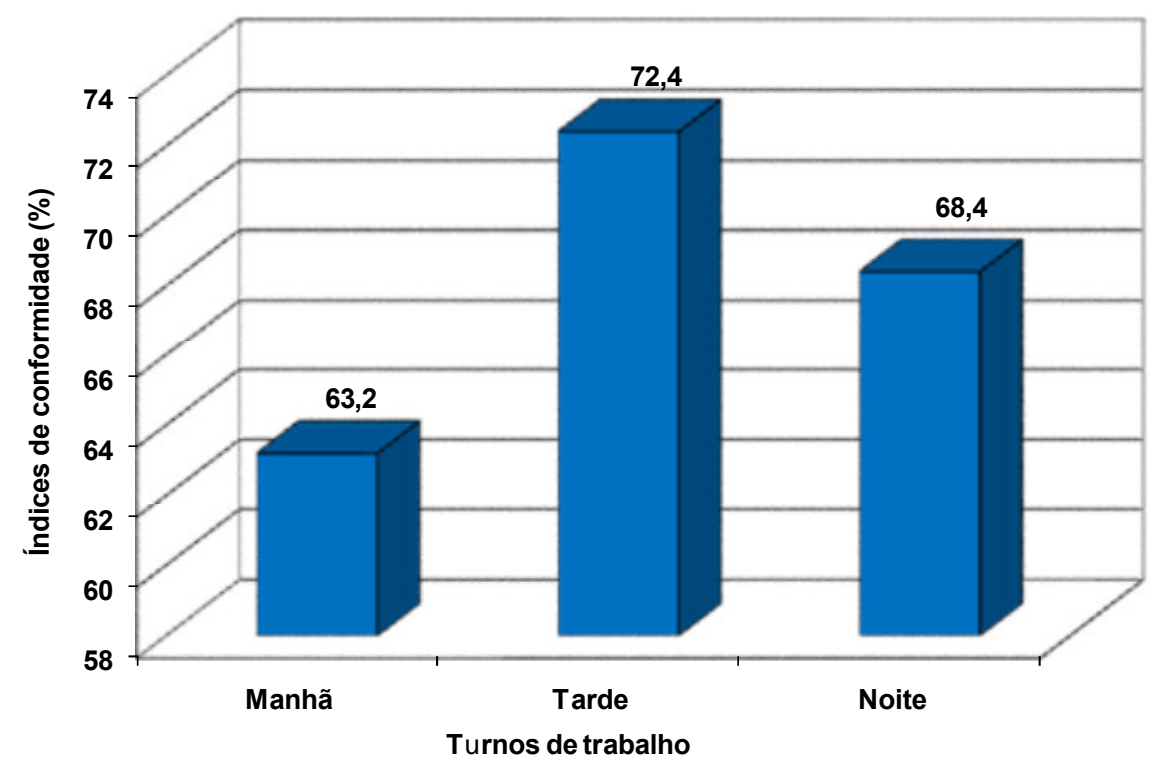

A Tabela 6, por sua vez, permite reconhecer conformidade e não conformidade a cada medida específica de prevenção e controle de PAVM, assim como os turnos de trabalho e associações de significância. 
Tabela 6 - Distrib $\square$ ição de conformidade e não conformidade de cada medida específica de controle e prevenção de PAVM, seg $\square$ ndo o $t$ rno de trabalho. São Pa $\square$ lo, 2009

\begin{tabular}{|c|c|c|c|c|c|c|}
\hline \multirow{2}{*}{ Variáveis } & \multirow{2}{*}{ Total } & \multicolumn{2}{|c|}{ Conforme } & \multicolumn{2}{|c|}{$\begin{array}{c}\text { Não } \\
\text { conforme }\end{array}$} & \multirow{2}{*}{$\mathbf{p}$} \\
\hline & & $\mathbf{n}$ & $\%$ & $\mathbf{n}$ & $\%$ & \\
\hline \multicolumn{7}{|l|}{ Manhã } \\
\hline $\begin{array}{l}\text { Troca de material de terapia } \\
\text { respiratória }\end{array}$ & 76 & 76 & 100,0 & - & - & \multirow{5}{*}{0,000} \\
\hline Fisioterapia & 76 & 69 & 91,0 & 7 & 9,0 & \\
\hline Cabeceira $\geq 30^{\circ}$ & 76 & 55 & 72,0 & 21 & 28,0 & \\
\hline Uso de solução estéril & 76 & 76 & 100,0 & - & - & \\
\hline Subtotal manhã & 304 & 276 & 90,8 & 28 & 9,2 & \\
\hline \multicolumn{7}{|l|}{ Tarde } \\
\hline $\begin{array}{l}\text { Troca de material de terapia } \\
\text { respiratória. }\end{array}$ & 76 & 74 & 97,0 & 2 & 3,0 & \multirow{5}{*}{0,000} \\
\hline Fisioterapia & 76 & 75 & 99,0 & 1 & 1,0 & \\
\hline Cabeceira $\geq 30^{\circ}$ & 76 & 59 & 78,0 & 17 & 22,0 & \\
\hline Uso de solução estéril & 76 & 74 & 97,0 & 2 & 3,0 & \\
\hline Subtotal tarde & 304 & 282 & 92,8 & 22 & 7,2 & \\
\hline \multicolumn{7}{|l|}{ Noite* } \\
\hline $\begin{array}{l}\text { Troca de material de terapia } \\
\text { respiratória }\end{array}$ & 76 & 75 & 99,0 & 1 & 1,0 & \multirow{6}{*}{0,000} \\
\hline Fisioterapia & $\ldots$ & $\ldots$ & $\ldots$ & $\ldots$ & $\ldots$ & \\
\hline Cabeceira $\geq 30^{\circ}$ & 76 & 54 & 71,0 & 22 & 29,0 & \\
\hline Uso de solução estéril & 76 & 76 & 100,0 & - & - & \\
\hline Subtotal noite & 228 & 205 & 89,9 & 23 & 10,1 & \\
\hline Total & 836 & 763 & 91,3 & 73 & 8,7 & \\
\hline
\end{tabular}

*No período noturno não há fisioterapia.

Verifica-se que apenas a manutenção de cabeceira elevada não obteve conformidade esperada acima de $80 \%$, e isso se repetiu nos três turnos. Houve associação de significância $(p<0,000)$ entre as conformidades e as medidas avaliadas para a prevenção e controle de PAVM.

Observa-se, ainda, que cada medida, isoladamente, obteve índice de conformidade sempre superior ao da conformidade geral $(68,0 \%)$, o qual associou todas as medidas por paciente. A manutenção da cabeceira elevada foi a medida que mais interferiu negativamente na obtenção dessa conformidade geral.

A distribuição dos resultados obtidos para cada uma dessas medidas, nos três turnos de trabalho, é apresentada no Gráfico 2. 
Gráfico 2 - Distrib ição de conformidade de cada medida específica de prevenção e controle de PAVM, seg $\square$ ndo o $t$ rno de trabalho. São Pa $\square$ lo, 2009

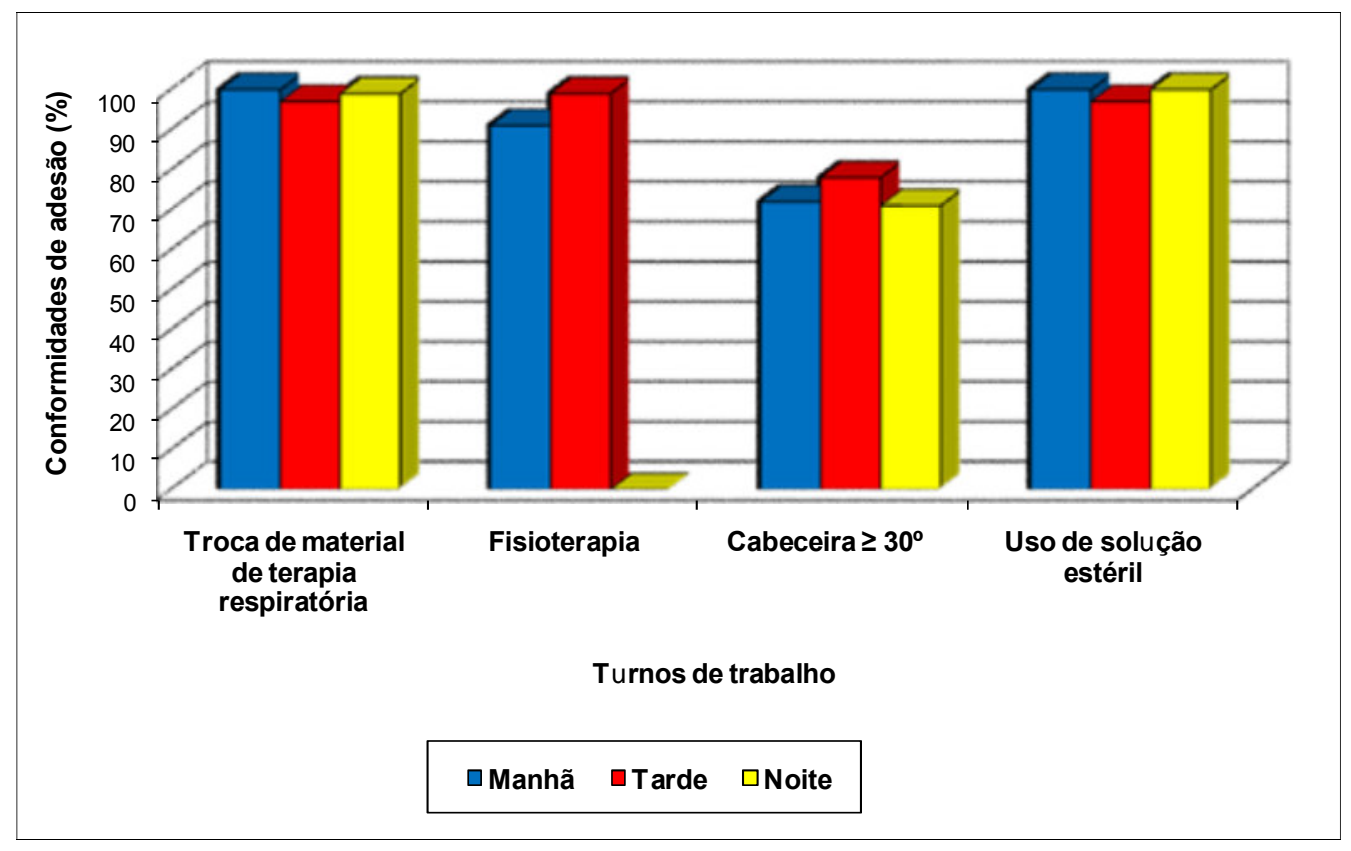

No Gráfico 2, as trocas de material de terapia respiratória e uso de solução estéril obtiveram os índices mais altos de conformidade e, em alguns casos, atingiram a totalidade $(100,0 \%)$.

A Tabela 7, a seguir, apresenta as situações encontradas que determinaram não conformidade às medidas de prevenção e controle de PAVM, em cada turno de trabalho. 
Tabela 7 - Distrib $\square$ ição de sit $\square$ ações de não conformidade das medidas específicas de controle e prevenção de PAVM, seg $\square$ ndo o $t$ rno de trabalho. São Pa $\square$ o, 2009

\begin{tabular}{|c|c|c|c|c|}
\hline \multirow[b]{2}{*}{ Variáveis } & \multicolumn{4}{|c|}{$\mathbf{T} \square$ rno de trabalho } \\
\hline & $\begin{array}{l}\text { Manhã } \\
\mathrm{n}(\%)\end{array}$ & $\begin{array}{l}\text { Tarde } \\
\mathrm{n}(\%)\end{array}$ & $\begin{array}{l}\text { Noite } \\
\text { n (\%) }\end{array}$ & $\begin{array}{l}\text { Total } \\
\text { n (\%) }\end{array}$ \\
\hline \multicolumn{5}{|l|}{ Cabeceira elevada } \\
\hline cabeceira a $20^{\circ}$ & $6(21,4)$ & $4(18,2)$ & $6(26,1)$ & $16(21,9)$ \\
\hline cabeceira a $25^{\circ}$ & $15(53,6)$ & $13(59,2)$ & $16(69,6)$ & $44(60,3)$ \\
\hline $\mathbf{S}$ btotal & $21(75,0)$ & $17(77,4)$ & $22(95,7)$ & $60(82,2)$ \\
\hline $\begin{array}{l}\text { Fisioterapia respiratória } \\
\text { Ausência de registro do } \\
\text { atendimento de } \\
\text { fisioterapia no prontuário }\end{array}$ & $7(25,0)$ & $1(4,5)$ & - & $8(11,0)$ \\
\hline $\mathbf{S} \square$ btotal & $7(25,0)$ & $1(4,5)$ & - & $8(11,0)$ \\
\hline \multicolumn{5}{|l|}{ Uso de sol $\square$ ção estéril } \\
\hline $\begin{array}{l}\text { - SF } 0,09 \%(100 \mathrm{ml}) \text { abert } \\
\text { sobre a mesa de } \\
\text { cabeceira e sem uso no } \\
\text { momento da observação }\end{array}$ & - & $1(4,5)$ & - & $1(1,4)$ \\
\hline $\begin{array}{l}\text { - Seringa com SF 0,09\% } \\
\text { sobre o ventilador } \\
\text { mecânico sem uso no } \\
\text { momento da observação }\end{array}$ & - & $1(4,5)$ & - & $1(1,4)$ \\
\hline $\mathbf{S} \square$ btotal & - & $2(9,0)$ & - & $2(2,8)$ \\
\hline \multicolumn{5}{|c|}{$\begin{array}{l}\text { Troca de material de terapia respiratória } \\
\text { Material de terapia }\end{array}$} \\
\hline $\begin{array}{l}\text { respiratória sem data de } \\
\text { troca }\end{array}$ & - & $2(9,1)$ & $1(4,3)$ & $3(4,0)$ \\
\hline $\mathbf{S}$ btotal & - & $2(9,1)$ & $1(4,3)$ & $3(4,0)$ \\
\hline Total & $28(100,0)$ & $22(100)$ & $23(100)$ & $73(100)$ \\
\hline
\end{tabular}

${ }^{*}$ No período noturno não há fisioterapia.

A cabeceira elevada, medida que obteve menor conformidade nos três turnos, observa-se que o motivo foi sempre sua manutenção abaixo do ângulo recomendado (acima de $30^{\circ}$ ). Ressalte-se que ela foi a principal responsável $(82,2 \%)$ pela não conformidade geral obtida, principalmente no turno da noite $(95,7 \%)$.

A fisioterapia respiratória, realizada somente nos turnos manhã e tarde, correspondeu à segunda frequência de não conformidade $(11,0 \%)$, e as causas foram seu não registro em prontuário, principalmente no turno da manhã.

Quanto ao uso de solução estéril, somente o turno da tarde apresentou não conformidade, por dois motivos: SF $0,09 \%$ aberto sobre a mesa de cabeceira do 
paciente e seringa com SF 0,09\% deixada sobre o ventilador mecânico. E as duas não conformidades para troca de material de terapia respiratória corresponderam, ambas, à ausência de informação de data de troca.

Note-se, que a avaliação dessas medidas correspondeu à averiguação de seu acato para cada paciente, nos períodos programados de observação, portanto, não foi possível associá-las com as categorias profissionais.

\subsection{Adesão à realização de higiene $b$ cal conforme rotina da instit $\square$ ição (Indicador IRHB)}

$\mathrm{Na}$ instituição, cenário do estudo, a higiene bucal é recomendada nos três turnos de trabalho, de acordo com avaliação das condições do pacientes pelos enfermeiros e consequente prescrição de enfermagem, nas seguintes modalidades: Higiene bucal com aplicação de solução de $\mathrm{CHX} 0,12 \%$; Higiene bucal com

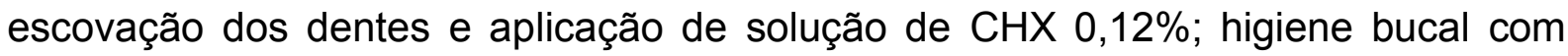
aplicação de colutório.

A Tabela 8, a seguir, apresenta a conformidade geral e por turno de trabalho obtidas.

Tabela 8 - Distrib $\square$ ição de conformidade geral e por $t$ rno de trabalho referente à prática de higiene $\mathrm{b} \square$ cal. São $\mathrm{Pa} \square$ lo, 2009

\begin{tabular}{lccc}
\hline \multirow{2}{*}{$\mathbf{T} \square$ rno de trabalho } & Total & \multicolumn{2}{c}{ Conformidade } \\
\cline { 3 - 4 } & $\mathbf{n}$ & $\mathbf{n}$ & $\mathbf{\%}$ \\
\hline Manhã & 76 & 55 & $72,4 \%$ \\
Tarde & 76 & 46 & $60,5 \%$ \\
Noite & 76 & 36 & $47,4 \%$ \\
Total & $\mathbf{2 2 8}$ & $\mathbf{1 3 7}$ & $\mathbf{6 0 , 1 \%}$ \\
\hline
\end{tabular}

Conforme se observa, a conformidade esperada de $80 \%$ também não foi obtida para a higiene bucal, tanto na conformidade geral $(60,1 \%)$, quanto por turnos de trabalho. Desta vez, o noturno apresentou o índice mais baixo $(47,4 \%)$, e o da manhã o mais alto $(72,4 \%)$.

O Gráfico 3 ilustra tais conformidades obtidas, por período de trabalho. 
Gráfico 3 - Distrib $\square$ ição de conformidade obtida na realização da higiene b $\square$ cal, seg $\square$ ndo t $\square$ rno de trabalho. São Pa $\square$ lo, 2009

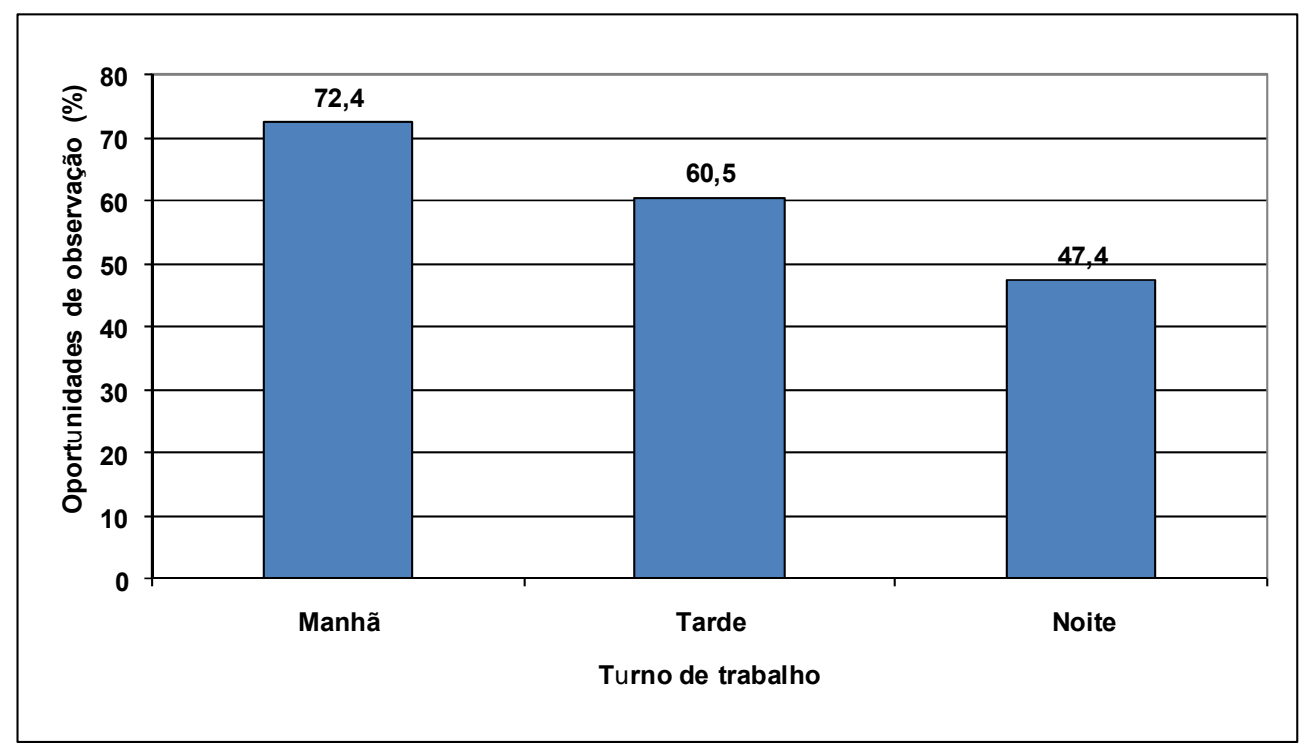

A Tabela 9, a seguir, apresenta as conformidades e não conformidades obtidas, de acordo com a modalidade de prescrição de enfermagem para higiene bucal, realizada diariamente, após avaliação do enfermeiro, nos turnos de trabalho. 
Tabela 9 - Distrib $\square$ ição de conformidade e não conformidade da higiene $\mathbf{b} \square$ cal, seg $\square$ ndo prescrição de enfermagem e t $\square$ rno de trabalho. São Pa $\square$ lo, 2009

\begin{tabular}{|c|c|c|c|c|c|c|}
\hline \multirow{2}{*}{ Variáveis } & \multicolumn{2}{|c|}{ Conforme } & \multicolumn{2}{|c|}{ Não conforme } & \multicolumn{2}{|c|}{ Total } \\
\hline & $\mathbf{n}$ & $\%$ & $\mathbf{n}$ & $\%$ & $\mathbf{n}$ & $\%$ \\
\hline Manhã & & & & & & \\
\hline $\begin{array}{l}\text { 1. Higiene bucal com aplicação de } \\
\text { solução } \mathrm{CHX} 0,12 \%\end{array}$ & 45 & $90,0 \%$ & 5 & $10,0 \%$ & 50 & $100,0 \%$ \\
\hline $\begin{array}{l}\text { 2. Higiene bucal com escovação dos } \\
\text { dentes e aplicação de sol. CHX } 0,12 \%\end{array}$ & 8 & $33,3 \%$ & 16 & $66,7 \%$ & 24 & $100,0 \%$ \\
\hline $\begin{array}{l}\text { 3. Higiene bucal com aplicação de } \\
\text { colutório }\end{array}$ & 2 & $100,0 \%$ & - & - & 2 & $100,0 \%$ \\
\hline $\mathbf{S} \square$ btotal & 55 & $72,4 \%$ & 21 & $27,6 \%$ & 76 & $100,0 \%$ \\
\hline Tarde & & & & & & \\
\hline $\begin{array}{l}\text { 1. Higiene bucal com aplicação de } \\
\text { solução } \mathrm{CHX} 0,12 \%\end{array}$ & 35 & $72,9 \%$ & 13 & $27,1 \%$ & 48 & $100,0 \%$ \\
\hline $\begin{array}{l}\text { 2. Higiene bucal com escovação dos } \\
\text { dentes e aplicação de sol. CHX } 0,12 \%\end{array}$ & 6 & $28,6 \%$ & 15 & $71,4 \%$ & 21 & $100,0 \%$ \\
\hline $\begin{array}{l}\text { 3. Higiene bucal com aplicação de } \\
\text { colutório }\end{array}$ & 5 & $71,4 \%$ & 2 & $28,6 \%$ & 7 & $100,0 \%$ \\
\hline $\mathbf{S} \square$ btotal & 46 & $60,5 \%$ & 30 & $39,5 \%$ & 76 & $100,0 \%$ \\
\hline Noite & & & & & & \\
\hline $\begin{array}{l}\text { 1. Higiene bucal com aplicação de sol. } \\
\text { CHX } 0,12 \%\end{array}$ & 28 & $73,7 \%$ & 10 & $26,3 \%$ & 38 & $100,0 \%$ \\
\hline $\begin{array}{l}\text { 2. Higiene bucal com escovação dos } \\
\text { dentes e aplicação de sol. CHX } 0,12 \%\end{array}$ & 1 & $3,6 \%$ & 27 & $96,4 \%$ & 28 & $100,0 \%$ \\
\hline $\begin{array}{l}\text { 3. Higiene bucal com aplicação de } \\
\text { colutório }\end{array}$ & 7 & $70,0 \%$ & 3 & $30,0 \%$ & 10 & $100,0 \%$ \\
\hline $\mathbf{S} \backsim$ btotal & 36 & $47,4 \%$ & 40 & $52,6 \%$ & 76 & $100,0 \%$ \\
\hline Total & 137 & $60,1 \%$ & 91 & $39,9 \%$ & 228 & $100,0 \%$ \\
\hline
\end{tabular}

Verifica-se, na Tabela 9, que a modalidade de prescrição de higiene bucal

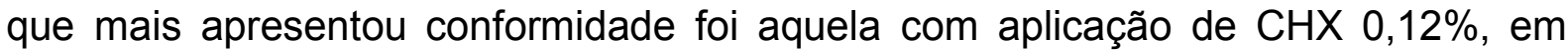
todos os turnos de trabalho, mas somente o da manhã atingiu a conformidade mínima esperada de 80\% (90\%-manhã; 73,7\%-noite; 72,9\%-tarde).

A prescrição de enfermagem menos seguida foi a higiene bucal com escovação de dentes e aplicação de $\mathrm{CHX} 0,12 \%$, em todos os turnos de trabalho (3,6\%-noite; 28,6\%-tarde; 33,3\%-manhã).

Constatou-se que a conformidade da higiene bucal vai diminuindo progressivamente do turno da manhã para o da noite.

O Gráfico 4 ilustra os resultados de não conformidade obtidos nas oportunidades de observação de higiene bucal nos turnos de trabalho. 
Gráfico 4 - Distrib $\square$ ição de sit $\square$ ações de não conformidade observadas referentes à higiene $b \square$ cal, seg $\square$ ndo tipo de prescrição de enfermagem e $\mathbf{t} \square$ rno de trabalho. São Pa $\square$ lo, 2009

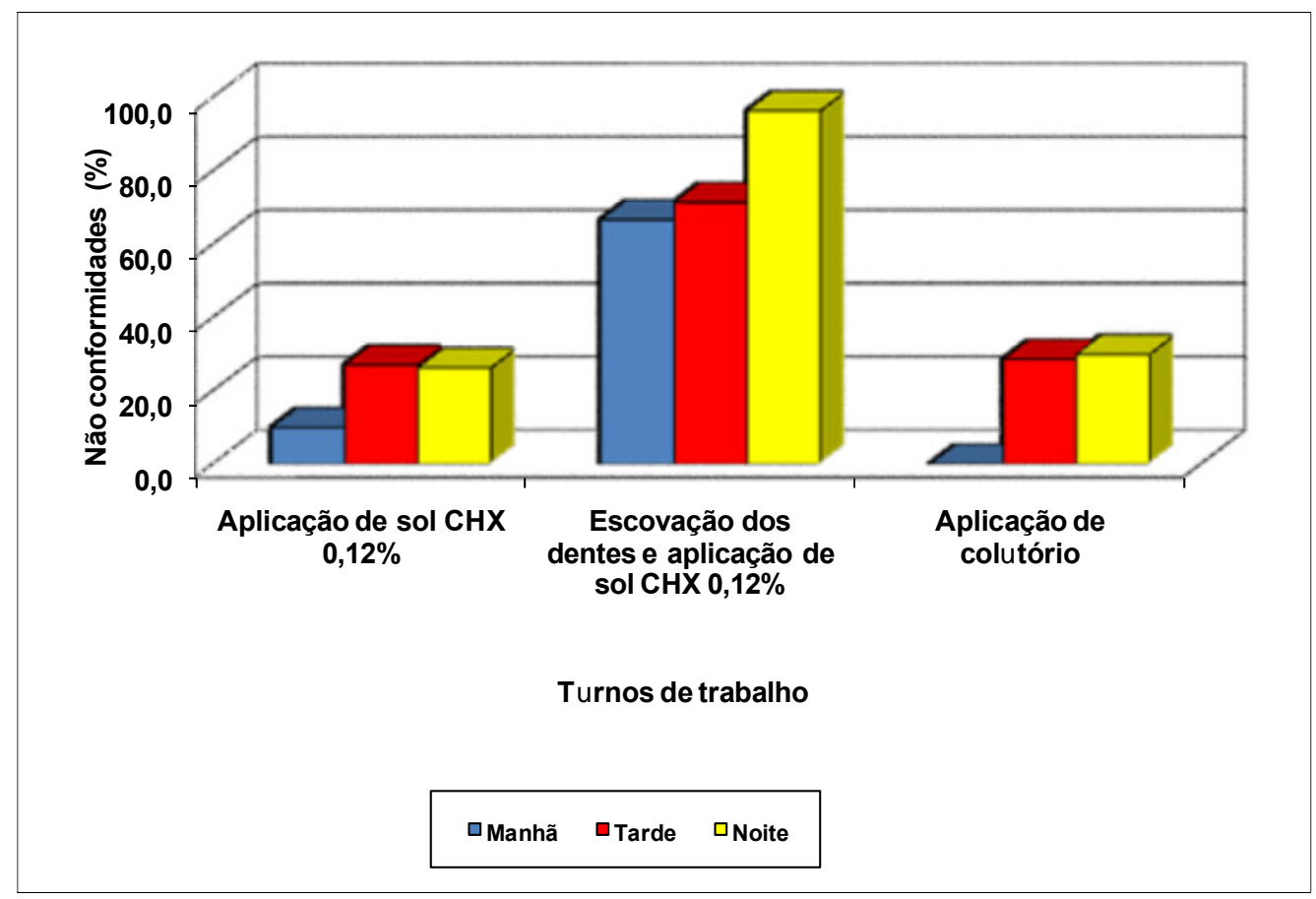

As situações de não conformidade relacionadas à higiene bucal, segundo as três possíveis modalidades prescritas pelos enfermeiros da UTI-Adulto, são apresentadas na Tabela 10, onde se constata que das 91 situações de não conformidade encontradas, 21 ocorreram no turno da manhã, 30 no turno da tarde e 40 no noturno. Houve progressão de situações, sendo nove do turno da manhã para o da tarde e de dez da tarde para o noturno. 


\section{Tabela 10 - Distrib $\square$ ição de não conformidades observadas referentes à higiene} b $\square$ cal, seg $\square$ ndo modalidade de prescrição de Enfermagem. São Pa $\square$ lo, 2009

\begin{tabular}{|c|c|c|c|c|}
\hline \multirow[b]{2}{*}{$\begin{array}{c}\text { Prescrição de enfermagem o } \square \text { rotina } \\
\text { padronizada }\end{array}$} & \multicolumn{4}{|c|}{$\mathbf{T} \square$ rno de trabalho } \\
\hline & $\frac{\text { Manhã }}{\text { n (\%) }}$ & $\begin{array}{l}\text { Tarde } \\
\mathbf{n}(\%)\end{array}$ & $\begin{array}{l}\text { Noite } \\
\text { n (\%) }\end{array}$ & $\begin{array}{l}\text { Total } \\
\text { n (\%) }\end{array}$ \\
\hline $\begin{array}{l}\text { 1. Higiene } b \square \text { cal com aplicação de } \\
\text { sol } \square \text { ção } \mathrm{CHX} 0,12 \%^{*}\end{array}$ & & & & \\
\hline $\begin{array}{l}\text { Não realizada durante o período estabelecido } \\
\text { para a observação, mas checada na } \\
\text { prescrição enfermagem }\end{array}$ & $\begin{array}{c}2 \\
(9,5)\end{array}$ & $\begin{array}{c}9 \\
(30,0)\end{array}$ & $\begin{array}{c}7 \\
(17,5)\end{array}$ & $\begin{array}{c}18 \\
(19,8)\end{array}$ \\
\hline $\begin{array}{l}\text { Solução } \mathrm{CHX} 0,12 \% \text { desprezada após o } \\
\text { banho do paciente (Higiene bucal não } \\
\text { realizada) }\end{array}$ & $\begin{array}{c}1 \\
(4,8)\end{array}$ & $\begin{array}{c}4 \\
(13,3)\end{array}$ & $\begin{array}{c}1 \\
(2,5)\end{array}$ & $\begin{array}{c}6 \\
(6,6)\end{array}$ \\
\hline Aplicado apenas SF $0,09 \%^{* *}$ com gaze & - & - & $\begin{array}{c}2 \\
(5,0)\end{array}$ & $\begin{array}{c}2 \\
(2,2)\end{array}$ \\
\hline Aplicado produto ignorado & $1(4,8)$ & - & - & $\begin{array}{c}1 \\
(1,1)\end{array}$ \\
\hline Aplicado um colutório & - & - & $\begin{array}{c}1 \\
(2,5)\end{array}$ & $\begin{array}{c}1 \\
(1,1)\end{array}$ \\
\hline Aplicado óleo essencial com gaze & $\begin{array}{c}1 \\
(4,8)\end{array}$ & - & - & $\begin{array}{c}1 \\
(1,1)\end{array}$ \\
\hline $\mathbf{S} \square$ btotal & $\begin{array}{c}5 \\
(23,8)\end{array}$ & $\begin{array}{c}13 \\
(43,3)\end{array}$ & $\begin{array}{c}11 \\
(27,5)\end{array}$ & $\begin{array}{c}29 \\
(31,9)\end{array}$ \\
\hline
\end{tabular}

\section{Higiene $\mathbf{b} \square$ cal com escovação dos} dentes e aplicação de sol. CHX 0,12\%*

Não realizada durante o período estabelecido para a observação, mas checada na prescrição enfermagem

$\begin{array}{cccc}2 & 2 & 4 & 8 \\ (9,5) & (6,7) & (10,0) & (8,8) \\ 13 & 10 & 21 & 44 \\ (61,9) & (33,3) & (52,5) & (48,4) \\ - & 3 & 1 & 4(4,) \\ & (10,0) & (1,0) & 1 \\ 1 & - & - & (1,1) \\ (4,8) & - & & \mathbf{5 7} \\ \mathbf{1 6} & \mathbf{1 5} & \mathbf{2 6} & \mathbf{( 6 2 , 6 )}\end{array}$

Aplicado apenas sol. CHX 0,12\%

Sol. CHX 0,12\% desprezada após o banho do paciente (Higiene bucal não realizada)

Realizada escovação sem qualquer produto

S $\square$ btotal

3. Higiene $\mathbf{b} \square$ cal com aplicação de col tório

Não realizada durante o período estabelecido para a observação, mas checada na prescrição enfermagem

Solução desprezada após o banho do paciente (Higiene bucal não realizada)

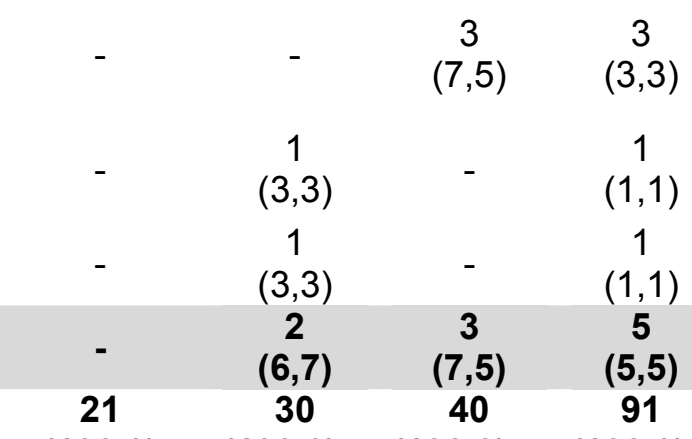

Aplicado produto ignorado

$\begin{array}{ccccc} & & & & (1,1) \\ & - & 2 & 3 & 5 \\ & - & (6,7) & (7,5) & (5,5) \\ & 21 & 30 & 40 & 91\end{array}$

${ }^{*} \mathrm{CHX} 0.12 \%$ = clorexidina $0,12 \%$; ** SF 0,09\% = soro fisiológico $0,09 \%$. 
Pela Tabela 10, extrai-se que a não realização da higiene bucal, sob qualquer modalidade prescrita, constituiu a situação de não conformidade mais frequentemente ocorrida (40), distribuindo-se entre não realizada, porém checada como realizada na prescrição de enfermagem (29) e não realizada, tendo sido desprezada após o banho (11). Tais situações ocorreram principalmente à tarde (18), seguindo-se o noturno (16) e manhã (6).

Proporcionalmente, a prescrição da higiene bucal com escovação e aplicação de $\mathrm{CHX} 0,12 \%$ foi a modalidade de não conformidade mais frequente $(62,6 \%)$, seguindo-se a modalidade aplicação de $\mathrm{CHX} 0,12 \%$ apenas $(31,9 \%)$.

\subsection{Adesão à higiene das mãos em procedimentos selecionados (Indicador HMSEL)}

Foram feitas 684 observações referentes a oportunidades de realização de higiene das mãos pelos profissionais durante os três turnos de trabalho, sendo 228 para cada procedimento previamente selecionado: aspiração orotraqueal, troca de cadarço das cânulas de intubação orotraqueal e higiene bucal. A conformidade foi considerada somente quando o profissional realizava a higiene das mãos ANTES e APÓS cada procedimento selecionado, seja com água e sabão líquido, seja com álcool gel. Portanto, a não conformidade foi conferida quando a higiene das mãos era realizada somente antes, somente após ou em nenhum momento.

A Tabela 11 apresenta os resultados de conformidade geral da higiene das mãos e por procedimento selecionado.

Tabela 11 - Distrib $\square$ ição de conformidade geral e por procedimento selecionado para a higiene das mãos. São $\mathrm{Pa} \square$ lo, 2009

\begin{tabular}{lccc}
\hline \multirow{2}{*}{ Variáveis } & \multicolumn{2}{c}{ Conformidade } & \multirow{2}{*}{ Total } \\
\cline { 2 - 3 } & $\mathbf{n}$ & $\mathbf{\%}$ & \\
\hline Aspiração orotraqueal & 43 & 18,9 & 228 \\
Troca de cadarço & 18 & 7,9 & 228 \\
Higiene bucal & 12 & 5,3 & 228 \\
Total & $\mathbf{7 3}$ & $\mathbf{1 0 , 7}$ & $\mathbf{6 8 4}$ \\
\hline
\end{tabular}


O índice de conformidade geral da higiene das mãos na realização dos procedimentos selecionados foi $10,7 \%$, portanto, muito inferior à conformidade esperada de $80 \%$. Com relação a cada procedimento, a melhor conformidade alcançada referiu-se à aspiração orotraqueal (18,9\%). Constata-se que a higiene das mãos na realização de troca de cadarço da cânula de intubação e na higiene bucal praticamente não foi considerada, tão baixas as conformidades obtidas $(7,9 \%$ e $5,3 \%$, respectivamente).

Tabela 12 - Distrib $\square$ ição de conformidade da higiene das mãos nos três $\mathbf{t} \square$ rnos de trabalho. São Pa $\square$ lo, 2009

\begin{tabular}{|c|c|c|c|c|c|c|c|}
\hline \multirow{3}{*}{$\begin{array}{l}\mathrm{T} \square \text { rno de } \\
\text { trabalho }\end{array}$} & \multicolumn{4}{|c|}{ Conformidade } & \multirow{2}{*}{\multicolumn{2}{|c|}{ Total }} & \multirow{3}{*}{ p } \\
\hline & \multicolumn{2}{|c|}{ SIM } & \multicolumn{2}{|c|}{ Não } & & & \\
\hline & $\mathrm{n}$ & $\%$ & $n$ & $\%$ & $n$ & $\%$ & \\
\hline Manhã & 38 & 16,7 & 190 & 83,3 & 228 & 100 & \\
\hline Tarde & 28 & 12,3 & 200 & 87,7 & 228 & 100 & 0,000 \\
\hline Noite & 7 & 3,1 & 221 & 96,9 & 228 & 100 & \\
\hline Total & 73 & 10,7 & 611 & 89,3 & 684 & 100 & \\
\hline
\end{tabular}

Pela Tabela 12, houve diferença estatisticamente significativa entre os três turnos de trabalho na adesão à higiene das mãos nos três procedimentos $(p<0,05)$. Observa-se que o turno da manhã apresentou o maior índice de conformidade $(16,7 \%)$.

Tabela 13 - Distrib $\square$ ição das oport $\square$ nidades de higiene das mãos, seg $\square$ ndo o $\mathbf{t} \square$ rno de trabalho e categoria profissional. São Pa $\square$ lo, 2009

\begin{tabular}{|c|c|c|c|c|c|c|c|c|}
\hline \multirow{3}{*}{$\begin{array}{c}\mathrm{T} \\
\text { de } \\
\text { deno } \\
\text { trabalho }\end{array}$} & \multicolumn{6}{|c|}{ Categoria profissional } & \multirow{2}{*}{\multicolumn{2}{|c|}{ Total }} \\
\hline & \multicolumn{2}{|c|}{ Enfermeiro } & \multicolumn{2}{|c|}{$\begin{array}{l}\text { A } \square \text { xiliar/Técnico } \\
\text { de enfermagem }\end{array}$} & \multicolumn{2}{|c|}{ Fisioterape ta } & & \\
\hline & $\mathbf{n}$ & $\%$ & $\mathbf{n}$ & $\%$ & $\mathbf{n}$ & $\%$ & $\mathbf{n}$ & $\%$ \\
\hline Manhã & 13 & 5,7 & 116 & 50,9 & 99 & 43,4 & 228 & 100 \\
\hline Tarde & - & - & 141 & 61,8 & 87 & 38,2 & 228 & 100 \\
\hline Noite* & 19 & 8,3 & 209 & 91,7 & $\ldots$ & & 228 & 100 \\
\hline Total & 32 & 4,7 & 466 & 68,1 & 186 & 27,2 & 684 & 100 \\
\hline
\end{tabular}

*No período noturno não há fisioterapia.

Do total de oportunidades de higiene das mãos, mais da metade $(68,1 \%)$ correspondeu às categorias auxiliar e técnico de enfermagem, seguindo-se o fisioterapeuta $(27,2 \%)$ e, por último, o enfermeiro $(4,7 \%)$. Tal sequência também foi obtida em cada turno de trabalho. No noturno, quase todas as oportunidades 
corresponderam aos auxiliares e técnicos de enfermagem (91,7\%). Na tarde, nenhuma oportunidade correspondeu ao enfermeiro e a mesma situação ocorreu com o fisioterapeuta no noturno, porque o mesmo não atuava neste turno. Ou seja, somente no período da manhã foi possível observar oportunidades de higiene das mãos de todas as categorias envolvidas.

Correlacionando as oportunidades de higiene das mãos com sua realização correta, conforme profissionais envolvidos e turno de trabalho, foram obtidas as conformidades que seguem (Tabela 14).

Tabela 14 - Distrib $\square$ ição de conformidade da higiene das mãos, seg $\square$ ndo a categoria de profissional. São Pa $\square$ lo, 2009

\begin{tabular}{|c|c|c|c|c|c|c|c|}
\hline \multirow{3}{*}{$\begin{array}{c}\text { Categoria } \\
\text { profissional }\end{array}$} & \multicolumn{4}{|c|}{ Conformidade } & \multirow{2}{*}{\multicolumn{2}{|c|}{ Total }} & \multirow{3}{*}{$\mathbf{p}$} \\
\hline & \multicolumn{2}{|c|}{ Sim } & \multicolumn{2}{|c|}{ Não } & & & \\
\hline & $\mathbf{n}$ & $\%$ & $\mathbf{n}$ & $\%$ & $\mathbf{n}$ & $\%$ & \\
\hline Enfermeiro & 5 & 15,6 & 27 & 84,4 & 32 & 100 & \\
\hline $\begin{array}{l}\text { Auxiliar /técnico de } \\
\text { enfermagem }\end{array}$ & 20 & 4,4 & 446 & 95,6 & 466 & 100 & 0,000 \\
\hline Fisioterapeuta & 48 & 25,8 & 138 & 74,2 & 186 & 100 & \\
\hline Total & 73 & 10,7 & 611 & 89,3 & 684 & 100 & \\
\hline
\end{tabular}

Pela Tabela 14, os fisioterapeutas alcançaram o maior valor percentual $(25,8 \%)$ de conformidade da higiene das mãos, seguidos dos enfermeiros $(15,6 \%)$ e auxiliar/técnicos de enfermagem $(4,4 \%)$. Houve diferença de significância nas três categorias profissionais $(p<0,05)$. 
Tabela 15 - Distrib $\square$ ição de conformidade da higiene das mãos, seg $\square$ ndo o tipo de procedimento observado. São $\mathrm{Pa} \square \mathrm{lo}, 2009$

\begin{tabular}{|c|c|c|c|c|c|c|c|}
\hline \multirow{3}{*}{ Variáveis } & \multicolumn{4}{|c|}{ Conformidade } & \multirow{2}{*}{\multicolumn{2}{|c|}{ Total }} & \multirow{3}{*}{$\mathbf{p}$} \\
\hline & \multicolumn{2}{|c|}{ Sim } & \multicolumn{2}{|c|}{ Não } & & & \\
\hline & $\mathbf{n}$ & $\%$ & $\mathbf{n}$ & $\%$ & $\mathbf{n}$ & $\%$ & \\
\hline \multicolumn{8}{|c|}{ Aspiração orotraq eal } \\
\hline Manhã & 18 & 23,7 & 58 & 76,3 & 76 & 100 & \multirow{4}{*}{0,011} \\
\hline Tarde & 19 & 25,0 & 57 & 75,0 & 76 & 100 & \\
\hline Noite & 6 & 7,9 & 70 & 92,1 & 76 & 100 & \\
\hline Total & 43 & 18,9 & 185 & 81,1 & 228 & 100 & \\
\hline \multicolumn{8}{|l|}{ Troca de cadarço } \\
\hline Manhã & 12 & 15,8 & 64 & 84,2 & 76 & 100 & \multirow{3}{*}{0,002} \\
\hline Tarde & 5 & 6,6 & 71 & 93,4 & 76 & 100 & \\
\hline Noite & 1 & 1,3 & 75 & 98,7 & 76 & 100 & \\
\hline Total & 18 & 7,9 & 210 & 92,1 & 228 & 100 & \\
\hline \multicolumn{8}{|l|}{ Higiene $\mathbf{b} \square$ cal } \\
\hline Manhã & 8 & 10,5 & 68 & 89,5 & 76 & 100 & \multirow{3}{*}{0,003} \\
\hline Tarde & 4 & 5,3 & 72 & 94,7 & 76 & 100 & \\
\hline Noite & - & - & 76 & 100,0 & 76 & 100 & \\
\hline Total & 12 & 5,3 & 216 & 94,7 & 228 & 100 & \\
\hline
\end{tabular}

A aspiração orotraqueal foi o procedimento que obteve a maior conformidade geral da higiene das mãos $(18,9 \%)$, seguindo-se a troca de cadarço $(7,9 \%)$ e, por último, a higiene bucal (5,3\%). O período noturno foi o que apresentou os menores índices de conformidade, nos três procedimentos. A análise estatística revelou diferença significante entre os turnos e os procedimentos, respectivamente, $p=$ $0,011, p=0,002$ e $p=0,003$. No procedimento de aspiração orotraqueal nos três turnos de trabalho, constata-se que estatisticamente houve significância $(p<0,05)$. Esse achado sugere que os profissionais apresentam adesão à higiene das mãos de modo diferente, nessa prática, em cada turno de trabalho.

A Tabela 16, a seguir, permite identificar as conformidades obtidas para cada procedimento selecionado, conforme a categoria profissional. 
Tabela 16 - Distrib $\square$ ição de conformidade da higiene das mãos, seg $\square$ ndo os procedimentos selecionados e a categoria profissional. São Pa $\square$ lo, 2009

\begin{tabular}{|c|c|c|c|c|c|c|c|}
\hline \multirow{3}{*}{ Variáveis } & \multicolumn{4}{|c|}{ Conformidade } & \multirow{2}{*}{\multicolumn{2}{|c|}{ Total }} & \multirow{3}{*}{ p } \\
\hline & \multicolumn{2}{|c|}{ Sim } & \multicolumn{2}{|c|}{ Não } & & & \\
\hline & $\mathbf{n}$ & $\%$ & $\mathbf{n}$ & $\%$ & $\mathbf{n}$ & $\%$ & \\
\hline \multicolumn{8}{|l|}{ Aspiração orotraq eal } \\
\hline Enfermeiro & 3 & 17,6 & 14 & 82,4 & 17 & 100 & \multirow{4}{*}{0,073} \\
\hline $\begin{array}{l}\text { Auxiliar/Técnico de } \\
\text { Enfermagem }\end{array}$ & 8 & 10,7 & 67 & 89,3 & 75 & 100 & \\
\hline Fisioterapeuta & 32 & 23,5 & 104 & 76,5 & 136 & 100 & \\
\hline Total & 43 & 18,9 & 185 & 81,1 & 228 & 100 & \\
\hline \multicolumn{8}{|l|}{ Troca de cadarço } \\
\hline Enfermeiro & - & - & 4 & 100,0 & 4 & 100 & \multirow{3}{*}{0,000} \\
\hline $\begin{array}{l}\text { Auxiliar/Técnico de } \\
\text { Enfermagem }\end{array}$ & 2 & 1,1 & 172 & 98,9 & 174 & 100 & \\
\hline Fisioterapeuta & 16 & 32,0 & 34 & 68,0 & 50 & 100 & \\
\hline Total & 18 & 7,9 & 210 & 92,1 & 228 & 100 & \\
\hline \multicolumn{8}{|l|}{ Higiene $\mathbf{b} \square$ cal } \\
\hline Enfermeiro & 2 & 18,2 & 9 & 81,8 & 11 & 100 & \multirow[b]{2}{*}{0,113} \\
\hline $\begin{array}{l}\text { Auxiliar/Técnico de } \\
\text { Enfermagem }\end{array}$ & 10 & 4,6 & 207 & 95,4 & 217 & 100 & \\
\hline Total & 12 & 5,3 & 216 & 94,7 & 228 & 100 & \\
\hline
\end{tabular}

Os fisioterapeutas apresentaram as conformidades mais altas em todas as oportunidades que tiveram para realizar a higiene das mãos (23,5\%-aspiração; 32,0\%-troca de cadarço). Mas somente para a troca de cadarço houve diferença estatisticamente significativa entre os profissionais $(p=0,000)$.

Com relação à equipe de enfermagem, nos procedimentos de higiene bucal e aspiração orotraqueal, o enfermeiro esteve mais conforme do que o técnico de enfermagem. No entanto, para a higiene bucal não se observou diferença estatística significante $(p=0,113)$ entre categoria profissional e conformidade da higiene das mãos.

A Tabela 17, a seguir, apresenta os valores de conformidade e não conformidade da higiene das mãos, segundo os procedimentos selecionados, categorias profissionais e turnos de trabalho. 
Tabela 17 - Distrib ição de conformidade e não conformidade da higiene das mãos nos procedimentos de aspiração orotraq $\square$ eal e troca de cadarço, seg $\square$ ndo categoria profissional e $t \square$ rno de trabalho. São Pa $\square$ lo, 2009

\begin{tabular}{|c|c|c|c|c|c|c|c|c|c|c|c|c|c|c|c|c|c|c|c|c|c|}
\hline \multicolumn{22}{|c|}{ Conformidade } \\
\hline & \multicolumn{7}{|c|}{ Aspiração orotraq eal } & \multicolumn{7}{|c|}{ Troca de cadarço } & \multicolumn{7}{|c|}{ Higiene $\mathbf{b} \square$ cal } \\
\hline & \multicolumn{2}{|c|}{ Sim } & \multicolumn{2}{|c|}{ Não } & \multicolumn{2}{|c|}{ Total } & \multirow[b]{2}{*}{ p } & \multicolumn{2}{|c|}{ Sim } & \multicolumn{2}{|c|}{ Não } & \multicolumn{2}{|c|}{ Total } & \multirow[b]{2}{*}{$\mathbf{p}$} & \multicolumn{2}{|c|}{ Sim } & \multicolumn{2}{|c|}{ Não } & \multicolumn{2}{|c|}{ Total } & \multirow[b]{2}{*}{$p$} \\
\hline & $\mathbf{n}$ & $\%$ & $n$ & $\%$ & $\mathrm{n}$ & $\%$ & & $\mathrm{n}$ & $\%$ & $\mathrm{n}$ & $\%$ & $\mathrm{n}$ & $\%$ & & $\mathbf{n}$ & $\%$ & $\mathrm{n}$ & $\%$ & $n$ & $\%$ & \\
\hline \multicolumn{22}{|l|}{ Manhã } \\
\hline Enfermeiro & 1 & 50,0 & 1 & 50,0 & 2 & 100,0 & & - & - & 3 & 100,0 & 3 & 100,0 & & 2 & 25,0 & 6 & 75,0 & 8 & 100,0 & \\
\hline $\begin{array}{l}\text { Auxiliar/Técnico } \\
\text { de Enfermagem }\end{array}$ & 2 & 25,0 & 6 & 75,0 & 8 & 100,0 & 0,708 & - & - & 40 & 100,0 & 40 & 100,0 & $<0,000$ & 6 & 8,8 & 62 & 91,2 & 68 & 100,0 & 0,211 \\
\hline Fisioterapeuta & 15 & 22,7 & 51 & 77,3 & 66 & 100,0 & & 12 & 36,4 & 21 & 63,6 & 33 & 100,0 & & - & - & - & - & - & - & \\
\hline Total & 18 & 23,7 & 58 & 76,3 & 76 & 100,0 & & 12 & 15,8 & 64 & 84,2 & 76 & 100,0 & & 8 & 10,5 & 68 & 89,5 & 76 & 100,0 & \\
\hline \multirow{5}{*}{$\begin{array}{l}\text { Tarde } \\
\text { Enfermeiro } \\
\text { Auxiliar/Técnico } \\
\text { de Enfermagem } \\
\text { Fisioterapeuta } \\
\text { Total }\end{array}$} & & & & & & & & & & & & & & & & & & & & & \\
\hline & - & - & - & - & - & - & & - & - & - & - & - & - & & - & - & - & - & - & - & \\
\hline & 2 & 33,3 & 4 & 66,7 & 6 & 100,0 & 0,633 & 1 & 1,7 & 58 & 98,3 & 59 & 100,0 & $<0,004$ & 4 & 5,3 & 72 & 94,7 & 76 & 100,0 & $\cdots$ \\
\hline & 17 & 24,3 & 53 & 75,7 & 76 & 100,0 & & 4 & 23,5 & 13 & 76,5 & 17 & 100,0 & & - & - & - & - & - & - & \\
\hline & 19 & 25,0 & 57 & 75,0 & 76 & 100,0 & & 5 & 6,6 & 71 & 93,4 & 76 & 100,0 & & 4 & 5,3 & 72 & 94,7 & 96 & 100,0 & \\
\hline \multirow{5}{*}{$\begin{array}{l}\text { Noite } \\
\text { Enfermeiro } \\
\text { Auxiliar/Técnico } \\
\text { de Enfermagem } \\
\text { Fisioterapeuta } \\
\text { Total }\end{array}$} & & & & & & & & & & & & & & & & & & & & & \\
\hline & 2 & 13,1 & 13 & 86,7 & 15 & 100,0 & & - & - & 1 & 100,0 & 1 & 100,0 & & - & - & 3 & 100,0 & 3 & 100,0 & \\
\hline & 4 & 6,6 & 57 & 93,4 & 61 & 100,0 & 0,412 & 1 & 1,3 & 74 & 98,7 & 75 & 100,0 & $<0,870$ & - & - & 73 & 100,0 & 73 & 100,0 & $\cdots$ \\
\hline & - & - & - & - & - & - & & - & - & - & - & - & - & & - & - & - & - & - & - & \\
\hline & 6 & 7,9 & 70 & 92,3 & 76 & 100,0 & & 1 & 1,3 & 75 & 98,7 & 76 & 100,0 & & - & - & 76 & 100,0 & 76 & 100,0 & \\
\hline
\end{tabular}


No procedimento de aspiração orotraqueal, os enfermeiros apresentaram maior conformidade de higiene das mãos no turno da manhã $(50,0 \%)$, os auxiliares e técnicos de enfermagem no turno da tarde $(33,3 \%)$ e os fisioterapeutas também no turno da tarde, embora em menor proporção que os auxiliares e técnicos de enfermagem $(24,3 \%)$.

$\mathrm{Na}$ troca de cadarço, a maior conformidade da higiene das mãos ocorreu entre os fisioterapeutas nos turnos em que tiveram oportunidades (36,4\%-M e 23,5\%-T). Auxiliares e técnicos de enfermagem praticamente não aderiram (1,7\%-T e $1,3 \%-N$ ) e o enfermeiro não teve oportunidade.

$\mathrm{Na}$ higiene bucal, procedimento realizado apenas pela equipe de enfermagem, foram os enfermeiros que alcançaram maior conformidade, cujas oportunidades ocorreram em sua maioria no turno da manhã $(25,0 \%)$. Auxiliares e técnicos alcançaram conformidade de apenas 8,8\% (manhã) e 5,3\% (tarde). Note-se que a conformidade da higiene das mãos neste procedimento no noturno foi nula.

Houve diferença estatística significativa nas observações da higiene das mãos para troca de cadarço entre fisioterapeutas e auxiliares/técnicos de enfermagem $(p<0,05)$ nos turnos da manhã e da tarde.

O turno da manhã alcançou maior conformidade da higiene das mãos tanto nos procedimentos realizados pelos enfermeiros $(25,0 \%)$, quanto pelos auxiliares e técnicos de enfermagem $(8,8 \%)$, embora sem diferença estatisticamente significativa $(p=0,211)$.

A seguir, são ressaltados os resultados de associação de não conformidades obtidas. Nota-se que apenas nas Tabelas 18 e 19, para a não conformidade adotouse a não higienização das mãos em nenhum momento, ou seja, nem antes e nem após a realização dos três procedimentos e para a conformidade, as seguintes situações: antes e após, somente antes e somente após a realização dos procedimentos. 
Tabela 18 - Distrib $\square$ ição de não conformidade e conformidade da higiene das mãos, seg $\square$ ndo categoria profissional e tipo de procedimento. São Pa $\square$ lo, 2009

\begin{tabular}{|c|c|c|c|c|c|c|c|}
\hline \multirow{3}{*}{ Variáveis } & \multicolumn{4}{|c|}{ Higiene das mãos } & \multicolumn{2}{|c|}{ Total } & \multirow{3}{*}{$\mathbf{p}$} \\
\hline & \multicolumn{2}{|c|}{ Não } & \multicolumn{2}{|c|}{ Sim } & \multirow[b]{2}{*}{$\mathbf{n}$} & \multirow[b]{2}{*}{$\%$} & \\
\hline & $\mathbf{n}$ & $\%$ & $\mathbf{n}$ & $\%$ & & & \\
\hline Aspiração orotraq eal & 6 & 35,3 & 11 & 64,7 & 17 & 100 & \multirow{4}{*}{0,000} \\
\hline $\begin{array}{l}\text { Auxiliar/Técnico de } \\
\text { Enfermagem }\end{array}$ & 40 & 53,3 & 35 & 46,7 & 75 & 100 & \\
\hline Fisioterapeuta & 27 & 19,9 & 109 & 80,1 & 136 & 100 & \\
\hline Total & 73 & 32,0 & 135 & 68,0 & 228 & 100 & \\
\hline $\begin{array}{l}\text { Troca de cadarço } \\
\text { Enfermeiro }\end{array}$ & \multicolumn{5}{|c|}{ Troca de cadarço } & 100 & \multirow{4}{*}{0,000} \\
\hline $\begin{array}{l}\text { Auxiliar/Técnico de } \\
\text { Enfermagem }\end{array}$ & 130 & 74,7 & 44 & 25,3 & 174 & 100 & \\
\hline Fisioterapeuta & 8 & 16,0 & 42 & 84,0 & 50 & 100 & \\
\hline Total & 141 & 61,8 & 87 & 38,2 & 228 & 100 & \\
\hline \multicolumn{7}{|l|}{ Higiene $\mathbf{b} \square$ cal } & \multirow[b]{2}{*}{0,038} \\
\hline $\begin{array}{l}\text { Auxiliar/Técnico de } \\
\text { Enfermagem }\end{array}$ & 147 & 67,7 & 70 & 32,3 & 217 & 100 & \\
\hline Total & 151 & 66,2 & 77 & 33,8 & 228 & 100 & \\
\hline
\end{tabular}

Na aspiração orotraqueal, a não adesão à higiene das mãos foi maior entre os auxiliar/técnicos de enfermagem (53,3\%).

$\mathrm{Na}$ troca de cadarço, a não adesão à higiene das mãos foi maior entre os enfermeiros $(75,0 \%)$, acompanhado bem próximo pelas auxiliares e técnicos $(74,7 \%)$.

$\mathrm{Na}$ higiene bucal, a não adesão foi maior entre auxiliares e técnicos de enfermagem $(67,7 \%)$.

A comparação dos procedimentos em relação às categorias mostra que essas diferenças nos índices de não adesão foram significativas $(p<0,05)$. Conclui-se que na aspiração orotraqueal e na higiene bucal os auxiliar/técnicos aderiram menos à higiene das mãos do que as demais categorias e na troca de cadarço, foram os enfermeiros $(p<0,038)$. Os fisioterapeutas, as não conformidades foram menores do que as demais categorias nos dois procedimentos em que houve oportunidades de observação. 
Tabela 19 - Distrib $\square$ ição de não conformidade e conformidade da higiene das mãos, seg $\square$ ndo o tipo de procedimento e o $t$ $\square$ rno de trabalho. São Pa $\square$ lo, 2009

\begin{tabular}{|c|c|c|c|c|c|c|c|}
\hline \multirow{3}{*}{ Variáveis } & \multicolumn{4}{|c|}{$\begin{array}{c}\text { Higiene } \\
\text { das mãos }\end{array}$} & \multirow{2}{*}{\multicolumn{2}{|c|}{ Total }} & \multirow{3}{*}{ p } \\
\hline & \multicolumn{2}{|c|}{ Não } & \multicolumn{2}{|c|}{ Sim } & & & \\
\hline & $\mathbf{n}$ & $\%$ & $\mathbf{n}$ & $\%$ & $\mathbf{n}$ & $\%$ & \\
\hline $\begin{array}{l}\text { Aspiração orotraq } \\
\text { Manhã }\end{array}$ & 18 & 237 & 58 & 76.3 & 76 & 1000 & \\
\hline Tarde & 12 & 15,8 & 64 & 84,2 & 76 & 100,0 & 0,000 \\
\hline Noite & 43 & 56,6 & 33 & 43,4 & 76 & 100,0 & \\
\hline Total & 73 & 32,0 & 155 & 68,0 & 228 & 100,0 & \\
\hline Troca de $c$ & & & & & & & \\
\hline Manhã & 34 & 44,7 & 42 & 55,3 & 76 & 100,0 & \\
\hline Tarde & 47 & 61,8 & 29 & 38,2 & 76 & 100,0 & 0,000 \\
\hline Noite & 60 & 78,9 & 16 & 21,1 & 76 & 100,0 & \\
\hline Total & 141 & 61,8 & 87 & 38,2 & 228 & 100,0 & \\
\hline Higiene $\mathbf{b} \square$ cal & & & & & & & \\
\hline Manhã & 36 & 47,4 & 40 & 52,6 & 76 & 100,0 & \\
\hline Tarde & 45 & 59,2 & 31 & 40,8 & 76 & 100,0 & 0,000 \\
\hline Noite & 70 & 92,1 & 6 & 7,9 & 76 & 100,0 & \\
\hline Total & 151 & 66,2 & 77 & 33,8 & 228 & 100,0 & \\
\hline
\end{tabular}

De acordo com a Tabela 19, nas oportunidades de observação da higiene das mãos por turno, o noturno apresentou maior proporção de não adesão à higiene das mãos, ou seja, foi o que menos higienizou as mãos antes e depois da realização de todos os procedimentos. Os testes estatísticos também apontam que essa diferença foi estatisticamente significante entre os turnos nos três procedimentos $(p<0,05)$.

A Tabela 20 sumariza os resultados de conformidade e não conformidade, incluindo todos os momentos registrados durante as oportunidades de observação da higiene das mãos nos três tipos de procedimentos. 
Tabela 20 - Distrib $\square$ ição de conformidade e não conformidade da higiene das mãos, seg $\square$ ndo o tipo de procedimento e a categoria profissional. São Pa $\square l o, 2009$

\begin{tabular}{|c|c|c|c|c|c|c|c|c|c|c|}
\hline \multirow{3}{*}{ Variáveis } & \multirow{2}{*}{\multicolumn{2}{|c|}{$\begin{array}{c}\text { Conforme } \\
\text { Antes e } \\
\text { após }\end{array}$}} & \multicolumn{6}{|c|}{ Não conforme } & \multicolumn{2}{|c|}{ Total } \\
\hline & & & \multicolumn{2}{|c|}{$\begin{array}{c}\text { Não } \\
\text { higienizo } \\
\end{array}$} & \multicolumn{2}{|c|}{$\begin{array}{c}\text { Somente } \\
\text { antes }\end{array}$} & \multicolumn{2}{|c|}{$\begin{array}{c}\text { Somente } \\
\text { após }\end{array}$} & \multirow[b]{2}{*}{$\mathbf{n}$} & \multirow[b]{2}{*}{$\%$} \\
\hline & $\mathbf{n}$ & $\%$ & $\mathbf{n}$ & $\%$ & $\mathbf{n}$ & $\%$ & $\mathbf{n}$ & $\%$ & & \\
\hline \multicolumn{11}{|c|}{ Aspiração orotraq eal } \\
\hline \multirow{4}{*}{$\begin{array}{l}\text { Enfermeiro } \\
\text { Auxiliar/Técnico } \\
\text { de Enfermagem } \\
\text { Fisioterapeuta } \\
\mathbf{S} \text { btotal }\end{array}$} & 3 & 17,6 & 6 & 35,3 & 2 & 11,8 & 6 & 35,3 & 17 & 100 \\
\hline & 8 & 10,7 & 40 & 53,3 & 10 & 13,3 & 17 & 22,7 & 75 & 100 \\
\hline & 32 & 23,5 & 27 & 19,9 & 6 & 4,4 & 71 & 52,2 & 136 & 100 \\
\hline & 43 & 18,9 & 73 & 32,0 & 18 & 7,9 & 94 & 41,2 & 228 & 100 \\
\hline \multicolumn{11}{|c|}{ Troca de cadarço } \\
\hline \multirow{3}{*}{$\begin{array}{l}\text { Enfermeiro } \\
\text { Auxiliar/Técnico } \\
\text { de Enfermagem } \\
\text { Fisioterapeuta }\end{array}$} & - & - & 3 & 75,0 & - & - & 1 & 25,0 & 4 & 100 \\
\hline & 2 & 1,1 & 130 & 74,7 & 4 & 2,3 & 38 & 21,8 & 174 & 100 \\
\hline & 16 & 32,0 & 8 & 16,0 & 1 & 2,0 & 25 & 50,0 & 50 & 100 \\
\hline $\mathbf{S}$ btotal & 18 & 7,9 & 141 & 61,8 & 5 & 2,2 & 64 & 28,1 & 228 & 100 \\
\hline \multicolumn{11}{|l|}{ Higiene $\mathbf{b} \square$ cal } \\
\hline Auxiliar/Técnico & 10 & 4,6 & 147 & 67,7 & 35 & 16,1 & 25 & 11,5 & 217 & 100 \\
\hline $\mathbf{S}$ btotal & 12 & 5,3 & 151 & 66,2 & 39 & 17,1 & 26 & 11,4 & 228 & 100 \\
\hline Total & 73 & 10,7 & 365 & 53,3 & 62 & 9,0 & 184 & 27,0 & 684 & 100 \\
\hline
\end{tabular}

Nas oportunidades de observação da adesão à higiene das mãos na aspiração orotraqueal e troca de cadarço os fisioterapeutas apresentaram as conformidades mais altas $(23,5 \%$ e $32,0 \%$, respectivamente). Na higiene bucal foram os enfermeiros (18,2\%). Auxiliares e técnicos de enfermagem alcançaram maior proporção de não higiene das mãos, respectivamente, na troca de cadarço $(74,7 \%)$, higiene bucal $(67,7 \%)$ e aspiração orotraqueal $(53,3 \%)$. Na troca de cadarço, proporcionalmente, os valores foram muito próximos entre enfermeiros $(75,0 \%)$ e auxiliares e técnicos de enfermagem (74,7\%).

Nos casos de não conformidade $(89,4 \%)$, a maior proporção deveu-se à não higiene das mãos, nem antes nem após, os procedimentos $(53,3 \%)$, seguindo-se sua realização somente após $(27,0 \%)$. Por tipo de procedimento, a não higiene das mãos, nem antes nem após, também foi mais frequente na higiene bucal $(66,2 \%)$ e na troca de cadarço (61,8\%). Já, na aspiração orotraqueal, a maior frequência de não conformidade referiu-se à não realização da higiene das mãos somente após $(41,2 \%)$. 
Auxiliares e técnicos de enfermagem foram os que menos frequentemente higienizaram as mãos, antes e depois, na realização de aspiração orotraqueal e higiene bucal $(53,3 \%$ e $67,7 \%$, respectivamente). O mesmo tipo de não conformidade foi mais frequente entre os enfermeiros na troca de cadarço $(75,0 \%)$. Já, os fisioterapeutas, a não higiene das mãos somente após o procedimento foi a não conformidade mais frequente (52,2\%-aspiração; 50,0\%-troca de cadarço). 
6 Discussão 
A infecção adquirida em serviços de saúde (IASS) é uma morbidade bastante fundamentada quanto às ações para seu controle e prevenção, por meio de estudos científicos isolados, diretrizes clínicas e regulamentações governamentais. Ainda que não sejam suficientes para erradicar sua ocorrência, o maior desafio é reconhecer se e como estes recursos já existentes estão sendo incorporados na prática assistencial (São Paulo, 2006).

Para tanto e, assim como ocorre com quaisquer outras ações a serem cumpridas em diversos âmbitos, além de sua instituição, um outro momento se apresenta necessário, que é a análise de sua implementação. Em outras palavras, trata-se da "visualização" de como uma ação se comporta na prática (Lacerda, Jouclas, Egry, 1996). Conforme Luz (1979) este é o momento privilegiado para reconhecer as contradições que aí se instalam, dadas pelas respostas das diversas realidades que são "instituídas" por tais ações e que incluem diferentes formas e níveis de resistência e dificuldade.

Contudo, no caso do trabalho atualmente dominante dos Programas de Controle e Prevenção de IASS, que se pauta na elaboração de indicadores epidemiológicos de eventos de $\mathrm{IH}$ e determinação de seus fatores de riscos, há praticamente um consenso de que ele é limitado tanto para identificar a conformidade da realidade instituída, quanto reconhecer as condições e situações que favoreçam ou não a implementação de tais ações (São Paulo, 2006).

A resposta para tal desafio tem sido uma busca de novos sistemas de atuação desses Programas de Controle e Prevenção de IASS. Um deles é a aplicação de avaliações processuais, as quais têm recebido cada vez mais destaque e incentivo pelas entidades governamentais e não governamentais e por especialistas na área de controle e prevenção de IASS.

O presente estudo buscou atender a tal desafio, voltado às práticas de controle e prevenção da pneumonia associada à ventilação mecânica, por meio da aplicação de três indicadores clínicos de avaliação processual na UTI-Adulto de um 
hospital público de ensino, nos três turnos de trabalho (manhã, tarde e noite), referentes a: Adesão a Medidas Específicas de Controle e Prevenção de PAVM (Indicador IRPR); Adesão a Práticas de Higiene das Mãos em Situações Selecionadas (Indicador HMSEL); Adesão à Prática de Higiene Bucal no Controle e Prevenção da PAVM (IRHB).

Os dois primeiros indicadores estavam previamente construídos e validados quanto ao seu conteúdo no Manual de Avaliação da Qualidade de Práticas de Controle e Prevenção de Infecção Hospitalar, disponibilizado pela Divisão de Infecção Hospitalar do Centro de Vigilância Epidemiológica da Secretaria de Estado da Saúde de São Paulo (São Paulo, 2006); o terceiro indicador foi elaborado exclusivamente para este estudo e acatou a mesma forma de construto operacional dos anteriores.

Em sua apresentação, este Manual considera que um sistema de avaliação e qualificação do controle e prevenção de IASS precisa atualizar-se constantemente, incorporando novas práticas e abordagens que dêem conta da dinamicidade da evolução da assistência clínica e de novas evidências científicas, como é o caso da relevância atualmente reconhecida da higiene bucal no controle e prevenção de pneumonia em pacientes críticos.

A maneira original de elaboração desses indicadores, na forma de construtos operacionais e sob fundamentações teórico-científicas, permite orientar tanto a aplicação da avaliação, quanto obter índices de conformidade com relação às melhores recomendações disponíveis.

Acatando as aplicações orientadas pelos indicadores, neste estudo as avaliações exigiram predominantemente a observação direta (OD), nos períodos correspondentes às três primeiras horas dos plantões, nos três turnos de trabalho.

No caso do indicador IRPR, a OD exigiu a averiguação da manutenção das medidas de elevação da cabeceira a $30-45^{\circ}$, uso de solução estéril e acato a rotina de troca de material de terapia respiratória. A outra medida - fisioterapia respiratória a avaliação consistiu de averiguação de seu registro no prontuário. Já, para as práticas de higiene bucal e higiene das mãos, a OD implicou acompanhar os momentos de sua realização.

A técnica de OD apresenta vantagens e desvantagens. Entre as vantagens, ela constitui a melhor oportunidade de avaliar "como se faz", além de poder obter variedade de informações sobre comportamentos e eventos, o que permite analisar 
as condições da realidade imediata que favorecem ou desfavorecem sua conformidade. Além disso, é possível distinguir as diversas categorias profissionais e os procedimentos envolvidos; em consequência, reconhecer aqueles que necessitarão de reforços e treinamento para adesão.

As desvantagens da OD se referem à necessidade de treinamento e testes de aferição de concordância para capacitar instrumentos e avaliadores (com implicações nos fatores tempo e custo) na realização da observação. Mesmo assim e, o mais importante, a influência dos avaliadores no comportamento dos avaliados (efeito Hawthorne) pode resultar em taxas falsamente elevadas de adesão (Haas, Larson, 2007).

Com referência à capacitação, os treinamentos foram realizados, neste estudo, pela própria autora, nos horários estabelecidos para as coletas dos dados. $\mathrm{E}$ a aferição foi obtida de acordo com a recomendação da Organização Mundial da Saúde (OMS), pelo teste estatístico de Kappa (WHO, 2009a), cujo objetivo é quantificar coincidências entre dois ou mais avaliadores. Atenção especial quanto ao preparo dos avaliadores é fundamental, já que após a realização do teste de Kappa obteve-se certeza de que as informações coletadas podiam ser captadas. Desse modo, eles também estavam aptos a dar prosseguimento à OD, de forma individualizada. Assim, a ação de OD foi facilitada e agilizada, uma vez que os avaliadores puderam ser redistribuídos entre diversos leitos e horários, aumentando as oportunidades de observação.

Quanto à possibilidade de influência da OD nos resultados da avaliação, a fim de se minimizar este viés (efeito Hawthorne), recomenda-se que ela seja realizada de forma discreta e sigilosa, de modo que o sujeito não saiba que está sendo observado (Polit, Beck, Hungler, 2004a).

A não comunicação, contudo, aos sujeitos sob observação remete à questão de não apresentação prévia do TCLE. Outra questão na aplicação deste método refere-se à não possibilidade de intervenção imediata, diante de situações de não conformidade de adesão às práticas recomendadas durante a OD.

Apesar disso, a OMS considera a técnica de OD um "padrão-ouro" para a detecção de adesão a práticas assistenciais (WHO, 2009a) e diversos autores têm utilizado-a, principalmente para avaliação da prática de higiene das mãos.

Pittet, Mourouga e Perneger (1999) identificaram fatores que contribuem para a não adesão à higiene das mãos, incluindo todas as oportunidades de OD em 
várias unidades assistenciais. De modo semelhante ao presente estudo, esses autores avaliaram todas as categorias profissionais nos três turnos de trabalho. Os profissionais avaliados não foram informados sobre os aspectos do estudo (com exceção dos diretores de departamento) e os avaliadores não interferiram nas situações de não conformidade no momento da observação. Houve, também, anuência da instituição e os profissionais avaliados não foram identificados individualmente.

Karabey et al. (2002) pesquisaram a adesão à higiene das mãos e quantificaram a carga microbiana nas mãos e nos materiais contaminados. Embora a amostra foi representada pelo número de oportunidades, nesse estudo os avaliadores acompanharam o mesmo profissional durante o seu turno de trabalho (manhã e tarde) em uma UTI geral. Os autores também aplicaram o teste de Kappa aos avaliadores, que permaneciam duas horas seguidas em cada turno, durante oito meses. Os profissionais avaliados só foram notificados dos objetivos da pesquisa porque alguns deles se recusaram em ser acompanhados pelos observadores durante a prática assistencial. Os autores não citam o TCLE, mas destacam que após uma reunião para esclarecimentos, os profissionais que inicialmente haviam se recusado passaram a concordar e participar do estudo.

Golan et al. (2006) compararam, em duas UTI dos EUA, os efeitos da obrigatoriedade do uso de avental em pacientes com precauções de contato na adesão à higiene das mãos. Foram observados dois grupos de profissionais e os avaliadores foram testados quanto ao grau de concordância entre eles, que permaneciam uma hora em cada UTI. Somente os diretores e enfermeiros chefes foram informados. De modo semelhante ao estudo anterior, os profissionais avaliados não foram corrigidos durante a observação, assim como adesões não foram divulgadas durante a investigação. As características do estudo fizeram com que o Comitê de Ética da instituição dispensasse os autores quanto à necessidade de distribuírem o TCLE entre os profissionais avaliados.

Semelhantemente, no presente estudo, durante as visitas ao local de avaliação, os objetivos foram informados parcialmente aos profissionais que seriam objeto de OD, mas não das práticas sob observação. Já, as chefias médica, de enfermagem e de fisioterapia foram plenamente notificadas a respeito da metodologia para captação dos dados, de acordo com a aprovação pelo Comitê de Ética e Pesquisa da instituição. 
Mesmo assim, tais características geraram desconforto tanto nos avaliadores quanto nos profissionais de saúde. Detectou-se resistência aos avaliadores no início do estudo, mesmo após esclarecimento de que não haveria identificação dos pacientes ou dos profissionais avaliados. É importante destacar que nos instrumentos utilizados para a avaliação não consta identificação do profissional, apenas sua categoria profissional. A identificação nominal foi utilizada apenas na captação de informações contidas nos prontuários de pacientes com o intuito de se evitar erros relacionados a pacientes homônimos e à mudança de leito. Os avaliadores realizaram a OD situando-se perto do paciente e dos avaliados, já que distanciados não era possível, devido à localização dos leitos ocupados pelos pacientes com IOT. A presença dos avaliadores contribuiu para prolongar a coleta de dados de alguns procedimentos, já que o desconhecimento dos avaliados, quanto à natureza da observação, fez com que muitos deles reduzissem ou retardassem suas atividades, bem como o próprio processo de trabalho já estabelecido para as atividades diárias, durante as três horas em que o avaliador permanecia no local. Isso acarretou maior tempo para se obter as oportunidades de observação, de acordo com a amostra previamente definida. Um deles, inclusive, questionou sobre a não intervenção imediata dos avaliadores, no momento em que estivesse realizando incorretamente alguma prática sob avaliação.

Ainda que a não informação prévia das práticas sob observação possa gerar desconforto, tal método constitui, sem dúvida, a melhor oportunidade de reconhecimento das condições de sua realização, que favorecem ou desfavorecem sua conformidade. A conjunção dos dados de maneira agregada e o compromisso de anonimato por parte do pesquisador oferecem acato à ética. Além disso, é um direito de segurança do paciente a melhoria contínua de ações assistenciais, que somente pode ocorrer pelo reconhecimento daquelas que não apresentam conformidade com melhores evidências disponíveis. Já, a não possibilidade de intervenção no momento em que uma dada prática é realizada incorretamente constitui uma questão intrigante e, infelizmente, ainda muito pouco discutida na aplicação desse método e suas implicações éticas.

No primeiro caso, a evidência da relevância deste método de obtenção de informações (OD) foi demonstrada nos resultados deste estudo. As três práticas avaliadas obtiveram índices de conformidade abaixo do previamente esperado (80\%), de modo que a hipótese inicial, de que este índice seria alcançado, foi 
refutada. Apesar disso, foi possível reconhecer, com maior especificidade, questões sobre recursos de infra-estrutura, processo de trabalho e necessidade de intensificação de treinamento em serviço. Neste último caso, tal reconhecimento dirige-se especificamente às equipes de fisioterapia e enfermagem, porque constituíram as categorias que realizavam as práticas avaliadas.

Com referência à prática do Indicador IRPR, composta de quatro medidas (adesão à rotina de troca de materiais de terapia respiratória, fisioterapia respiratória, manutenção da cabeceira elevada a $30-45^{\circ}$ e uso de solução estéril nos materiais de terapia respiratória), foram realizadas 836 avaliações, sendo 304 no turno da manhã, 304 no turno da tarde e 228 no turno da noite.

Utilizando-se a fórmula de cálculo de conformidade desse indicador, que considera a somatória das quatro medidas corretas ao mesmo tempo e em um mesmo paciente, obteve-se índice de conformidade geral de $68 \%$. Houve variação entre os turnos, uma vez que a maior conformidade foi de $72,4 \%$ (tarde) e a menor, $63,2 \%$ (manhã). Calculando cada medida, isoladamente, constatou-se que a manutenção da "cabeceira elevada a $30-45^{\circ}$ " foi a principal responsável pela não obtenção de conformidade geral esperada, ao variar de $71 \%$ a $78 \%$, entre os turnos. Já, as demais medidas obtiveram, cada uma, conformidade acima da esperada, de $91 \%$ a $100 \%$, entre os turnos.

As medidas que alcançaram 100\% de conformidade foram troca de material de terapia respiratória no turno da manhã e o uso de solução estéril nos turnos da manhã e da noite, permitindo constatar que tais recomendações estão bem estabelecidas na assistência ao paciente em ventilação mecânica.

A $\mathrm{CCIH}$ do local do estudo tem se caracterizado pelo conhecimento e divulgação das medidas de prevenção entre os profissionais envolvidos. Desse modo, foi elaborado um manual contendo as medidas de prevenção básicas que determina, dentre outras recomendações, o período de troca de materiais de terapia respiratória e o uso de solução estéril nesses materiais (Cassettari, Balsamo, Silveira, 2009). Tais medidas são essenciais no atendimento ao paciente nos serviços de saúde, sendo consideradas, portanto, "necessárias" dentro da rotina hospitalar.

Houve facilidade para verificação do grau de inclinação da cabeceira da cama no momento da observação devido à disponibilidade do instrumento medidor conhecido como goniômetro, nas grades de proteção das camas elétricas dos 
pacientes. As baixas conformidades de adesão à recomendação de cabeceira elevada a $30-45^{\circ}$ obtidas surpreenderam, uma vez que as camas possuem goniômetro. Ressalte-se que, quando os pacientes foram submetidos a procedimentos que exigiam a redução do grau da cabeceira ou outras posições (supina, por exemplo), tais momentos não eram contabilizados; o mesmo ocorreu para os pacientes em ventilação mecânica que ocupavam camas sem o goniômetro. Considere-se, também, que a manutenção da cabeceira elevada no grau adequado pode ser realizada por todos os profissionais de saúde que atuam na unidade, e tal procedimento demanda pouco tempo e esforço, quando comparado a outras medidas, como higiene bucal, realizada apenas pelos profissionais de enfermagem.

Em relação às 60 situações de não conformidade relacionadas à cabeceira elevada, todas se referiram a graus inferiores $\left(20^{\circ}-25^{\circ}\right)$ aos recomendados, em todos os períodos (75\%-manhã; 77,4\%-tarde; $82,2 \%$-noite). Tais resultados indicam que muitos profissionais não se habituaram a conferir a elevação da cabeceira a partir do goniômetro das camas elétricas dos pacientes, restringindo-se apenas à própria impressão visual.

Segundo Grap e Munro (1997), o benefício da manutenção da cabeceira elevada a $30-45^{\circ}$ consiste na redução do risco de refluxo e aspiração do conteúdo gástrico nos pacientes sob ventilação mecânica.

Embora a manutenção da cabeceira da cama elevada represente medida não farmacológica, simples e de baixo custo, ela ainda carece de maior incorporação pelos profissionais de saúde, envolvidos na prática assistencial, ainda que a medida conste no guia clínico para prevenção de pneumonia associada aos serviços de saúde do CDC, desde 2003 (Tablan et al., 2004).

Krein et al. (2008) apontam a importância dos enfermeiros na promoção da adesão à manutenção da cabeceira elevada a $30-45^{\circ}$ É compreensível essa afirmação, haja vista que a equipe de enfermagem apresenta o maior contingente em relação às outras equipes de profissionais assistenciais, além de realizar muitos procedimentos no mesmo paciente durante os três turnos de trabalho. Este fato aumenta a possibilidade de poder corrigir o posicionamento do paciente.

Ressalte-se que, no local do presente estudo, a manutenção da inclinação da cabeceira a $30-45^{\circ}$, assim como a higiene bucal, compõe a prescrição de enfermagem, realizada diariamente por um enfermeiro.

Com relação à fisioterapia respiratória, ela é realizada somente nos turnos da 
manhã e da tarde, conforme rotina da instituição. As não conformidades obtidas $(11 \%)$ se referiram à ausência de registro de sua realização no prontuário do paciente. Uma vez que tal avaliação restringiu-se a esta forma de captação da informação, conforme solicitava o indicador IRPR, cabe, aqui, a questão: a fisioterapia não foi de fato realizada ou houve esquecimento de seu registro? Por outro lado, o registro no prontuário é garantia de que ela é corretamente realizada? A melhor avaliação, sem dúvida, seria utilizar também a OD no momento de sua realização. Ocorre que, neste caso, o tempo de observação teria que ser ampliado, a fim de garantir se ela foi ou não realizada em algum momento do plantão. Fica, aqui, a consideração de que a forma de avaliação utilizada pelo indicador IRPR para avaliação desta prática não é a mais adequada, ao contrário do que ocorreu na avaliação das demais medidas, por meio de OD.

Na revisão de literatura, foram encontrados poucos estudos a respeito de OD de medidas de prevenção e controle de PAVM na prática assistencial. Em um deles, Grap et al. (2003) avaliaram, em três UTIs, a manutenção da cabeceira elevada a 30-45 , totalizando 506 medições em 170 pacientes com e sem ventilação mecânica, escolhidos aleatoriamente. Concluíram que cerca de $70 \%$ de todos os pacientes estavam em posição supina, com média do grau de inclinação da cabeceira em $19^{\circ}$, e que nos pacientes intubados o posicionamento abaixo de $30^{\circ}$ foi mais comum do que nos não intubados.

Baxter et al. (2005) analisaram a introdução de três novas medidas de prevenção ao protocolo de redução da incidência de PAVM em cinco UTIs de um mesmo hospital, junto às equipes médica e de enfermagem. Antes da avaliação da frequência de adesão foi implementado um programa educacional para reforçar antigas e novas recomendações, quanto a: manutenção da cabeceira elevada a 30$45^{\circ}$ (com o auxílio de um instrumento de medição dos graus de inclinação da cabeceira); alimentação enteral (transpilórica); dentre outras medidas. Ao longo de seis meses, as medidas resultaram em redução de $51,3 \%$ nas taxas de PAVM, concluindo que a implementação e manutenção de um programa educacional, incluindo auditorias e retorno aos profissionais das informações obtidas, contribuíram para a adesão ao novo protocolo. Embora este estudo não cite a conformidade de adesão às medidas de prevenção, os autores destacaram a importância dos treinamentos antes e após a implementação de novas medidas.

Outros estudos optaram pelo auto-relato para medir o conhecimento e a 
prática realizada pelos profissionais.

Ricart et al. (2003) analisaram, a adesão dos enfermeiros às recomendações dos guias clínicos para a prevenção de PAVM, aplicando um questionário distribuído em congresso anual europeu de enfermeiros que atuavam em UTI. Houve participação de cerca da metade dos 110 enfermeiros, obtendo-se os seguintes resultados sobre os hábitos de adoção das medidas de prevenção: 96,8\% responderam que usavam luvas e aventais de proteção diante do risco de contaminação com material biológico ao assistirem um paciente; $90,1 \%$ realizavam higiene das mãos entre os pacientes; $88,5 \%$ faziam fisioterapia respiratória nos pacientes; $84,3 \%$ acatavam rotina da instituição quanto à troca de circuito do ventilador mecânico; $76,4 \%$ posicionavam a cabeceira a $30-45^{\circ}$; e $72,5 \%$ aderiam ao uso da solução de $\mathrm{CHX} 0,12 \%$ para higiene bucal, entre outras medidas.

Outro estudo avaliou o conhecimento sobre cuidados intensivos de guias clínicos recomendados para a prevenção da PAVM. Com participação mais expressiva de enfermeiros $(74,6 \%)$, dentre as várias questões da pesquisa, obtevese: o circuito do ventilador mecânico deve ser trocado entre pacientes (49\%); a troca do umidificador do ventilador deve ser realizada uma vez por semana no mesmo paciente $(13 \%)$; conhecem a recomendação do posicionamento da cabeceira da cama do paciente em $30-45^{\circ}$ (90\%) (Blot et al.,2007).

Num levantamento junto a 1200 enfermeiros que participavam de dois eventos educacionais nos EUA, sobre a implementação dos guias clínicos de pneumonia associada à ventilação mecânica publicados pelo CDC, realizado por Cason et al. (2007), 34\% dos enfermeiros afirmaram manter a cabeceira da cama elevada a $30-45^{\circ}$ durante $75 \%$ do dia e $52 \%$ durante $100 \%$ do dia.

Pelos estudos citados, conclui-se que as conformidades variaram muito e, algumas abaixo da obtida no presente estudo. No entanto, é importante que as diferenças entre teoria e prática sejam avaliadas, o que permitirá a elaboração de um plano de intervenções capaz de melhorar as estratégias educacionais e a prática assistencial.

A higiene bucal também vem constituindo outra medida relevante no controle e prevenção de pneumonia, principalmente em pacientes críticos (Azarpazhooh, Leake, 2006; Berry et al., 2007; Chan et al., 2007; Garcia, 2005; Lorente, Blot, Rello, 2006; Weitzel, Robinson, Holmes, 2006). Optou-se por avaliá-la isoladamente das medidas anteriores, elaborando-se um indicador específico-IRHB, por dois motivos: 
a) não constava como medida no indicador de avaliação de medidas específicas de controle e prevenção de pneumonia em pacientes de alto risco (IRPR); b) exigiu avaliação no momento de sua realização, diferentemente das medidas anteriores, que implicavam somente averiguar sua manutenção.

$\mathrm{Na}$ instituição, campo deste estudo, a realização de higiene bucal nos pacientes internados na UTI-Adulto é recomendada nos três turnos de trabalho e, conforme a prescrição de enfermagem, ela pode ser de três modalidades, de acordo com as condições de cada paciente: a) Pacientes dêntulos sem lesão e ou sangramento na cavidade bucal e ou reações alérgicas ao produto - creme dental com escovação dos dentes e aplicação de solução de $\mathrm{CHX} \mathrm{0,12 \% ;} \mathrm{b)} \mathrm{Pacientes}$ edêntulos sem lesão e ou sangramento na cavidade bucal e ou reações alérgicas ao produto - aplicação da solução de $\mathrm{CHX} 0,12 \%$ com swab de esponja; c) aplicação de colutório em pacientes com lesões bucais e/ou contra-indicado. Antes de iniciar a OD os avaliadores conferiam na prescrição de enfermagem a modalidade indicada para cada paciente incluído no estudo.

Dentre as 228 oportunidades de realização de higiene bucal observadas, 76 para cada turno, a conformidade geral à higiene bucal $(60,1 \%)$ também não alcançou conformidade mínima esperada de $80 \%$. Quanto à conformidade entre os turnos de trabalho, foi possível demonstrar que a adesão à higiene bucal vai diminuindo acentuadamente do turno da manhã para o da noite $(72,4 \%$ de manhã, $60,5 \%$ de tarde e $47,4 \%$ de noite).

Em relação às modalidades prescritas para higiene bucal, aquela que apresentou maior conformidade foi aplicação apenas de $\mathrm{CHX} 0,12 \%$, em todos os turnos de trabalho, mas somente o da manhã atingiu a conformidade mínima esperada de $80 \%$ (90\%-manhã; 73,7\%-noite; 72,9\%-tarde). A modalidade menos acatada foi escovação de dentes e aplicação de $\mathrm{CHX}$ 0,012\%, em todos os turnos de trabalho (3,6\%-noite; 28,6\%-tarde; 33,3\%-manhã). Já, a aplicação de outro produto (colutório) restringiu-se à minoria das oportunidades avaliadas (19), obtendo conformidades 100\% (manhã), 71,4\% (tarde), 70,0\% (noite).

Destaque-se que, na modalidade escovação com uso de $\mathrm{CHX} 0,12 \%$, as situações de não conformidade referiram-se ao uso somente de CHX 012\% (44), não realização da higiene bucal (12) e escovação com uso de outro produto (1). No noturno, dentre as 28 oportunidades para a modalidade com escovação, ela foi realizada apenas em um paciente de forma adequada. 
Além da aspiração gástrica, a formação de placa dental constitui fator importante para o desenvolvimento de pneumonia (Cardeñosa Cendrero et al., 1999; Gibbsons, 1989) e a higiene bucal pode desempenhar papel relevante na sua prevenção.

Tablan et al. (2004) afirmam que a colonização da cavidade bucal é um precursor importante para o desenvolvimento da PAVM. Cerca de 63\% dos pacientes internados em UTI estão colonizados com microrganismos associados a PAVM e, em $76 \%$ dos casos de PAVM, o microrganismo que coloniza a boca é o mesmo encontrado nos pulmões.

Estudos vêm demonstrando que a escovação dos dentes é o método mais indicado para remoção da placa dental. Pearson (1996), comparando uso de swab com espuma e escova dental em 34 voluntários saudáveis evidenciou que as escovas foram melhores na capacidade de remoção da placa bacteriana, na maioria dos voluntários. Considerou, também, que enfermeiros e profissionais de apoio necessitam de treinamentos específicos para escovação dos dentes dos pacientes, pois a eficácia da escova dental pode ser afetada pela técnica do usuário. Para Berry e Davidson (2006), tanto a ausência quanto a higiene bucal inadequada provocam não somente acúmulo de placa dental, como também a possibilidade de inflamação das gengivas.

Nos resultados obtidos no presente estudo, além da conformidade da higiene bucal ter sido aquém da esperada, principalmente na modalidade escovação, chama a atenção o fato de que a não realização de higiene bucal, sob qualquer modalidade prescrita, constituiu 40 das 91 situações de não conformidades. O uso de $\mathrm{CHX}$, portanto, também obteve baixa adesão.

A aplicação de $\mathrm{CHX}$ vem sendo amplamente divulgada, apoiada em diversos resultados de pesquisas bem controladas e revisões sistemáticas com metanálise, como um produto eficaz na redução da colonização da cavidade bucal por microrganismos, diretamente relacionados com a pneumonia. Embora os estudos apresentem metodologia, aplicação de $\mathrm{CHX}$ com variadas concentrações e técnicas heterogêneas (Beraldo, Andrade, 2008; Chan et al., 2007; Chlebicki, Safdar, 2007; Kola, Gastmeier, 2007).

Além da conformidade geral abaixo da esperada para higiene bucal, as situações constatadas para sua não realização são preocupantes: em 29 casos, ela foi checada na prescrição como realizada; e em 11 casos, ela foi desprezada após o 
banho. Tais situações ocorreram principalmente à tarde (18), seguindo-se o noturno (16) e manhã (5).

Diante disso, vários questionamentos emergem: Pouco conhecimento dos profissionais sobre a importância desse procedimento em pacientes de UTI? Redução de pessoal e excesso de carga de trabalho? Supervisão insuficiente dos enfermeiros? Dificuldade em realizar o procedimento, perante a condição crítica do paciente, principalmente pela presença da cânula orotraqueal, a qual representa uma barreira que dificulta a abertura da cavidade bucal? Foi realizada posteriormente, após o período de OD?

O conhecimento e a prática dos enfermeiros em relação à higiene bucal vêm sendo investigados. Citando mais uma vez o estudo de Cason et al. (2007), sobre a implementação dos guias clínicos de pneumonia associada à ventilação mecânica publicado pelo CDC. Dentre os vários procedimentos propostos para investigação, apenas $56 \%$ dos enfermeiros relataram que os hospitais em que trabalhavam tinham protocolo para higiene bucal. A sua frequência variou conforme a técnica adotada: $49 \%$ realizavam escovação dos dentes em intervalos de oito a doze horas e $46 \%$ usavam swab a cada duas horas. A solução mais frequentemente adotada para a higiene bucal foi o colutório (38\%) e em seguida a $\mathrm{CHX}(26 \%)$.

A baixa adesão à higiene bucal, portanto, não constitui uma questão exclusiva do presente estudo.

Tradicionalmente, a higiene bucal compõe a higiene corporal como um todo e constitui um dos mais importantes cuidados de enfermagem, muito relacionado ao conforto do paciente. E ela geralmente é realizada junto com o banho no leito. O seu reconhecimento como prática preventiva para a pneumonia em pacientes críticos, contudo, é recente não apenas para a enfermagem, como também para as demais categorias profissionais envolvidas na assistência. Isso implica uma nova visão da higiene bucal na assistência e, talvez, seja o caso dela ser realizada, doravante, em momento distinto da higiene corporal, em pacientes críticos. Tal decisão, além de enfatizá-la como prática diretamente voltada ao controle e prevenção de pneumonia, também poderá favorecer outra situação de não conformidade encontrada, na prática avaliada de higiene das mãos, adiante. Antecipando, foi observado que o profissional geralmente usa a mesma luva e/ou não realiza higiene das mãos entre o banho no leito e a higiene bucal. 
No entanto, por ser prescrita em todos os turnos na instituição do estudo, ela não necessariamente é realizada sempre e ao mesmo tempo com a higiene corporal, o que não justifica todas as não conformidades obtidas.

De todas as medidas de prevenção avaliadas neste estudo, somente duas fazem parte da prescrição de enfermagem: cabeceira elevada a $35-45^{\circ}$ e higiene bucal. A partir dos resultados obtidos, é possível indagar sobre o seguimento da prescrição de enfermagem pelos profissionais de enfermagem. Apesar de tais medidas constituírem, atualmente, recomendações básicas para o controle e prevenção de pneumonia e devendo ser de conhecimento de todas as categorias profissionais que atuam na unidade, a higiene bucal é realizada somente pelos profissionais de enfermagem. Tal medida básica de prevenção, portanto, constitui uma responsabilidade da enfermagem.

$\mathrm{Na}$ instituição, cenário deste estudo, os enfermeiros realizam diariamente prescrição e evolução de enfermagem de cada paciente sob seus cuidados, portanto a condição clínica do paciente deve ser avaliada. Além disso, a instituição adota o Sistema de Assistência de Enfermagem (SAE) desde 1981, que é uma atividade exclusiva dos enfermeiros. O SAE é um método que orienta o cuidado individualizado a cada paciente, processo que fundamenta toda a assistência de enfermagem na instituição (Gaidzinski et al., 2008).

Por outro lado, há que se questionar se a situação de não conformidade relacionada à checagem na prescrição de enfermagem, embora não realizada, não comporia o hábito, ainda resistente na prática assistencial, de checar na prescrição de enfermagem o procedimento, muito antes da sua realização. Cabe destacar que na prescrição de enfermagem não é estabelecido um horário fixo para a realização de higiene bucal. Neste caso, o período de observação, de três horas, no início de cada turno, pode não ter sido suficiente para obter esta informação.

Porém, outras situações de não conformidade ocorreram, entre elas, a aplicação somente de $\mathrm{CHX} \quad 0,12 \%$ e não realização de escovação. Portanto, é pertinente também questionar sobre as condições de trabalho que possam estar interferindo na adesão adequada à higiene bucal: Será que apenas realizam a modalidade que exige menos recursos em termos de técnica, preparo de material e tempo no cumprimento das tarefas assistenciais? Ou existem outras razões, como as dificuldades que o procedimento exige na sua execução? 
Durante as oportunidades de observação foi possível reconhecer em situação real situações que contribuem para a não realização de higiene bucal adequada nos pacientes. Uma delas, a dificuldade de acesso à cavidade bucal, devido presenças da cânula orotraqueal e do cadarço que fixa a própria cânula, o que não favorece o uso de escova dental e a remoção total do creme dental. Dependendo do nível de sedação e consciência do paciente, a abertura da cavidade bucal pode ser comprometida. Houve uma situação em que o paciente mordeu parte do swab com espuma, material utilizado para a realização de higiene bucal, aumentando o risco do paciente aspirar pedaços de espuma.

Embora a higiene bucal seja fundamental na prática de enfermagem, principalmente quando associada aos cuidados para os pacientes críticos, a sua adoção ainda pode ser um desafio na atualidade.

Grap et al. (2003) afirmam que os enfermeiros que atuam em UTI podem evitar a higiene bucal nos pacientes sob seus cuidados, pela dificuldade de acesso à cavidade oral e pelo receio de deslocamento da cânula orotraqueal.

O'Reilly (2003) sugere que o momento que apresenta mais facilidade para a realização da escovação dos dentes do paciente é durante a troca de cadarço da cânula orotraqueal. Enquanto Hatlestad (2005), afirma que esta prática não é recomendável pelo risco de deslocamento da cânula.

No local do estudo, a realização da higiene bucal estava frequentemente associada aos pacientes que recebiam o banho no leito. A distribuição era baseada no total de leitos, porém dependendo do número de leitos ocupados, isso poderia ser modificado.

Essa condição de priorizar os cuidados de higiene nos pacientes em que o banho no leito estava programado, independente do grau de complexidade, dificultou a observação direta da higiene bucal, pois alguns profissionais realizavam a higiene bucal antes de iniciar o banho, e outros no final. Em vários momentos, toda a atenção do profissional estava voltada exclusivamente para o banho no leito que, dependendo das condições do paciente, este podia ser mais demorado, ocasionando, às vezes, a não adesão à higiene bucal conforme prescrição de enfermagem. A escala fixa dos banhos no leito, acrescentada à alta carga de trabalho, talvez favoreça que o procedimento seja realizado de forma mecânica e rápida, a fim de cumprir todas as atividades programadas e não programadas no turno de trabalho. Outro aspecto também pode estar relacionado com a não 
incorporação, ainda, da importância dada a esse procedimento em pacientes sob ventilação mecânica.

Estudo quali-quantitativo, para identificar aspectos da higiene corporal mais valorizados pela equipe de enfermagem, foi realizado em oito instituições públicas de saúde, junto a 126 profissionais de enfermagem, os quais destacaram: cuidado com as unhas das mãos e pés (63,2\%); com os cabelos $(68,9 \%)$; higiene bucal (58,5\%); higiene das mãos $(31,1 \%)$. Quanto à atenção dispensada a respeito da higiene corporal, predominou o banho $(79,5 \%)$, seguindo-se higiene bucal $(61,4 \%)$ e unhas das mãos e pés (52,3\%). Segundo os autores, a valorização do cuidado com as unhas e cabelos pode estar vinculada à vaidade feminina, já que a enfermagem consiste em profissão formada majoritariamente por mulheres. Cabe destacar que os cuidados com unhas e cabelos foram mais citados do que a higiene das mãos, considerada importante medida preventiva para a assistência à saúde (Oliveira, Garcia, Sá, 2003).

Jones, Newton e Bower (2004) avaliaram o conhecimento e a prática do cuidado bucal e a adesão ao protocolo por 103 enfermeiros de várias UTI de um mesmo hospital por meio de questionários. Foi encontrado que os enfermeiros valorizavam a higiene bucal do mesmo modo que outros aspectos da higiene corporal, de forma que apenas $13,3 \%$ deles consideraram o cuidado bucal como pouco prioritário e $98 \%$ responderam que faziam avaliação bucal diária dos pacientes. Quanto ao método, 85,5\% citaram realizar a escovação pelo menos uma vez por dia, 50,5\% utilizavam a solução de $\mathrm{CHX}$ rotineiramente e 23,5\% não receberam treinamento específico para o cuidado bucal.

Outro estudo explorou, por meio de questionário, o tipo e a frequência do cuidado bucal praticado em UTI de hospitais de sete países europeus, incluindo as atitudes e o conhecimento dos profissionais, dos quais $91,0 \%$ eram enfermeiros. Nos resultados, $77 \%$ relataram ter recebido treinamento; $88 \%$ consideraram o cuidado bucal importante para o paciente em ventilação mecânica, e que ele era realizado em sua maioria pelos enfermeiros; $68 \%$ consideraram a limpeza da cavidade bucal difícil e 32\% a consideraram também desagradável, além de difícil; para 37\% havia piora da saúde bucal dos pacientes em ventilação mecânica, apesar dos esforços assistenciais. Quanto à frequência da higiene bucal, 37\% citaram que era realizado pelo menos três vezes ao dia. Em relação à técnica, para $88 \%$ dos entrevistados a higiene era realizada com soluções bucais, destacando-se a $\mathrm{CHX}(61 \%) ; 22 \%$ 
responderam utilizar swabs de espumas e $42 \%$ agentes hidratantes. Segundo os autores, apesar da literatura afirmar que a higiene bucal é mais efetiva quando realizada com escova, apenas $42 \%$ dos profissionais relataram utilizar a escova manual para a higiene bucal (Rello et al., 2007).

Os estudos citados mostram que os profissionais reconhecem a importância da higiene bucal para a saúde dos pacientes, porém nem sempre as percepções teóricas são aplicadas na prática assistencial.

Embora a metodologia dos estudos citados fosse diferente (respostas a questionários), o presente estudo apresentou melhores índices de conformidade.

A única investigação semelhante ao do presente estudo foi a de Cutler e Davis (2005), que avaliaram na prática assistencial a higiene bucal, hidratação dos lábios e aspiração das secreções da orofaringe antes e depois da implementação de um protocolo para o cuidado bucal, em oito UTIs nos EUA. Parte da observação foi realizada em cinco UTIs durante quatro horas diárias, nos sete dias da semana por dois meses, de forma aleatória. Os profissionais observados foram informados parcialmente a respeito dos objetivos, o qual foi dividido em dois períodos: basal e de intervenção. No basal os dados foram coletados antes da implementação educacional, enquanto que no período de intervenção os dados foram coletados depois da implementação do protocolo. Foram observados 253 pacientes, sendo 139 (55\%) no período basal e 114 (45\%) no período de intervenção. No período basal a higiene bucal foi realizada principalmente com swabs com sucção e umedecidos com solução bicarbonatada ou solução de peróxido de hidrogênio. Neste período não houve avaliação da cavidade bucal, escovação dos dentes, hidratação dos lábios e boca ou aspiração da cavidade orofaringe. No período de intervenção, $33 \%$ dos pacientes tiveram os dentes escovados, $65 \%$ receberam higiene com swabs e $63 \%$ aplicação de hidratantes nos lábios. Os autores concluíram que a implementação de um protocolo baseado em evidências e a educação multiprofissional motivaram os profissionais a melhorarem a adesão ao cuidado bucal dos pacientes em ventilação mecânica.

No presente estudo não houve uma fase de intervenção, já que das três modalidades de prescrição de enfermagem para a higiene bucal existentes duas delas (escovação e aplicação de solução de $\mathrm{CHX} 0,12 \%$ ou apenas aplicação de solução de $\mathrm{CHX} 0,12 \%$ ) foram padronizadas há aproximadamente um ano, com base em revisão da literatura e em discussão sobre as melhores práticas, havendo 
participação de enfermeiros da própria unidade, da CCIH e do Serviço de Educação Continuada da instituição. À época, foram adquiridos materiais para as novas técnicas como escovas dentais, creme dental com $\mathrm{CHX} 0,12 \%$ e solução de $\mathrm{CHX}$ $0,12 \%$. Os novos produtos foram apresentados e aulas ministradas com o intuito de treinar os profissionais a respeito das técnicas. Pelos resultados obtidos, contudo, é possível inferir que os profissionais observados ainda não incorporaram ou não dispõem de informações suficientes quanto ao impacto dessa prática na prevenção da PAVM, evidenciando-se a necessidade de implantação de melhorias de qualidade, bem como de estratégias que sejam eficazes na promoção de mudanças de comportamento.

Babcock et al. (2004) mostraram que as taxas de PAVM podem ser reduzidas com intervenções educacionais e que o envolvimento de profissionais como terapeutas respiratórios e enfermeiros é fundamental para o sucesso das intervenções voltadas para a prevenção da PAVM.

A inclusão da avaliação da higiene das mãos (HM) foi motivada pelo seu reconhecimento como uma das principais medidas de prevenção da transmissão de microrganismos de origem hospitalar (Pittet et al., 2000). Para o presente estudo foram selecionados, do Indicador HMSEL (Anexos C e D), os seguintes procedimentos, implicados com prevenção e controle de PAVM, e nos quais se recomenda a HM: aspiração orotraqueal, troca de cadarço da cânula orotraqueal e higiene bucal.

Foram realizadas 684 observações referentes a oportunidades de HM pelos profissionais de saúde, durante os três turnos de trabalho, sendo 228 para cada procedimento selecionado. A conformidade foi considerada somente quando 0 profissional realizava a $\mathrm{HM}$ antes e após cada procedimento. Portanto, a não conformidade foi conferida quando a HM era realizada somente antes, somente após ou em nenhum momento.

A conformidade geral de adesão à $\operatorname{HM~}(10,7 \%)$ foi muito inferior àquela esperada $(80 \%)$ e, ressalte-se, inferior também às das demais práticas avaliadas. $O$ procedimento de aspiração orotraqueal foi o que obteve maior conformidade $(18,9 \%)$, seguindo-se troca de cadarço $(7,9 \%)$ e higiene bucal $(5,3 \%)$.

O impacto da HM na ocorrência de IASS tem sido muito estudado e a avaliação dos surtos de infecção tem evidenciado a importância da transmissão cruzada de microrganismos. Wang et al. (2001) mostraram que a baixa adesão à HM 
foi responsável por surto de Staphylococcus aureus, apesar de não ter sido comprovada a colonização das mãos dos profissionais de saúde. Souza e Santana (2009) consideram que, embora as evidências sejam fortes a respeito do papel da HM na redução da transmissão de microrganismos e na redução da incidência de IASS, os profissionais ainda mantêm uma atitude passiva diante deste problema de saúde pública.

A questão da HM é universal. Pela revisão de literatura realizada para este estudo, constata-se grande variabilidade de sua adesão e, na maioria deles, os índices foram baixos também.

Golan et al. (2006), avaliando 1619 oportunidades de observação em duas UTI identificaram adesão à HM, antes e após, inferior à do presente estudo (5\%), em pacientes sob precauções de contato.

Envolvendo 2834 oportunidades de observação, em 48 unidades de internação, Pittet, Mourouga e Perneger (1999) encontraram índices de adesão à HM entre $48 \%$ e $36 \%$ nas unidades de internação e na UTI, respectivamente. Já, Novoa et al. (2007) obtiveram índice menor (20\%) nas unidades gerais do que na UTI (69\%), em um hospital terciário.

Karabey et al. (2002) investigaram a adesão à HM em uma UTI por OD, quanto à duração, método, técnica e uso de luvas, nos seguintes momentos: antes e após o contato direto com o paciente ou com feridas; ao se retirarem da unidade; antes de procedimento invasivo, medicação, manuseio de cateter; após contato com secreções e excretas, membrana mucosa e equipamentos contaminados. A taxa geral de adesão obtida foi apenas $12,9 \%$.

Já, investigação de Sharir et al. (2001) vem sendo reconhecida como aquela que contraria os baixos índices de adesão à HM encontrados na grande maioria dos estudos. A duração e alguns passos da técnica da HM (uso de sabão, papel toalha e presença de jóias), antes e após 1035 procedimentos (33\% de médicos, $60 \%$ de enfermeiros e $6 \%$ de auxiliares), em unidades de internação e quatro UTI, foram estudados. Os avaliadores foram dez estudantes de enfermagem treinados e sem uniformes, para que não fossem reconhecidos nas unidades. Os avaliados desconheciam os objetivos da pesquisa. Obteve-se um índice geral de adesão de $76 \%$. Contudo, em seguida, é informado que a adesão ocorreu mais após (81\%) do que antes do cuidado prestado (68\%). Não ficou claro se o índice geral de adesão considerou a HM antes e após. 
Este estudo também obteve variações de adesão, conforme o local: 97\% (UTI) e $61 \%$ (demais unidades de internação). Nas UTI, 95\% realizaram HM somente antes e $99 \%$ apenas após os procedimentos. Foi constatado, também, variações de adesão, conforme as ocasiões: determinados procedimentos invasivos (87\%), após contato com sangue (84\%), fluidos corpóreos (94\%), secreções e excretas (85\%), membranas mucosas (83\%) e materiais contaminados (79\%). Os altos índices obtidos foram atribuídos aos resultados de um programa educacional implantado há mais de vinte anos, que incluía treinamentos enfatizando a HM através de manuais e monitores responsáveis pela coleta de cultura das mãos em situações especiais.

Outra investigação que encontrou alto índice de adesão à $\operatorname{HM}(90,1 \%)$ entre enfermeiros foi o Ricart et al. (2003), porém ele foi realizado com questionário, por meio de auto-relato, e a resposta se referiu à $\mathrm{HM}$ entre os pacientes, ou seja, não significando, necessariamente, antes e após procedimentos.

Dentre os procedimentos selecionados no presente estudo para avaliação da adesão à HM, um constitui-se em técnica asséptica (aspiração da cânula orotraqueal) e dois em manipulação da membrana mucosa e pele (troca de cadarço da cânula orotraqueal e higiene bucal). Embora o foco da avaliação fosse somente a HM antes e após o procedimento, durante a observação constatou-se que o uso de luvas foi frequente, sendo esterilizadas na realização da aspiração orotraqueal e limpas na troca de cadarço e higiene bucal.

Nessas ocasiões, foram considerados como não conformes quando, após o término dos procedimentos selecionados o profissional, sem higienizar as mãos: realizava outra atividade; retirava-se do quarto ou do local próximo ao leito; trocava de luvas; sobrepunha luvas estéreis ou de procedimento sobre as mãos já enluvadas e utilizadas no mesmo paciente.

O recente guia de HM divulgado pela OMS considera como categoria IB a recomendação de que o uso de luvas não substitui a HM (WHO, 2009b).

A indicação da higiene das mãos está embasada na intensidade do contato com o paciente e/ou com materiais orgânicos, na probabilidade de transmissão microbiana, na susceptibilidade do paciente aos agentes infecciosos e no procedimento que será realizado (Boyce, Pittet, 2002).

O uso de luvas, contudo, vem sendo considerado como uma barreira para a adesão às recomendações de HM, dando a impressão de que a luva elimina tal necessidade (Pittet et al., 2000). 
Para Karabey et al. (2002), em seu estudo por OD em uma UTI, a baixa adesão obtida na adesão à HM (12,9\%) pode ser justificada pelos seguintes fatores: uso excessivo de luvas; número insuficiente de profissionais em relação aos pacientes, resultando em sobrecarga dos profissionais; problemas de estrutura, como ausência de lavatórios e o fato do álcool-gel não ser disponibilizado para os profissionais, o que pode ter contribuído para os profissionais substituírem a HM pelas luvas.

Os fatores para baixa adesão, sugeridos por Karabey et al. (2002), também podem ser aplicados ao presente estudo, com exceção dos recursos de infraestrutura para a realização da HM, porque uma avaliação prévia dos mesmos foi realizada, quanto às condições dos lavatórios, sua localização e dispensadores de papel-toalha e álcool-gel. As inadequações identificadas foram prontamente resolvidas pela chefia de enfermagem. Além disso, os lavatórios são acessíveis e localizados dentro dos quartos (exceto em dois quartos de isolamento, onde estão localizados no banheiro). Portanto, o excesso de uso de luvas sem realizar HM não pode ser justificado por inadequações de infra-estrutura.

Resultados diferentes foram obtidos por Zimakoff, Stormark e Larsen (1993), ao avaliarem a frequência da HM com e sem o uso de luvas pelos profissionais em quatro UTI de dois hospitais universitários. Após aproximadamente 40 horas de OD, distribuídas entre os turnos da manhã, tarde e noite, foi constatado que somente em 17\% das ocasiões, em 1623 procedimentos observados, as luvas foram usadas. Obteve-se, também, maior adesão à HM com uso de luvas $(57 \%)$ do que quando sem seu uso.

Sabidamente, o incremento do uso de luvas, principalmente de procedimentos, pelos profissionais de saúde remonta a meados da década de 80 do Século $X X$, com o amplo reconhecimento da presença de patógenos em substâncias orgânicas e o risco de sua transmissão não somente aos pacientes, como também aos profissionais. Desde então, inúmeras questões têm sido geradas, entre elas, um efeito oposto à sua finalidade, qual seja, a ampliação de disseminação de contaminação ao invés de sua contenção, por seu uso inadequado. Outra consequência de seu uso excessivo tem sido o aumento exponencial de reações alérgicas ao talco e a proteínas do látex (Lacerda, 2003b). Percebe-se certo predomínio de concepção de "auto-proteção", o qual é plenamente questionável, quando mãos sem luvas frequentemente tocam os mesmo locais tocados por mãos com luvas. 
A recomendação praticamente universal de se higienizar as mãos após retirar as luvas não apresenta, ainda, evidências científicas claras sobre diferença de incidência de infecção ocupacional. Sua principal justificativa pauta-se no risco de rasgo da luva e contato direto com substâncias orgânicas. Não há, contudo, registro na literatura de transmissão de doenças transmissíveis por substâncias orgânicas pelo contato na pele íntegra, e sim em mucosas e perfuração cutânea (Lacerda, 2003b). Além disso, luvas não impedem acidentes percutâneos.

Por outro lado, pouco se discute sobre as condições do processo de trabalho assistencial quando, em certas ocasiões, um profissional não consegue sozinho realizar isolamento de contato no mesmo paciente e precisa tocar, ao mesmo tempo, superfícies contaminadas e não contaminadas.

Não minimizando, obviamente, situações de realização de procedimentos inadequados, porém já se faz eminentemente necessário discutir com mais profundidade a questão do uso de luvas e higiene das mãos de forma mais contextualizada com as condições reais da prática assistencial.

Quanto às diferenças de conformidade observadas na HM entre os turnos de trabalho no presente estudo (16,7\%-M; 12,3\%-T; 3,1\%-N) elas não coincidiram com as de outras investigações.

Enquanto no presente estudo o período noturno apresentou conformidade de adesão mais baixa, Sharir et al. (2001) encontraram-na no turno da manhã (72,9-M; 78,2-N; 80,0\%-T). Já, Pittet, Mourouga e Perneger (1999) e Novoa et al. (2007) encontraram adesão mais elevada no turno da noite, explicadas pelas menores oportunidades de observação em relação ao dia e pela menor carga de trabalho sobre os profissionais.

De certo modo, ocorreu o oposto no presente estudo, cuja baixa conformidade obtida no noturno pode estar relacionada com o quadro insuficiente de profissionais e a máxima lotação em alguns períodos de avaliação.

Proporções diferentes de oportunidades de avaliação entre turnos podem influir nos resultados de conformidade. Ressalte-se que, no presente estudo, a amostra foi calculada de modo a assegurar representatividade de cada turno, ou seja, o número de oportunidades de avaliação foi o mesmo. De outro modo, a não coincidência de conformidade nos turnos, entre os estudos, também denota a impossibilidade de buscar causas simplificadas ou genéricas, exigindo análises caso a caso, de acordo com as diferentes realidades e suas variadas situações. 
Além do local do estudo possuir atividades pertinentes a um hospital de ensino, com participação de muitos alunos, ele apresenta elevada demanda de procedimentos agendados, coleta de exames, encaminhamentos, etc., porém tais atividades estão praticamente restritas aos turnos da manhã e da tarde, de modo que o noturno apresenta características próprias. Embora em todos os turnos as oportunidades de observação e os procedimentos observados tenham sido os mesmos, assim como o tempo de permanência (3h/turno), no entanto, no turno da noite as oportunidades de observação da higiene bucal foram reduzidas.

Esses resultados são importantes para o reconhecimento da dinâmica comportamental de cada turno e a identificação de demandas específicas para reforços de atividades educativas.

Segundo Souza e Santana (2009), a avaliação da adesão à HM deve incluir também avaliação do tempo que o profissional de saúde leva para higienizar suas mãos e a facilidade de acesso aos produtos. Para Pittet et al. (2000) o uso de produtos à base de gel alcoólico é a melhor opção, por representar um facilitador, ao agir rapidamente e irritar menos a pele das mãos. Porém, Muto, Sistron e Farr (2000) constataram que dois meses após breve campanha de divulgação de um produto alcoólico, em um hospital de ensino, houve redução da adesão. Isso lhes permitiu concluir que, na ausência de campanhas educativas permanentes (além de outras atividades pertinentes), o uso de produtos alcoólicos poderá não resultar em melhora definitiva da adesão à HM.

Do mesmo modo, Oliveira Junior (2009) afirma que a simples disponibilização desses produtos não levará à adesão duradoura da prática de higiene das mãos se não houver um plano de atividades educativas e motivacionais.

De qualquer forma, não se justifica, no presente estudo, a baixa utilização do álcool-gel observada, uma vez que seu dispensador estava localizado junto ao leito dos pacientes.

Com relação às categorias profissionais envolvidas no presente estudo, apesar de ter ocorrido variações por turno e procedimento, o maior índice de conformidade geral à HM foi obtido entre os fisioterapeutas $(25,8 \%)$, seguindo-se os enfermeiros $(15,6 \%)$ e, por último, auxiliares e técnicos $(4,4 \%)$. Em todas as categorias, contudo, a conformidade foi muito abaixo daquela esperada.

No período de observação foi possível identificar as condutas dos profissionais frente a tais procedimentos. A rotina dos fisioterapeutas caracterizava- 
se por atitude repetitiva, no que se refere à aspiração orotraqueal e à troca de cadarço. O atendimento iniciava-se nos pacientes que tinham indicação, a partir da fisioterapia motora, quando os profissionais colocavam as luvas de procedimentos; em seguida, começava a fisioterapia respiratória e, na maioria das vezes, os profissionais não realizavam HM, tampouco trocavam as luvas; ao invés, sobrepunham nelas luvas estéreis, para iniciar a aspiração orotraqueal. Este foi o principal aspecto observado que não condiz com práticas recomendadas, sugerindo que ambos os procedimentos (fisioterapia motora e respiratória) tratam-se de um só. Após a aspiração orotraqueal, os fisioterapeutas trocavam o cadarço. Algumas vezes, as luvas eram removidas e as mãos higienizadas antes de preparar o cadarço da cânula orotraqueal para, então, realizar o procedimento.

Com relação à adesão da HM na higiene bucal, procedimento realizado somente pela equipe de enfermagem, a diferença de conformidade foi significativa entre enfermeiros (25\%) e auxiliares/técnicos de enfermagem $(8,8 \%)$. Foi possível observar que a equipe de enfermagem frequentemente associa a troca de cadarço e a higiene bucal ao banho. Quando a higiene corporal era iniciada pela higiene bucal, constatou-se maior preocupação com a HM antes da colocação das luvas do que quando a higiene bucal era realizada após o banho. Neste caso, havia baixa adesão à HM porque o profissional, ao realizar o banho no leito, já estava de luvas. Em algumas situações ocorria a troca de luvas, mas não a HM. Quando a troca de cadarço acontecia após o banho, a situação era semelhante, ou seja, a luva não era trocada ou a troca acontecia, porém sem realização de HM.

De acordo com as recomendações dos guias do CDC e da OMS, a HM deve ser realizada sempre que: houver troca de luvas, o mesmo paciente receber procedimentos distintos; troca de uma área contaminada para outra área do mesmo corpo (Boyce, Pittet, 2002; WHO, 2009b)

$\mathrm{Na}$ higiene bucal e na troca de cadarço sempre ocorre manipulação de membrana mucosa e o uso da mesma luva utilizada anteriormente durante o banho do paciente pode favorecer a contaminação da cavidade bucal com microrganismos entéricos, mesmo que se trate do mesmo indivíduo.

Estudo de Golan et al. (2006) encontrou sequência de conformidade diferente entre as categorias profissionais: enfermeiros (39\%), médicos (38\%), terapeutas respiratórios $(22 \%)$. Já, os fisioterapeutas também apresentaram as melhores taxas de conformidade de $\mathrm{HM}$, e até mais altas do que no presente estudo, na 
investigação de Zimakoff, Stormark e Larsen (1993), em hospitais de dois países europeus. Na Dinamarca: fisioterapeutas (50\%), técnicos de laboratório (41\%), enfermeiros (32\%), médicos (21\%). Na Noruega: fisioterapeutas (84\%), enfermeiras (50\%), técnicos de laboratório (35\%), médicos (25\%).

Por outro lado, se houve uniformidade de oportunidades observadas entre os turnos, o mesmo não ocorreu com relação às categorias profissionais, já que os auxiliares e técnicos excederam, e muito, os fisioterapeutas e os enfermeiros. (68,1\% - auxiliares e técnicos; $27,2 \%$ - fisioterapeuta; 4,7\% - enfermeiro).

Há que se questionar: se tivesse havido distribuição de oportunidade semelhante entre as categorias, as taxas de conformidade entre as categorias teriam sido diferentes? Esta questão é válida para os demais estudos semelhantes pesquisados na revisão da literatura, que também apresentaram proporções diferentes de categorias profissionais. Isto porque, quando a proporção de uma categoria é menor em relação às demais, um único profissional necessariamente é avaliado mais vezes, a fim de se atingir as oportunidades previamente definidas. Portanto, esse único profissional poderá interferir mais nos índices de conformidade de sua categoria, seja para mais, seja para menos.

Outra questão constatada durante as observações: algumas vezes, os mesmos profissionais ora realizavam procedimentos em conformidade, ora não. Isso permite considerar se tais ações não estariam antes relacionadas com contextos dos momentos de atuação (condições individuais do paciente, excesso de trabalho, recursos materiais etc.) do que com desconhecimento sobre como realizar corretamente o procedimento. A análise do contexto de atuação, portanto, mostra-se fator relevante também para a melhoria de conformidade de práticas assistenciais.

Desde 1994 a Associação das Enfermeiras Americanas (ANA) vem desenvolvendo atividades junto a outras instituições na elaboração de indicadores que avaliem a qualidade da assistência de enfermagem. Para a ANA, o primeiro passo é fazer com que os enfermeiros sejam informados sobre aspectos do atendimento de enfermagem como mensuração, melhorias, custos clínicos, qualidade e resultados específicos de enfermagem. A ANA adotou as taxas de IASS como importante indicador da qualidade da assistência de enfermagem (Gallagher, 2005).

Não há dúvidas de que as IASS elevam os custos da assistência à saúde. A promoção da HM também, pois exige recursos financeiros para compra de insumos, 
capacitação de pessoal, treinamentos e materiais didáticos. Embora em nosso país ainda faltem estudos a respeito, os custos de promoção da higienização das mãos são significativamente inferiores aos custos relacionados às IASS.

Pittet et al. (2004) estimaram o custo da campanha de promoção de higiene das mãos em hospitais da Universidade de Genebra após uma ampla divulgação e distribuição de produtos alcoólicos para assepsia em todos os hospitais. Os gastos foram estimados em 57.000 dólares anuais, com média de 1.42 dólares por paciente.

Por outro lado, as principais situações encontradas que envolveram as baixas conformidades obtidas no presente estudo (uso de luvas de procedimentos; rotina estabelecida sem avaliação dos procedimentos assistenciais; aumento da carga de trabalho; procedimentos realizados pelos auxiliares/técnicos de enfermagem; procedimentos realizados durante o turno da noite), além de representar importante problema quanto à transmissão cruzada na unidade e favorecer o aparecimento de surtos, pode elevar os custos para seu tratamento para muito acima daqueles dispensados para ações de prevenção, sem contar o alto custo de vida aos acometidos.

O reconhecimento dos principais aspectos que envolveram as baixas conformidades chama à ação uma série de providências, junto aos profissionais e setores envolvidos. Algumas, mais simples e imediatas, tais como: avaliação criteriosa de cada paciente quanto à modalidade de higiene bucal mais exequível; realização das práticas de higiene corporal, troca de cadarço e aspiração separadas da higiene corporal, etc. Outras demandam análises de processo, rotinas, fluxo e carga de trabalho, além dos graus de dificuldade para realização de procedimentos.

É eminente, também, buscar o reconhecimento das razões para não realização de práticas cujas conformidades já são conhecidas pelos avaliados e, por conseguinte, não demandam reforços por meio de treinamento. É, principalmente, o caso da HM que ou não são realizadas nem antes, nem após $(53,4 \%)$, ou apenas após $(27,0 \%)$, conforme ocorreu predominantemente no presente estudo.

Algumas investigações também encontraram resultados semelhantes em relação ao hábito dos profissionais de saúde de higienizar as mãos mais frequentemente após a realização do cuidado assistencial. Golan et al. (2006), 
evidenciaram que $39 \%$ das enfermeiras, $38 \%$ dos médicos e $22 \%$ dos terapeutas respiratórios e técnicos higienizaram as mãos somente após a assistência aos pacientes. No estudo de Freire, Farias e Ramos (2006) os profissionais realizaram HM mais frequentemente após $(49,6 \%)$ a aspiração traqueal do que antes $(20,5 \%)$.

Seria possível inferir que tal atitude denota maior preocupação com a higiene pessoal? Para Golan et al. (2006), a maior adesão à HM após reflete a crença generalizada de que antes do cuidado não é tão importante.

Outros fatores identificados por Pittet (2001) também não podem ser desprezados: lesões produzidas na pele pelos produtos utilizados; carência de lavatórios e outros suprimentos; interferência na relação-paciente; prioridade de procedimentos; uso de luvas; falta de conhecimento a respeito das recomendações; tempo insuficiente; aumento da carga de trabalho e deficiência do número de profissionais; falta de informações científicas que comprovem o impacto da HM na redução das IASS.

Finalmente, há que se enfatizar a grande vantagem da avaliação realizada com indicadores de processo e da técnica de observação direta aplicada no presente estudo, pois, além delas terem permitido reconhecer índices de conformidade em relação à melhor prática esperada, também favoreceram, sobremaneira, o reconhecimento das situações que contribuíram com os baixos valores encontrados.

Conclui-se, também, sobre a relevância dos programas de controle e prevenção de IASS incorporarem, em suas ações, avaliações de processo e agir, portanto, de maneira prospectiva. As ações tradicionais, como vigilância epidemiológica, elaboração de normas, treinamento em serviço, intervenções junto às equipes e, mesmo, rastreamento continuado de pacientes críticos, apesar de relevantes, não são suficientes, conforme se constatou neste e nos outros estudos citados, para obter, seja imediata, seja duradoramente, altos índices de conformidade. Melhores desempenhos implicam, necessariamente, atuar em parceria com os profissionais da assistência, colaborando na análise dos contextos das realidades nas quais as recomendações são destinadas. Enfim, as ações necessitam ser antes específicas do que genéricas.

Além do mais, a avaliação direta das práticas pelos profissionais de controle e prevenção de IASS favorece sua presença mais amiúde nos momentos em elas são realizadas, assim como intervenções imediatas. Desse modo, pode-se, também, 
solucionar o desconforto revelado por um dos profissionais observados por ocasião da realização deste estudo, cuja necessidade de dados agregados não permitia, incomodamente, realizar intervenções imediatas.

A avaliação processual também resulta em importante ferramenta para o serviço de educação continuada, no sentido de se poder atuar mais direta e especificamente junto às práticas e profissionais com problemas de conformidade. 


\section{CONCLUSÕES}


Este estudo avaliou a conformidade de práticas de controle e prevenção da pneumonia associada à ventilação mecânica, por meio da aplicação de indicadores de processo (IRPR, IRHB e HMSEL), os quais possibilitaram a identificação de índices de adesão dessas práticas entre os turnos de trabalho e categoriais profissionais.

De modo geral, nenhum dos três indicadores alcançou o índice da conformidade esperada de $80 \%$, embora em algumas medidas que compõem o indicador IRPR tenha superado esse índice (troca de material de terapia respiratória e uso de solução estéril), em todos os turnos de trabalho, evidenciando que tais recomendações estão bem estabelecidas.

A manutenção de cabeceira elevada de $30-45^{\circ}$ da cama do paciente, incluída nesse mesmo indicador, apresentou a menor conformidade nos três turnos de trabalho. Demonstrando que mesmo sendo uma recomendação simples e que demanda pouco tempo para ser realizada, os profissionais ainda não desenvolveram o hábito de verificar junto ao instrumento ("goniômetro") localizado nas grades de proteção das camas elétricas o grau adequado.

Quanto ao indicador IRHB, concluímos que apesar dos profissionais de enfermagem terem recebido treinamento para a realização da higiene bucal nos pacientes com IOT, não foi suficiente para incorporar essa prática como indicada na prescrição de enfermagem. O que nos levou a vários questionamentos, tais como: ausência de conhecimento que fortaleça a importância do procedimento, alta demanda da carga de trabalho ocasionada pela redução de pessoal, supervisão insuficiente, a rotina de realizá-la próxima ao horário do banho no leito do paciente e a dificuldade em realizar a higiene bucal, devido às condições clínicas do paciente. Destacamos que no turno da noite o índice de conformidade foi mais baixo que nos demais.

$\mathrm{Na}$ aplicação do indicador HMSEL, dos três procedimentos observados, a higiene das mãos antes e após a realização de higiene bucal, foi o procedimento mais comprometido. Sendo que o turno da noite, mais uma vez apresentou o menor 
índice de adesão. Evidenciamos que houve diferenças significativas entre os turnos de trabalho. Foi possível constatar que a baixa adesão a higiene das mãos nos procedimentos (aspiração orotraqueal, troca de cadarço da cânula orotraqueal e higiene bucal) pode estar relacionada com o frequente uso de luvas, devido a não realização da higiene das mãos durante as trocas das mesmas; tornando um substituto da higiene das mãos; o baixo consumo de álcool-gel e até mesmo a rotina associada com a realização desses procedimentos.

Em relação à categoria profissional, os fisioterapeutas apresentaram não só um número maior de oportunidades de observação que as demais categorias (enfermeiros, auxiliares e técnicos de enfermagem), bem como de adesão geral a higiene das mãos. Considerando que eles, realizam a aspiração orotraqueal e troca de cadarço nos turnos da manhã e da tarde.

Esses resultados implicam diretamente na qualidade assistencial, não só porque facilitam a contaminação cruzada de microrganismos entre os pacientes, por meio das mãos contaminadas dos profissionais, mas pelas conformidades comprometidas apresentada pelos outros dois indicadores.

Neste estudo acreditamos ter identificado fatores relevantes para explicar a adesão ou não às práticas de controle e prevenção de PAVM, a partir da aplicação de indicadores de processo e da observação direta, os quais apontaram que as normas, embora instituídas, nem sempre são seguidas na prática.

É preciso destacar que o Serviço de Controle de Infecção Hospitalar deve incluir em seu programa anual as avaliações de processo, além de atuar em parceria com os profissionais da assistência, buscando analisar o contexto da realidade e de forma prospectiva.

Acreditamos que esta pesquisa poderá contribuir para novas discussões a respeito da prática assistencial e colaborar na criação de estratégias educativas junto ao Serviço de Educação Continuada e da CCIH da instituição. 


\section{REFERÊNCIAS}


Akerman M, Nadanovsky P. Avaliação dos serviços de saúde: avaliar o quê? Cad Saúde Públ. 1992; 8(4):361-5.

American Thoracic Society Documents (ATS). Guidelines for the management of adults with hospital-acquired pneumonia, ventilator-associated pneumonia and healthcare-associated pneumonia. Am J Respir Crit Care Med. 2005; 171(4):388416.

Assis DB, Madalosso G, Ferreira SA, Yassuda YY; Geremias AL. Análise dos dados de infecção hospitalar do Estado de São Paulo: ano de 2007. Bol Epidemiol Paul. 2008 [citado 2009 maio 5]; 5(53):1-18. Disponível em: http://www.cve.saude.sp.gov.br/agencia/bepa53_ih.htm.

Atkins D, Best D, Briss PA, Eccles M, Falck-Ytter Y, Flottorp S, et al. GRADE Working Group. Grading quality of evidence and strengh of recommendations. BMJ. $2004 ; 328(7454): 1490$.

Azarpazhooh A, Leake JL. Systematic review of the association between respiratory diseases and oral health. J Periodontol. 2006; 77(9):1465-82.

Babcock HM, Zack JE, Garrison T, Trovillion E, Jones M, Fraser VJ, et al. An educational intervention to reduce ventilator-associated pneumonia in an integrated health system: a comparison of effects. Chest. 2004; 125(6):2224-31.

Baxter AD, Allan J, Bedard J, Malone-Tucker S, Slivar S, Langill M, et al. Adherence to simple and effective measures reduces the incidence of ventilator-associated pneumonia. Can J Anaesth. 2005; 52(5):535-41. 
Beraldo CC, Andrade D. Higiene bucal com clorexidina na prevenção de pneumonia associada à ventilação mecânica. J Bras Pneumol. 2008; 34(9):707-14.

Berenholtz SM, Milanovich S, Faircloth A, Prow DT, Earsing K, Lipsett P, et al. Improving care for the ventilated patient. Perfomance Improvement. Jt Comm J Qual Saf. 2004; 30(4):195-204.

Berry AM, Davidson PM, Masters J, Rolls K. Systematic literature review of oral hygiene practices for intensive care patients receiving mechanical ventilation. Evidence-based Practice Critical Care. Am J Crit Care. 2007; 16(6):552-62.

Berry AM, Davidson PM. Beyond comfort: oral hygiene as a critical nursing activity in the intensive care unit. Intensive Crit Care Nurs. 2006; 22(6):318-28.

Blot SI, Labeau S, Vandijck D, Van Aken P, Claes B, Executive Board of the Flemish Society for Critical Care Nurses. Evidence-based guidelines for the prevention of ventilator-associated pneumonia: results of a knowledge test among intensive care nurses. Intensive Care Med. 2007; 33(8):1463-7.

Bontem MJM. Strategies for prevention of hospital-acquired pneumonia: oral and selective decontamination of the gastrointestinal tract. Semin Respir Crit Care Med. 2002; 23(5):481-8.

Boyce JM, Pittet D. Guideline for hand hygiene in health-care settings: recommendations of the Healthcare Infection Control Practices Advisory Committee and the SHEA, APIC, IDSA Hand Hygiene Force Task. Infect Control Hosp Epidemiol. 2002; 23(Suppl):3-40.

Brasil. Ministério da Saúde. Portaria n. 2.616, de 12 de maio de 1998. Dispõe sobre as diretrizes e normas para a prevenção e o controle das infecções hospitalares. Diário Oficial da União, Brasília, 12 maio 1998. p. 232-36.

Campbell SM, Braspenning J, Hutchinson A, Marshall M. Research methods used in developing and applying quality indicators in primary care. Qual Saf Health Care. 2002; 11(4):358-64. 
Cardeñosa Cendrero JA, Solé-Violán J, Bordes BA, Noguera Catalan J, Arroyo Fernandéz J, Saavedra Santana $\mathrm{P}$, et al. Role of different routes of tracheal colonization of pneumonia in patients receiving mechanical ventilation. Chest. 1999; 116(2):462-70.

Carvalho CRR. Pneumonia associada à ventilação mecânica [editorial]. J Bras Pneumol. 2006; 32(4):xx- xxii.

Cason CL, Tyner T, Saunders S, Broome L; Centers for Disease Control and Prevention. Nurses $\square$ implementation of guidelines for ventilator-associated pneumonia from the Centers for Disease Control and Prevention. Am J Crit Care. 2007; 16(1):28-38.

Cassettari VC, Balsamo AC, Silveira IR. Manual para prevenção das infecções hospitalares. São Paulo: Comissão de Infecção Hospitalar do Hospital Universitário da Universidade de São Paulo; 2009 [citado 2009 set. 20]. Disponível em: http://www.hu.usp.br/arquivos/Manualccih_2005.pdf.

Chan EY, Ruest A, Meade MO, Cook DJ. Oral decontamination for prevention of pneumonia in mechanically ventilated adults: systematic review and meta-analysis. BMJ. 2007; 334(7599):889.

Chlebicki MP, Safdar N. Topical chlorhexidine for prevention of ventilator-associated pneumonia: a meta-analysis. Crit Care Med. 2007; 35(2):595-602.

Collard HR, Saint S, Matthay MA. Prevention of ventilator-associated pneumonia: an evidence-based systematic review. Ann Intern Med. 2003; 138(6): 494-501.

Craven DE; Steger KA. Epidemiology of nosocomial pneumonia: new perspectives on old disease. Chest. 1995; 108(Suppl. 2):1-16.

Crunden E, Boyce C, Woodman H, Bray B. An evaluation of the impact of the ventilator care bundle. Nurs Crit Care. 2005; 10(5):242-6. 
Cutler CJ, Davis N. Improving oral care in patients receiving mechanical ventilation. Am J Crit Care. 2005; 14(5):389-94.

DeRiso AJ II, Ladowsky JS, Dillon TA, Justice JW, Petersen AC. Chlorhexidine gluconate $0,12 \%$ oral rinse reduces the incidence of total nosocomial respiratory infection and nonprophylatic systemic antibiotic use in patients undergoing heart surgery. Chest. 1996; 109(6):1556-61.

Donaldson MS, editor. Measuring the quality of health care. Washington: Institute of Medicine; 1999. p. 1-43.

Edwards JR, Peterson KD, Andrus ML, Dudeck MA, Pollock DA, Horan TC, et al. National Healthcare Safety Network (NHSN) report, data summary for 2006 through 2007, issued November 2008. Am J Infect Control. 2008; 36(9):609-26.

El-Solh AA, Pietrantoni C, Bhat A, Okada M, Zambon J, Aquilina A, et al. Colonization of dental plaques: a reservoir of respiratory pathogens for hospitalacquired pneumonia in institutionalized elders. Chest. 2004; 126(5):1575-82.

Fagon JY, Chastre J, Hance AJ, Montravers P, Novara A, Gibert C. Nosocomial pneumonia in ventilator patients: a cohort study evaluating attributable mortality and hospital stay. Am J Med. 1993; 94(3):281-88.

Fernandes AT, Zamorano PO, Torezan Filho MA. Pneumonia hospitalar. In: Fernandes AT, Fernandes MO, Ribeiro Filho N, editores. Infecção hospitalar e suas interfaces na área da saúde. São Paulo: Atheneu; 2000. p. 516-51.

Ferreira DP. Indicadores de saúde: construção e uso. In: Cianciarullo TI, Cornetta VK, organizadores. Saúde, desenvolvimento e globalização: desafio para os gestores do terceiro milênio. São Paulo: Ícone; 2002. p. 259-270.

Freire ILS, Farias GM, Ramos CS. Prevenindo pneumonia nosocomial: cuidados da equipe de saúde ao paciente em ventilação mecânica invasiva. Rev Eletrônica Enferm. 2006; 8(3):377-97. 
Fulbrook P, Mooney S. Care bundles in critical care: a practical approach to evidence-based practice. Nurs Crit Care. 2003; 8(6):249-55.

Gaidzinski R, Lima AFC, Soares AVN, Fugulin FMT, Sancinetti TR, Castilho V. Gestão de pessoal de enfermagem e o sistema de assistência de enfermagem. In: Gaidzinski R, Soares AVN, Lima AFC, Gutierrez BAO, Cruz DALM, Rogenski NMB, et al editores. Diagnóstico de enfermagem na prática clínica. Porto Alegre: Artmed; 2008. p. 47-61.

Gaidzinski RR, Fugulin FMT, Castilho V. Dimensionamento de pessoal de enfermagem em instituições de saúde. In: Kurcgant $P$, coordenadora.

Gerenciamento em enfermagem. Rio de Janeiro: Guanabara Koogan; 2005. p.12537.

Gallagher RM. National quality efforts: what continuing and staff development educators need to know. J Contin Educ Nurs. 2005; 36(1):39-45.

Garcia R. A review of the possible role of oral and dental colonization on the occurrence of health care-associated pneumonia: underappreciated risk and a call for interventions. Am J Infect Control. 2005; 33(9):527-41.

Gibbsons RJ. Bacterial adhesion to oral tissues: a model for infections diseases. J Dent Res.1989; 68(5):750-60.

Golan Y, Doron S, Griffith J, El Gamal H, Tanios M, Blunt K, et al. The impact of gown-use requirement on hand hygiene compliance. Clin Infect Dis. 2006; 42(3):3706.

Grap MJ, Munro CL, Ashtiani B, Bryant S. Oral care interventions in critical care: frequency and documentation. Am J Crit Care. 2003; 12(2):113-8.

Grap MJ; Munro CL. Ventilator-associated pneumonia: clinical significance and implications for nursing. Heart Lung. 1997; 26(6):419-29. 
Haas JP, Larson EL. Measurement of compliance with hand hygiene. J Hosp Infect. 2007; 66(1):6-14.

Haley RW, Culver DH, White JW, Morgan WM, Emori TG, Munn VP. et al. The efficacy of infection surveillance and control programs in preventing nosocomial infections in US hospitals. Am J Epidemiol. 1985; 121(2):182-205.

Hatlestad D. Securing the endotracheal tube. In: RT for Decision Makers in Respiratory Care. 2003 [cited 2009 sept. 30]; April/May. Disponível em: <http://www.rtmagazine.com/issue/articles/2003-04_05.asp>.

Horan TC, Andrus M, Dudeck M A. CDC/NHSN surveillance definition of health careassociated infection and criteria for specific types of infections in the acute care setting. Am J Infect Control. 2008; 36(5):309-32.

Hulley SB, Martin JN, Cummings SR. Planejando as medições: precisão e acurácia. In: Hulley SB, Cummings SR, Browner WS, Grady D, Hearst N, Newman TB. Delineando a pesquisa clínica: uma abordagem epidemiológica. $2^{\mathrm{a}}$ ed. Porto Alegre: Artmed; 2003. p. 55-66.

Huxley EJ, Viroslav J, Gray WR, Pierce AK. Pharyngeal aspiration in normal adults and patients with depressed consciousness. Am J Med. 1978; 64(4):564-8.

Isakou W, Kollef $\mathrm{MH}$. Preventing ventilator-associated pneumonia: in evidence-based approach of modifiable risk factors. Semin Respir Crit Care Med. 2006; 27(1):5-17.

Johanson WG, Pierce AK. Nosocomial respiratory with Gram-Negative Bacilli. The significance of colonization of the respiratory tract. Ann Intern Med. 1972; 77(5):7016.

Jones $\mathrm{H}$, Newton JT, Bower EJ. A survey of the oral care practices of intensive care nurses. Intensive Crit Care Nurs. 2004; 20(2):69-76. 
Karabey S, Ay P, Derbentli S, Nakipoglu Y, Esen F. Handwashing frequencies in an intensive care unit. J Hosp Infect. 2002; 50(1):36-41.

Kelleghan RN, Salemi C, Padilla S, McCord M, Mermilliod G, Canola T, et al. An effective continuous quality improvement approach to the prevention of ventilatorassociated pneumonia. Am J Infect Control. 1993; 21(6):322-30.

Kola A, Gastmeier P. Efficacy of oral chlorhexidine in preventing lower respiratory tract infections. Meta-analysis of randomized controlled trials. J Hosp Infect. 2007; 66(3):207-16.

Kollef MH, Silver P, Murphy DM, Trovillion E. The effect of late-onset ventilatorassociated pneumonia in determining patient mortality. Chest. 1995; 108(6):1655-62.

Krein SL, Kowalski CP, Damschroder L, Forman J, Kaufman SR, Saint S. Preventing ventilator-associated pneumonia in the United States: a multicenter mixed-methods study. Infect Control Hosp Epidemiol. 2008; 29(10):933-40.

Lacerda RA, Jouclas VMG, Egry EY. A face iatrogênica do hospital. As demandas para o controle de infecção hospitalar. São Paulo: Atheneu; 1996.

Lacerda RA. Introdução. In: Lacerda RA, coordenadora. Controle de infecção em centro cirúrgico: fatos, mitos e controvérsias. São Paulo: Atheneu São Paulo; 2003a. p. 1-6.

Lacerda RA. Riscos de infecção ocupacional por exposição a substâncias orgânicas e medidas de precauções. In: Lacerda RA, coordenadora. Controle de infecção em centro cirúrgico: fatos, mitos e controvérsias. São Paulo: Atheneu São Paulo; 2003b. p. 469-92.

Landis JR, Koch GG. The measurement of observer agreement for categorical data. Biometrics. 1977; 33(1):159-74.

Larson EL. APIC guideline for handwashing and hand antisepsis in health care settings. Am J Infect Control. 1995; 23(4):251-69. 
Lorente L, Blot S, Rello J. Evidence on measures for the prevention of ventilatorassociated pneumonia. Eur Respir J. 2007; 30(5):1193-207.

Luz MT. As instituições médicas no Brasil: instituições e estratégia de hegemonia. Rio de Janeiro: GRAAL; 1979.

Lynn MR. Determination and quantification of content validity. Nurs Res. 1986; 35(6):382-5.

McGlynn EA, Steven MA. Developing a clinical performance measure. Am J Prev Med. 1998; 14(3):14-21.

Mckibben L, Horan TC, Tokars JI, Fowler G, Cardo DM, Pearson ML, et al. Healthcare Infection Control Practices Advisory Committee. Guidance on public reporting of healthcare-associated infections: recommendations of the Healthcare Infection Control Practices Advisory Committee. Infect Control Hosp Epidemiol. 2005; 26(6):580-7.

Medeiros EAS, Menezes FG, Valle LMC. Pneumonias bacterianas associadas à saúde. In: Manual de prevenção de infecções hospitalares do trato respiratório. $2^{a}$ ed. São Paulo: Associação Paulista de Estudos e Controle de Infecção Hospitalar, 2005. p. 1-17.

Medeiros EAS. Fatores de risco para aquisição e letalidade de pneumonia hospitalar em adultos internados em unidade de terapia intensiva [tese]. Escola Paulista de Medicina, Universidade Federal do Estado de São Paulo, São Paulo, 1993. p. 152.

Menezes PR. Validade e conbiabilidade das escalas de avaliação em psiquiatria. Psiq Clin. 1998; 25(n. esp.):214-6.

Mori H, Hirasawa H, Oda S, Shiga H, Matsuda K, Nakamura M. Oral care reduces incidence of ventilator-associated pneumonia in ICU populations. Intensive Care Med. 2006; 32(2):230-6. 
Morley S, Sanith P. Principles of psychological assessment. In: Freeman C, Tyrer P (eds.). Research methods in psycahitry. Londres: Gaskell; 1989.

Muto CA, Sistrom MG, Farr BM. Hand hygiene rates unaffected by installation of dispensers of a rapidly acting hand antiseptic. Am J Infect Control. 2000; 28(3):273-6.

National Nosocomial Infections Surveillance (NNIS). National Nosocomial Infections Surveillance (NNIS) System Report, data summary from January 1992 to June 2004, issued October 2004. Am J Infect Control. 2004; 32(8):470-85.

Newman T, Browner WS, Cunnings SR. Delineando estudos de testes médicos. In: Hulley SB, Cummings SR, Browner WS, Grady D, Hearst N, Newman T. Delineando a pesquisa clínica: uma abordagem epidemiológica. $2^{\mathrm{a}}$ ed. Porto Alegre: Artmed; 2006. p. 203-44.

Niederman MS. Nosocomial pneumonia. In: Crapo JD, et al editores. Baum's text book of pulmonary disease. 7th ed. Philadelphia: Lippincott Willians \& Wilkins; 2004. p. 424-454.

Nonino EAPM. Avaliação da qualidade dos procedimentos de enfermagem - banho e curativo - segundo o grau de dependência assistencial dos pacientes internados em um Hospital Universitário [tese]. Ribeirão Preto: Escola de Enfermagem, Universidade de São Paulo; 2006.

Novaes HMD. Avaliação de programas, serviços e tecnologias em saúde. Rev Saúde Pública. 2000; 34(5):547-59.

Novoa AM, Pi-Sunyer T, Sala M, Molins E, Castells X. Evaluation of hand hygiene adherence in a tertiary hospital. Am J Infect Control. 2007; 35(10):676-83.

Oliveira CAC. Prática de medicina baseada em evidência em um centro de terapia intensiva pediátrico [tese]. São Paulo: Faculdade de Medicina, Universidade de São Paulo; 2003. 
Oliveira EA, Garcia TR, Sá LD. Aspectos valorizados por profissionais de enfermagem na higiene corporal pessoal e na higiene corporal do paciente. Rev Bras Enferm. 2003; 56(5):479-83.

Oliveira Junior FI. Salve vidas: higienize suas mãos [editorial]. APECIH Informativo. 2009; 22(2):1-2.

O'Reilly M. Oral care of the critically ill: a review of the literature and guidelines for practice. Aust Crit Care. 2003; 16(3):101-10.

Ovretveit J, Gustafson D. Using research to inform quality programmes. BMJ. 2003; 326(5):759-61.

Pearson LS. A comparison of the ability of foam swabs and toothbrushes to remove dental plaque: implications for nursing practice. J Adv Nurs. 1996; 23(1):62-69.

Pineda LA, Saliba RG, El Solh AA. Effect of oral decontamination with chlorhexidine of the incidence of nosocomial pneumonia: a meta-analysis. Crit Care. 2006 [cited 2009 Jan. 6]; 10(1):R35. Disponível em: http://ccforum.com/content/10/1/R35.

Pittet D, Hugonnet S, Harbarth S, Mourouga P, Sauvan V, Touveneau S, et al. Effectiveness of a hospital-wide programme to improve compliance with hang hygiene. Lancet. 2000; 356(9238):1307-12.

Pittet D, Mourouga P, Perneger TV. Compliance with handwashing in a teaching hospital. Infection Control Program. Ann Intern Med. 1999; 130(2):126-30.

Pittet D, Sax H, Hugonnet S, Harbarth S. Cost implications of successful hand hygiene promotion. Infect Control Hosp Epidemiol. 2004; 25(3):264-6.

Pittet D. Compliance with hand disinfection and its impact on hospital-acquired infections. J Hosp Infect. 2001; 48 Suppl A:40-6. 
Polit DF, Beck CT, Hungler BP. Avaliação dos métodos de coleta de dados. In: Hungler BP, Beck CT, Polit DF. Fundamentos de pesquisa em enfermagem: métodos, avaliação e utilização. $5^{a}$ ed. Porto Alegre: Artmed; 2004a. p. 247-84.

Polit DF, Beck CT, Hungler BP. Compreensão do delineamento da pesquisa quantitativa. In: Hungler BP, Beck CT, Polit DF. Fundamentos de pesquisa em enfermagem: métodos, avaliação e utilização. $5^{\text {a }}$ ed. Porto Alegre: Artmed; 2004b. p. 163-98.

Prade SS, Felix J, Mendes A, Gadelha MZ, Pereira M. Estudo brasileiro da magnitude das infecções hospitalares em hospitais terciários. Rev Cont Infec Hospital. 1995; 2(2):11-24.

Pringle M, Wilson T, Grol R. Measuring "goodness" in individuals and healthcare systems. BMJ. 2002; 325(28):704-7.

Rello J, Koulenti D, Blot S, Sierra R, Diaz E, De Waele JJ, et al. Oral care practices in intensive care units: a survey of 59 European ICUs. Intensive Care Med. 2007; 33(6):1066-70.

Rello J, Ollendorf DA, Oster G, Vera-Llonch M, Bellm L, Redman R, et al. Epidemiology and outcomes of ventilator-associated pneumonia in a large US database. Chest. 2002; 122(6):2115-21.

Ricart M, Lorente C, Diaz E, Kollef MH, Rello J. Nursing adherence with evidencebased guidelines for preventing ventilator-associated pneumonia. Crit Care Med. 2003; 31(11):2693-6.

Rosenthal VD, Guzman S, Safdar N. Reduction in nosocomial infection with improved hand hygiene in intensive care units of a tertiary care hospital in Argentina. Am J Infect Control. 2005; 33(7):392-7.

Rosner B. Fundamentals of biostatistics. 6a ed. Belmont: Thomson Brooks; 2006. 
Russel AP. Mechanism of bacterial insusceptibility to biocides. Am J Infect Control. $2001 ; 29(4): 259-61$.

Sanders NR. Health care organizations can learn from the experiences of others. Qual Prog. 1997; 30(2):47-9.

São Paulo (Estado). Secretaria da Saúde. Divisão de Infecção Hospitalar. Centro de Vigilância Epidemiológica. Controle e prevenção de infecção respiratória. Manual de avaliação da qualidade de práticas de controle de infecção hospitalar. São Paulo; 2006 [citado 2008 jul. 19]. p. 102-15. Disponível em:

http://www.cve.saude.sp.gov.br/htm/ih/lH_MANUALFAPESP06.pdf.

Scannapieco FA, Stewart EM, Mylotte J. M. Colonization of dental plaque by respiratory pathogens in medical intensive care patients. Crit Care Med. 1992; 20(6):740-5.

Schleder B, Stott K, Lloyd RC. The effect of a comprehensive oral care protocol on patients at risk for ventilator-associated pneumonia. J Advocate Health Care. 2002; 4(1):27-30.

Sharir R, Teitler N, Lavi I, Raz R. High-level handwashing compliance in a community teaching hospital: a challenge that can be met. J Hosp Infect. 2001; 49(1):55-8.

Shorr AF, O'Malley PG. Continuous subglottic suctioning for the prevention of ventilator-associated pneumonia: potential economic implications. Chest. 2001; 119(1):228-35.

Sierra R, Benítez E, León C, Rello J. Prevention and diagnosis of ventilatorassociated pneumonia. A survey on current practices in Southern Spanish. Chest. 2005; 128(3):1667-73.

Society for Healthcare Epidemiology of America (SHEA). An approach to the evaluation of quality indicators of the outcome of care in hospitalized patients, with a 
focus on nosocomial infection indicators. Infect Control Hosp Epidemiol. 1995; 16(5):308-15.

Souza FC, Santana HT. Higienização das mãos. In: Agência Nacional de Vigilância Sanitária (ANVISA). Manual de prevenção de infecções associadas a procedimentos estéticos. Brasíllia: ANVISA; 2009.

Tablan OC, Anderson LJ, Besser R, Bridges C, Hajjeh R; Healthcare Infection Control Practices Advisory Committee. Guidelines for preventing health-care associated pneumonia, 2003. Recommendations of CDC and Prevention and Healthcare Infection Control Practices Advisory Committee. MMWR Recomm Rep. 2004; 53(RR-3):1-36.

Terpening M. Geriatric oral health and pneumonia risk. Clin Infect Dis. 2005; 40(15):1807-10.

Thomas L, Maillard JY, Lambertr RJ, Russell AD. Development of resistance to chlorhexidine diacetate in Pseudomonas aeroginosa and the effect of a "residual" concentration. J Hosp Infect. 2000; 46(4):297-303.

Tolentino-DelosReyes A, Ruppert SD, Shiao SYPK. Evidence-based practice: use of the ventilator bundle to prevent ventilator-associated pneumonia. Am J Crit Care. 2007; 16(1):20-7.

Torres A, Carlet J. Ventilator-associated pneumonia. European Task Force on ventilator-associated pneumonia. Eur Respir J. 2001; 17(5):1034-45.

Torres MM, Andrade D, Santos CB. Punção venosa periférica: avaliação de desempenho dos profissionais de enfermagem. Rev Latino-am Enfermagem. 2005; 13(3):299-304.

Toufen Junior C, Houvnanian ALD, Franca SA, Carvalho CRR. Prevalence rates of infection in intensive care units of a tertiary teaching hospital. Rev Hosp Clin. 2003; 58(5):254-9. 
Vallés J, García-Esquirol O, Mariscal D, Real J, Fernández R. Excess ICU mortality attributable to ventilator-associated pneumonia: The role of early vs late onset. Intensive Care Med. 2007; 33(8):1363-8.

Van Nieuwenhoven CA, Buskens E, Bergmans DC, van Tiel FH, Ramsay G, Bonten MJ. Oral decontamination is cost saving in the prevention of ventilator-associated pneumonia in intensive care units. Crit Care Med. 2004; 32(1):126-30.

Villas Bôas PJF, Ruiz T. Ocorrência de infecção hospitalar em idosos internados em hospital universitário. Rev Saúde Pública. 2004; 38(3):372-8.

Vincent JL, Bihari DJ, Suter PM, Bruining HA, White J, Nicolas-Chanoin MH, et al. The prevalence of nosocomial infection in intensive care units in Europe: results of the European Prevalence of in Infection in Intensive Care (EPIC) Study. EPIC International Advisory Committee. JAMA. 1995; 274(8):639-44.

Wang JT, Chang SC, Ko WJ, Chang YY, Chen ML, Pan HJ, et al. A hospital-acquired outbreak of methicillin-resistant Staphylococcus aureus infection initiated by a surgeon carrier. J Hosp Infect. 2001; 47(2):104-9.

Warren DK, Shukla SJ, Olsen MA, Kollef MH, Hollenbeak CS, Cox MJ, et al. Outcome and attributable cost of ventilator-associated pneumonia among intensive care unit patients in a suburban medical center. Crit Care Med. 2003; 31(5):1312-7.

Weitzel T, Robinson SB, Holmes J. Preventing nosocomial pneumonia. Am J Nurs. 2006; 106(9):72A-72G.

Westmoreland D, Wesorick B, Hanson D, Wyngarden K. Consensual validation of clinical practice model practice guidelines. J Care Qual. 2000; 14(4):16-27.

Whorld Health Organization (WHO). Guidelines and hand hygiene in health care. Parte III Process and outcome measurement. Hand hygiene as a performance indicator. Genebra: WHO. 2009a [cited 2009 Jun. 23]. p. 157-163. Disponível em: http://www.who.org. 
Whorld Health Organization (WHO). Guidelines and hand hygiene in health care. Part II Consensus recommendatins. Ranking system for evidence. Genebra: WHO; 2009b [cited 2009 Jun. 23]. Disponível em: http://www.who.org.

Zack JE, Garrison T, Trovillion E, Clinkscale D, Coopersmith CM, Fraser VJ, Kollef $\mathrm{MH}$. Effect of an education program aimed at reducing the occurrence of ventilatorassociated pneumonia. Crit Care Med. 2002; 30(11):2407-12.

Zimakoff J, Stormark M, Larsen SO. Use of gloves and handwashing behaviour among health care workers in intensive care units. A multicentre investigation in four hospitals in Denmark and Norway. J Hosp Infect. 1993; 24(1):63-7. 
9 APÊNDICES 


\section{Apêndice A - Constr to operacional do indicador IRHB: avaliação da adesão à higiene b $\square$ cal conforme rotina da instit $\square$ ição}

Descrição: Embora a higiene bucal seja uma prática tradicional na assistência ao paciente, até recentemente não havia evidências científicas de sua relevância direta para a prevenção de infecção hospitalar $(\mathrm{IH})$, principalmente pneumonia. Tanto é verdade, que as atuais diretrizes e recomendações para o controle de infecção respiratória do CDC e HICPAC, apesar de sugerirem a implantação de um programa que contemple a higiene bucal e a descontaminação da cavidade bucal com antissépticos em pacientes com quadro agudo, internados em instituições de longa permanência e com risco aumentado para a pneumonia hospitalar, a higiene bucal não é categorizada como recomendação baseada em evidências científicas. No entanto, vários estudos isolados posteriores, como revisões sistemáticas e metanálises, vêm determinando a higiene bucal como uma medida significativa para reduzir a PAVM em pacientes de cirurgias cardíacas e demais pacientes críticos. A higiene bucal auxilia na eliminação ou redução da colonização da região da orofaringe e da placa dental, consideradas as fontes mais importantes para infecções respiratórias, principalmente da PAVM. Ressalte-se que a higiene bucal com clorexidina ( $\mathrm{CHX}$ ) tem sido apontada como o procedimento mais eficaz para redução e descolonização do trato gastrointestinal, assim como da placa bacteriana bucal, devido ao risco de desenvolvimento de resistência bacteriana pelo uso rotineiro de antibióticos. Contudo, uma vez que ainda não há consenso sobre frequência e técnica de realização da higiene bucal, assim como concentração de $\mathrm{CHX}$, fica a critério das instituições estabelecerem rotinas específicas.

\section{$\mathbf{F} \square$ ndamentação científica:}

Torres A, Carlet J. Ventilator-associated pneumonia. European task force on ventilatorassociataded pneumonia. Eur Respir J. 2001, 17(5):1034-45.

Garcia R. A review of the possible role of oral and dental colonization on the occurrence of health care-associated pneumonia: underappreciated risk and a call for interventions. $A m \mathrm{~J}$ Infect Control. 2005, 33(9): 527-41.

Lorente L, Blot S, Rello J. Evidence on measures for the prevention of ventilator-associated pneumonia. Eur Respir J. 2006, 30(6):1193-1207.

Azarpazhooh A, Leake JL. Systematic review of the association between respiratory diseases and oral health. J Periodontol. 2006, 77(9):1465-81. 
Berry AM, Davidson PM, Masters J. Systematic literature review of oral hygiene practices for intensive care patients for intensive care patients receiving mechanical ventilation. Evidencebased practice in critical care. Am J Crit Care. 2007, 16(6):552- 62.

Chan EY, Ruest A, Meade MO, Cook DJ. Oral decontamination for prevention of pneumonia in mechanically ventilated adults: systematic review and meta-analysis. BMJ. 2007, 334 (7599):889.

Kola A, Gastmeier P. Efficacy of oral chlorhexidine in preventing lower respiratory tract infections. Meta-analysis of randomized controlled trials. J Hosp Infect. 2007, 66(3):207-16.

\section{Categoria de evidência: A (pacientes em pré e pós-operatório de cir $\square$ rgia cardíaca) e B (demais pacientes críticos)}

Tipo de avaliação: processo

Critérios de incl $\square$ são: pacientes internados sob assistência ventilatória com rebaixamento de consciência e/ou nutrição por sondas digestivas.

$\mathbf{N} \square$ merador do indicador: pacientes sob assistência ventilatória ou com rebaixamento de consciência e/ou nutrição por sondas digestivas, para os quais a higiene bucal foi realizada de acordo com as normas da instituição sob avaliação.

Denominador do indicador: pacientes sob assistência ventilatória ou com rebaixamento de consciência e/ou nutrição por sondas digestivas, nos quais a realização de higiene bucal foi avaliada.

Fórm $\square$ la do Indicador:

$N^{\circ}$ total de pacientes sob assistência ventilatória ou com rebaixamento de consciência e/ou nutrição por sondas digestivas, nos quais a higiene bucal foi realizada de acordo com as normas da instituição sob avaliação

$N^{\circ}$ total de pacientes avaliados, sob as condições descritas no $X 100$ numerador

Fonte de informação: observação direta do profissional de saúde realizando o procedimento em:
A) Pacientes em pré-operatório de cirurgia cardíaca
B) Pacientes críticos e de instituições de longa permanência. 
Critérios para avaliação: realização de higiene bucal de acordo com rotina implantada pela instituição.

OBS: Para este estudo, acatar-se-á a rotina existente na instituição sob avaliação para higiene bucal em pacientes com IOT, conforme segue:

Registrar "Atende (A)" na realização de higiene bucal 3 vezes/dia, nas seguintes situações:

- Pacientes dêntulos sem lesão e/ou sangramento na cavidade bucal ou reações alérgicas ao produto: padronizada a utilização de creme dental com escovação dos dentes e aplicação de solução de CHX 0,12\%;

- Pacientes edêntulos e/ou com lesão e/ou sangramento na cavidade bucal e/ou reações alérgicas ao produto: é padronizada a aplicação da solução de $\mathrm{CHX} 0,12 \%$ com swab de esponja.

- Aplicação de outro tipo de solução, conforme avaliação e prescrição do enfermeiro.

- Registrar "Sem Aplicação (SA)" nos casos em que o paciente tenha contra-indicação e haja prescrição contrária.

Amostra para análise de conformidade: deverá ser definida previamente, de forma a garantir representatividade da totalidade da realizada sob observação 


\section{Apêndice B - Planilha para registro da avaliação do indicador IRPHB: avaliação da adesão à higiene $b$ cal conforme rotina da instit $\square$ ição.}

\begin{tabular}{|c|c|c|c|c|c|}
\hline \multicolumn{3}{|c|}{ Avaliador: } & \multicolumn{3}{|c|}{ Data: / / } \\
\hline $\mathbf{E}$ & \multicolumn{5}{|c|}{ Evidências: A (paciente de cirurgia cardíaca) e B (demais pacientes críticos) } \\
\hline & & Avaliação 1 & Avaliação 2 & Avaliação 3 & Avaliação 4 \\
\hline 1 & $\begin{array}{l}\text { Identificação } \\
\text { (paciente) }\end{array}$ & $\begin{array}{l}\text { Nome: } \\
\text { Leito: } \\
\text { RH: }\end{array}$ & $\begin{array}{l}\text { Nome: } \\
\text { Leito: } \\
\text { RH: }\end{array}$ & $\begin{array}{l}\text { Nome: } \\
\text { Leito: } \\
\text { RH: }\end{array}$ & $\begin{array}{l}\text { Nome: } \\
\text { Leito: } \\
\text { RH: }\end{array}$ \\
\hline \multirow{3}{*}{2} & \begin{tabular}{|l|}
$* * *$ Técnicas de Higiene \\
b $\square$ cal prescritas o $\square$ \\
padronizadas: \\
1 - Aplicação de solução de \\
CHX $0,12 \%$ com swab
\end{tabular} & 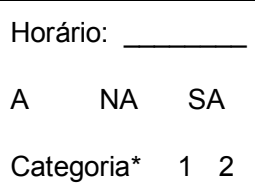 & $\begin{array}{lll}\text { Horário: } & & \\
& \mathrm{NA} & \mathrm{SA} \\
\text { Categoria } & 1 & 2\end{array}$ & $\begin{array}{l}\text { Horário: } \\
\quad \mathrm{NA} \\
\begin{array}{lll} & \\
\text { Categoria } & 1 & 2\end{array}\end{array}$ & 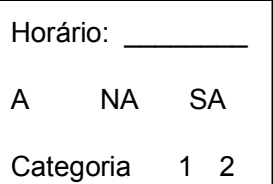 \\
\hline & $\begin{array}{l}2 \text { - Escovação com creme } \\
\text { dental e aplicação de } \mathrm{CHX} \\
0,12 \%\end{array}$ & 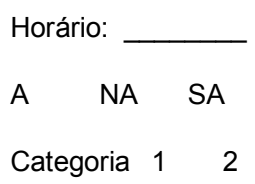 & \begin{tabular}{lrr} 
Horário: & \\
\cline { 2 - 2 } & NA & SA \\
Categoria & 1 & 2
\end{tabular} & $\begin{array}{ll}\text { Horário: } & \\
\quad \text { NA } & \text { SA } \\
\text { Categoria } & 12\end{array}$ & 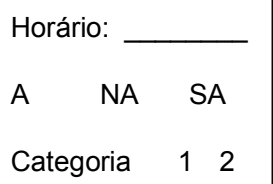 \\
\hline & $\begin{array}{l}3 \text { - Aplicação de outra } \\
\text { solução. } \\
\text { Qual? }\end{array}$ & 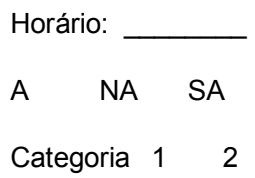 & \begin{tabular}{lrr} 
Horário: & \\
\cline { 2 - 2 } & NA & SA \\
Categoria & 1 & 2
\end{tabular} & 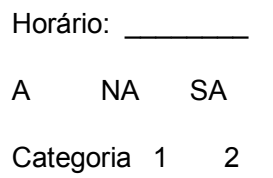 & 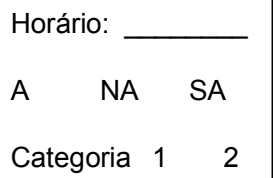 \\
\hline 3 & Concl $\square$ são & $\begin{array}{l}\square \text { Conforme } \\
\square \quad \text { Não conforme }\end{array}$ & $\begin{array}{ll}\square & \text { Conforme } \\
\square \quad \text { Não conforme }\end{array}$ & $\begin{array}{l}\square \text { Conforme } \\
\square \quad \text { Não conforme }\end{array}$ & $\begin{array}{l}\square \text { Conforme } \\
\square \quad \text { Não conforme }\end{array}$ \\
\hline & $\begin{array}{l}\text { Atende; NA - Não Atende; SA - Sem a } \\
\text { HX = clorexidina. } \\
\text { Observação direta da execução do pro } \\
\text { enfermagem o } \square \text { rotina padronizada } \\
\text { ausência dos produtos padronizados n } \\
\text { acordo com a rotina de cada instituição } \\
\text { ervações: Avaliação 1: } \\
\text { Avaliação 2: } \\
\text { Avaliação 3: } \\
\text { Avaliação 4: }\end{array}$ & $\begin{array}{l}\text { cação. *Categoria: re } \\
\text { dimento pelo profissio } \\
\text { instit ição, conform } \\
\text { sstituição, assinalar a }\end{array}$ & $\begin{array}{l}\text {-se à categoria profis } \\
\text { Considera-se ATEND } \\
\text { tipo de paciente, prod } \\
\text { âo SEM APLICACÃAO } \\
\end{array}$ & $\begin{array}{l}\text { nal, sendo: } 1 \text {. Tec. Enf; } 2 \\
\text { ando a técnica realizada } \\
\text { ndicado e a frequência. } \\
\text { gistrar o produto utilizado }\end{array}$ & fermeiro \\
\hline
\end{tabular}




\section{Apêndice C - Termo de Consentimento Livre e Esclarecido}

\section{TERMO DE CONSENTIMENTO LIVRE E ESCLARECIDO}

Pesquisa intitulada: "Avaliação da conformidade de práticas de controle e prevenção de pne $\square$ monia associada à ventilação mecânica em $\square$ m Hospital Público de Ensino".

A pesquisa a ser desenvolvida consiste na dissertação de mestrado junto ao Programa de Pós-Graduação em Saúde do Adulto - PROESA - da Escola de Enfermagem da USP e tem como objetivo geral avaliar a conformidade de práticas recomendadas para o controle e prevenção da pneumonia associada à ventilação mecânica em pacientes adultos internados na UTI de adulto.

No decorrer do trabalho, a pesquisadora e outros profissionais treinados para auxiliar na coleta de dados realizaram visitas em horários oportunos, distribuídos nos três turnos de trabalho na UTI.

Empregou-se a seguinte metodologia:

1. consulta aos registros do paciente submetido à intubação orotraqueal (IOT), para identificar alterações na padronização das práticas estabelecidas no local do estudo;

2. observação das práticas selecionadas para avaliação, isto é, recomendações e rotinas assistenciais estabelecidas e realizadas pelos profissionais de saúde da UTI adulto nos pacientes acima referidos. Exemplos: decúbito elevado de $30-45^{0}$; período de troca de acessórios e de equipamentos respiratórios, utilização de solução estéril para artigos respiratórios, fisioterapia respiratória, aspiração de vias aéreas inferiores, dentre outros.

Cumpre esclarecer que a pesquisa não implicará quaisquer riscos a nenhum participante, sejam biológicos, éticos e morais. Isso porque os resultados foram obtidos através de observação e apresentados de forma agregada, sem qualquer tipo de identificação, seja do paciente, seja dos profissionais participantes. O interesse do estudo não reside na prática individual, mas coletiva, e o que isso representa na qualidade assistencial.

Dessa maneira, o pesquisador compromete-se ao anonimato dos participantes e ao sigilo de resultados individuais, tendo ciência de que tais resultados contribuirão de forma relevante para a identificação de necessidades de treinamentos coletivos, de controle e prevenção de infecção hospitalar e da capacitação de recursos materiais e estruturais, auxiliando na melhoria da assistência ao paciente de alto risco. Pretende-se utilizar os dados obtidos em publicações de caráter científico; o participante poderá solicitar acesso aos achados da pesquisa a qualquer tempo. 
“Declaro q $q$ e compreendi $t$ do o q $\square$ me foi convenientemente esclarecido pelo pesq isador e consinto em participar da pesq isa".

São Paulo, de de 2009.

Assinatura do Participante

Assinatura da pesquisadora

Pesq isadora: Isa Rodrig $\square$ es da Silveira (enfermeira)

Em caso de dúvidas, os participantes poderão entrar em contato com a pesquisadora pelos telefones: 11- 3091-9242. 
10 Anexos 


\section{Anexo A - Constr $\square$ to operacional do indicador IRPR: avaliação da adesão às medidas de controle e prevenção de pne $\square$ monias em pacientes de risco (São Pa $\square$ lo, 2006).}

Descrição: Monitora a aplicação de algumas medidas específicas ao controle de pneumonia hospitalar: decúbito elevado (igual ou maior que 30o), fisioterapia respiratória, utilização de soluções estéreis nos equipamentos de terapia respiratória e adesão à rotina de troca dos inaladores estabelecida na instituição. A critério do grupo avaliador, outras medidas podem ser incorporadas, conforme surjam novas fundamentações científicas.

\section{$\mathbf{F} \square$ ndamentação científica:}

Guideline for Prevention of Nosocomial Pneumonia, 1994. Centers for Disease Control and Prevention. Hospital Infection Control Practices Advisory Committee.

Tablan OC, Anderson LJ, Besser R, Bridges C, Hajjeh R. Guidelines for Prevention of Healthcare-Associated Pneumonia, 2003. Recommendations of CDC and Healthcare Infection Control Practices Advisory Committee. MMWR recomm rep March 26, 53(RR3):140, 2004.

\section{Categorias de evidência:}

- Soluções estéreis: $(A)$

- Inalador e/ou umidificador respeitando a rotina de troca estabelecida: (C)

- Atendimento diário de fisioterapia respiratória: (C)

- Cabeceira elevada a 30-45: (C)

Tipo de avaliação: processo

Critérios de incl $\square$ são: pacientes internados sob assistência ventilatória com rebaixamento de consciência e/ou nutrição por sondas digestivas.

$\mathbf{N} \square$ merador do indicador: Pacientes sob assistência ventilatória ou com rebaixamento de consciência e/ou ainda nutrição por sondas digestivas, para os quais as medidas para a prevenção de pneumonia hospitalar (decúbito elevado igual ou maior que $30^{\circ}$, fisioterapia respiratória diária, utilização de soluções estéreis nos materiais de terapia respiratória e adesão à rotina de troca dos materiais de terapia inalatória estabelecida na instituição) são corretamente aplicadas.

Denominador do indicador: pacientes sob assistência ventilatória ou com rebaixamento de consciência e/ou nutrição por sondas digestivas em que as medidas de controle para pneumonia hospitalar, descritas no numerador, foram avaliadas. 
Fórm $\square$ la do Indicador:

$N^{0}$ total de pacientes sob assistência ventilatória, com rebaixamento de consciência e/ou nutrição por sondas digestivas em que todos os componentes de controle para pneumonia hospitalar contidos neste indicador estão corretamente aplicados

$N^{\circ}$ total de pacientes avaliados, sob as condições descritas no numerador

OBS: a forma de construção da planilha do indicador possibilita realizar também índices individuais de conformidade para cada medida.

Valor ideal: $100 \%$

\section{Fontes de informação:}

A) Uso de soluções estéreis para nebulizadores e umidificadores: observação direta.

B) Circuito de terapia respiratória (inalador e/ou umidificador): observação direta do uso e do acato à rotina de troca estabelecida pela instituição.

C) Atendimento diário de fisioterapia respiratória: observação direta do profissional de fisioterapia durante o atendimento diário ao paciente.

D) Cabeceira elevada a $30-45^{\circ}$ : observação direta.

\section{Critérios para avaliação:}

A) Uso de soluções estéreis para nebulizadores e umidificadores: considerar Atende (A) quando não forem encontrados frascos de água destilada abertos ou seringas com soro fisiológico preparadas.

B) Circuito de terapia respiratória (inalador e ou umidificador) em uso e respeitando a rotina de troca estabelecida: pode ser feita a avaliação direta (caso a rotina institucional preconize a necessidade de datar o material) ou indireta (prontuário com informações na prescrição de enfermagem ou fisioterapia com registro das trocas). Considerar Atende (A) quando a rotina estabelecida na instituição está sendo seguida pelas equipes das unidades. Para isso, é fundamental que a rotina esteja descrita e disponível. Caso isso não ocorra, classificar como "Não Atende (NA)".

C) Atendimento diário de fisioterapia respiratória: Considerar Atende $(A)$ para a realização de fisioterapia diária ao paciente.

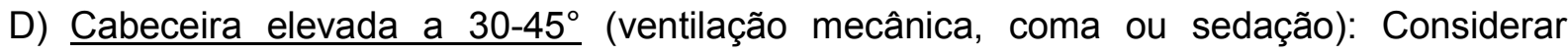
"Atende (A)" para a observação positiva. Registrar "Sem Aplicação (SA)" nos casos em que o paciente tenha contra-indicação desse posicionamento e haja prescrição contrária. 


\section{Observações:}

- As avaliações são consideradas como "Sem Aplicação (SA)" em pacientes que, mesmo sob os critérios de inclusão, apresentam alguma contra-indicação para atender aos procedimentos sob observação. Essa informação deve estar registrada em prontuário.

- Caso haja duas unidades de avaliação classificadas como "Sem Aplicação", não considerar a avaliação desse paciente. A presença da situação "Não Atende" para qualquer componente sob avaliação deve ser avaliada como "Não conforme" na conclusão desse paciente;

- O mesmo paciente pode ser avaliado várias vezes durante o período de auditoria, em turnos e dias consecutivos, pois a situação encontrada pode ser diferente.

- Avaliações sucessivas com finalidade comparativa devem utilizar sempre o mesmo tipo de amostragem.

Amostra para análise de conformidade: deverá ser definida previamente, de forma a garantir representatividade da totalidade da realizada sob observação. 
Anexo B - Planilha para registro da avaliação do indicador IRPR: avaliação da adesão às medidas de prevenção e controle de pne $\square$ monia em pacientes de risco (São $\mathrm{Pa} \square$ lo, 2006)

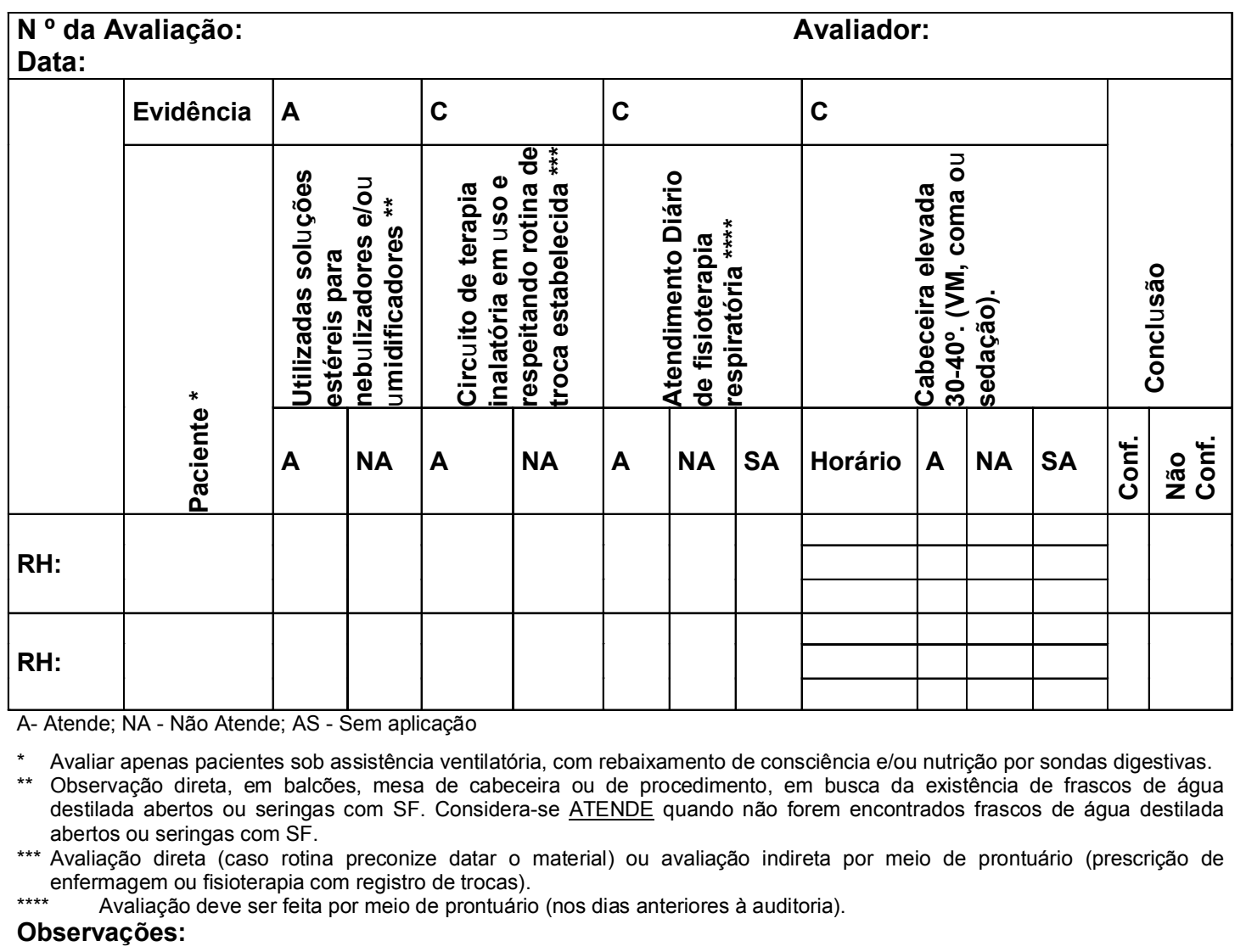




\section{Anexo C - Constr to operacional do indicador HMSEL: avaliação da adesão à higiene das mãos (São Pa $\square$ lo, 2006).}

Descrição: Monitora e registra as ocasiões de adesão à higiene das mãos, nas oportunidades em que é necessária. Essa é uma prática unanimemente considerada como uma das principais ações de controle de infecção adquirida em serviços de saúde e internacionalmente recomendada nos seguintes casos: antes e após o contato direto com pacientes, após contato com materiais orgânicos e hospitalares contaminados, quando as mãos estiverem visivelmente sujas, após contato com membrana mucosa, com pele não íntegra, curativos e após a retirada das luvas, mesmo quando não estiverem visivelmente sujas. Dentro das recomendações, visando à redução de transmissão de microrganismos potencialmente patogênicos para pacientes e entre os próprios profissionais de saúde, inclui-se a higienização das mãos ao realizar um procedimento em uma área contaminada para outra no mesmo paciente. A descontaminação das mãos pode ser realizada com água e sabão com ou sem antissépticos ou, ainda, com solução alcoólica (Boyce e Pittet, 2002). Outras recomendações importantes referem-se à higienização das mãos antes de hábitos higiênicos, bem como antes de se alimentar e após uso do toalete.

A avaliação pode ser aplicada em todas as unidades do hospital, em unidades previamente selecionadas (a critério do grupo avaliador) ou sempre que houver algum surto de infecção que possa estar diretamente relacionado à má prática da higiene das mãos (onfalite, conjuntivite, impetigo, infecções cutâneas, infecção de sítio cirúrgico e outros).

\section{F $\square$ ndamentação científica:}

CCDR. Infection Control Guidelines: hand washing, cleaning, disinfection and sterilization in health care. Health Canada. Can Commun Dis Rep. 1998, 24S8:1-55. Disponível em: <http://www.hc-sc.gc.ca/hph/lcdc>. Acesso em 24 mai 2009.

Boyce JM, Pittet D. Guideline for hand hygiene in health-care settings: recommendations of the Healthcare Infection Control Practices Advisory Committee and the SHEA, APIC, IDSA Hand Hygiene Force Task. Infect Control Hosp Epidemiol. 2002, 23(S): 3-40.

Brasil. Ministério da Saúde. Portaria n 2.616, de 12 de maio de 1998. Dispõe sobre as diretrizes e normas para a prevenção e o controle das infecções hospitalares. Diário Oficial da União n 89, 12 de maio de 1998 p. 232-6. 


\section{Categorias de evidências:}

- C: os componentes de avaliação (categoria profissional, situação de emergência, cateter venoso central, isolamento, ventilação mecânica e traqueostomia) não apresentam classificação específica nos guias de diretrizes estudadas, mas são importantes para auxiliar a interpretação dos resultados encontrados. A identificação da categoria profissional contribui para definir estratégias específicas, segundo o achado. As situações de emergência interferem na adesão à higiene das mãos. A presença de dispositivos invasivos (cateter venoso central, ventilação mecânica e traqueostomia) e/ou a condição infecciosa do paciente com necessidade de isolamento demonstra, indiretamente, a gravidade de cada paciente e determinam o volume de trabalho dos profissionais de saúde naquela unidade;

- A e B: Trato respiratório (aspiração traqueal, higiene oral, troca de cadarço, coleta secreção, troca de equipamento respiratório);

- A e B: Linhas vasculares (punção, troca do sistema de infusão, instalação de cateter vascular central, administração de medicamentos, troca ou realização de curativo, coleta de sangue);

- A e B: Trato urinário (instalação de sonda vesical, higiene íntima, coleta de urina para exame laboratorial, controle de diurese);

- A e B: Pele (banho no leito, curativos de incisão/inserção/escara, massagem de conforto, cuidados com estoma);

- A e B: Sondas digestivas, gástrica ou enteral: instalação ou retirada de sonda ou alimentação, controle de débito;

- A e B: Outros (mudança de decúbito, medicação intramuscular, transporte, exame físico).

Tipo de avaliação: processo.

$\mathbf{N} \square$ merador do indicador: oportunidades que o profissional de saúde teve para higienizar as mãos e efetivamente o fez (total de adesão à higiene das mãos entre as oportunidades selecionadas).

Denominador do indicador: oportunidades de higiene das mãos observadas.

\section{Fórm $\square$ la do Indicador:}

$N^{\circ}$ total de oportunidades que o profissional de saúde teve para higienizar as mãos e efetivamente o fez

$N^{\circ}$ total de oportunidades de higiene das mãos observadas $X 100$

Valor ideal: $100 \%$ 
Fontes de informação: conforme a planilha para registro:

- 1 a 6: Categoria profissional, situação de emergência, cateter venoso central, isolamento, ventilação mecânica e traqueostomia: observação direta ou prontuário do paciente.

- 7 a 12: Oportunidades descritas no cuidado com o trato respiratório, as linhas vasculares, o trato urinário, a pele, as sondas digestivas ou outros procedimentos: observação direta do profissional quanto à higiene das mãos antes e depois de qualquer uma das oportunidades descritas.

Critérios para avaliação: avaliação pontual ou por pequeno período. Definir qual ou quais unidades serão visitadas. Essa escolha deve ser feita de maneira sigilosa para que a equipe local haja de maneira natural. Preencher o cabeçalho do instrumento com as informações necessárias e dirigir-se à unidade. Cada coluna desse instrumento descreve uma categoria profissional que está sendo observada. O instrumento foi criado de maneira que um observador possa simultaneamente observar e registrar informações referentes a várias oportunidades e a muitas categorias profissionais. Cada linha do instrumento referese a uma ou mais oportunidades observadas para um profissional. Caso haja observação de mais de uma categoria profissional, colocar em colunas distintas, pois cada um pode ter uma postura com relação à higiene das mãos. Quando um profissional está sendo observado, concentrar no preenchimento da linha (7 a 10) da oportunidade que está ocorrendo.

- 1 a 6: Categoria profissional, situação de emergência, cateter venoso central, isolamento, ventilação mecânica e traqueostomia: Categoria profissional - apenas uma constatação; demais itens (linha 2 a 6 ) - a resposta Sim vai demonstrar indiretamente a invasividade e gravidade dos pacientes.

- 7 a 12: Oportunidades descritas no cuidado com trato respiratório, linhas vasculares, trato urinário, pele, sondas digestivas ou outros procedimentos: registrar $\underline{\operatorname{Sim}}$ ou $\underline{\mathrm{Não}}$, antes ou depois da oportunidade observada, classificando-se como "Conforme" a observação positiva. Caso não tenha sido possível observar a oportunidade do início (higiene das mãos antes), deixar essa linha em branco. No final, a situação para essa oportunidade não será computada.

\section{Observação:}

a) Contar quantas oportunidades foram observadas no total, somando todos os itens preenchidos das linhas 7 a 12;

b) Contar quantas oportunidades para cada sítio específico (linhas 7 a 12) somando as colunas $x$ linhas preenchidas e subdividindo em ANTES e DEPOIS; 
c) Contar quantas oportunidades cuja resposta à aderência foi SIM, considerando que isso signifique conformidade;

d) O indicador pode ser calculado de forma geral, utilizando-se todas as oportunidades observadas (denominador) e todas as respostas positivas (numerador) ou estudado por oportunidade (trato respiratório, linhas vasculares, etc) e/ou por categoria profissional e/ou por situação de emergência, etc;

e) Os períodos de observação devem ser selecionados de forma aleatória com o objetivo de assegurar o máximo de sigilo ao observador para que a coleta da informação seja a mais próxima da verdadeira prática;

f) Cada observador deve ser treinado para identificar a oportunidade e preencher $o$ instrumento de forma discreta.

Amostra para análise de conformidade: deverá ser definida previamente, de forma a garantir representatividade da totalidade da realizada sob observação. 


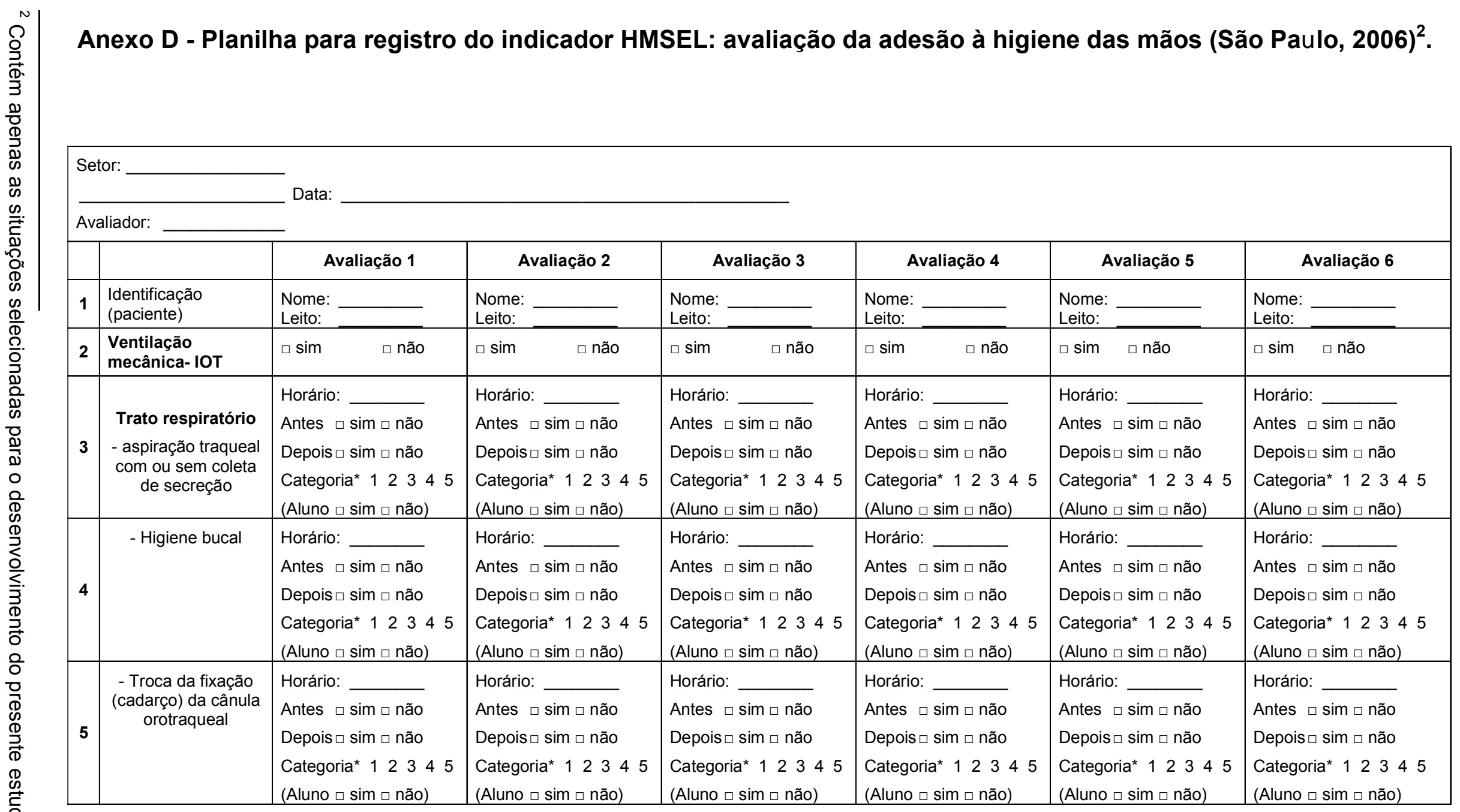

* Categoria: refere-se à categoria profissional, sendo respectivamente: 1 - Técnico de Enfermagem $\quad 2$-Enfermeiro 3 -Médico 4 - Fisioterapeuta 5 -Outros Profissionais

\section{Observações:}




\section{Anexo E - Aprovação do Comitê de Ética e Pesq $\square$ isa.}

Så Paulo, 19 de dezembro de 2008.

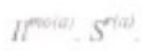

REFERENTE: Projeto de Pesquisa "Avaliaçåo da conformidade de práticas de controle e prevenção de pneumonia associada à ventilação mecânica" - Co-autor(res): Isa Rodrigues da Silveira Cabral de Menezes - Registro CEP-HU/USP: 843/08 SISNEP CAAE: 0054.0 .198 .196 .08

Prezado(a) Senhor(a)

O Comitê de Ética em Pesquisa do Hospital Universitârio da Iniversidade de São Paulo, ent reuniào ordinària realizada no dia 19 de dezembro de 2008, analisou o Projeto de Pesquisa acima citado, considerando-o como APROVADO, bem como o seu Termo de Consentimento Livre e Esclarecido.

Lembramos que cabe ao pesquisador elaborar e apresentar a este Comitê. relatórios anuais (parciais ou final, em função da duraçào da pesquisa). de acordo com a Resoluçầ 196.96 do Conselho Nacional de Saúde. item IX.2.c.

O primeiro relatório está previsto para 19 de dezembro de 2009.

Atenciosamente.

Dr. Mauricio Seckler Coordenador do Comitê de Ética em Pesquisa Hospital Universitário da USP 